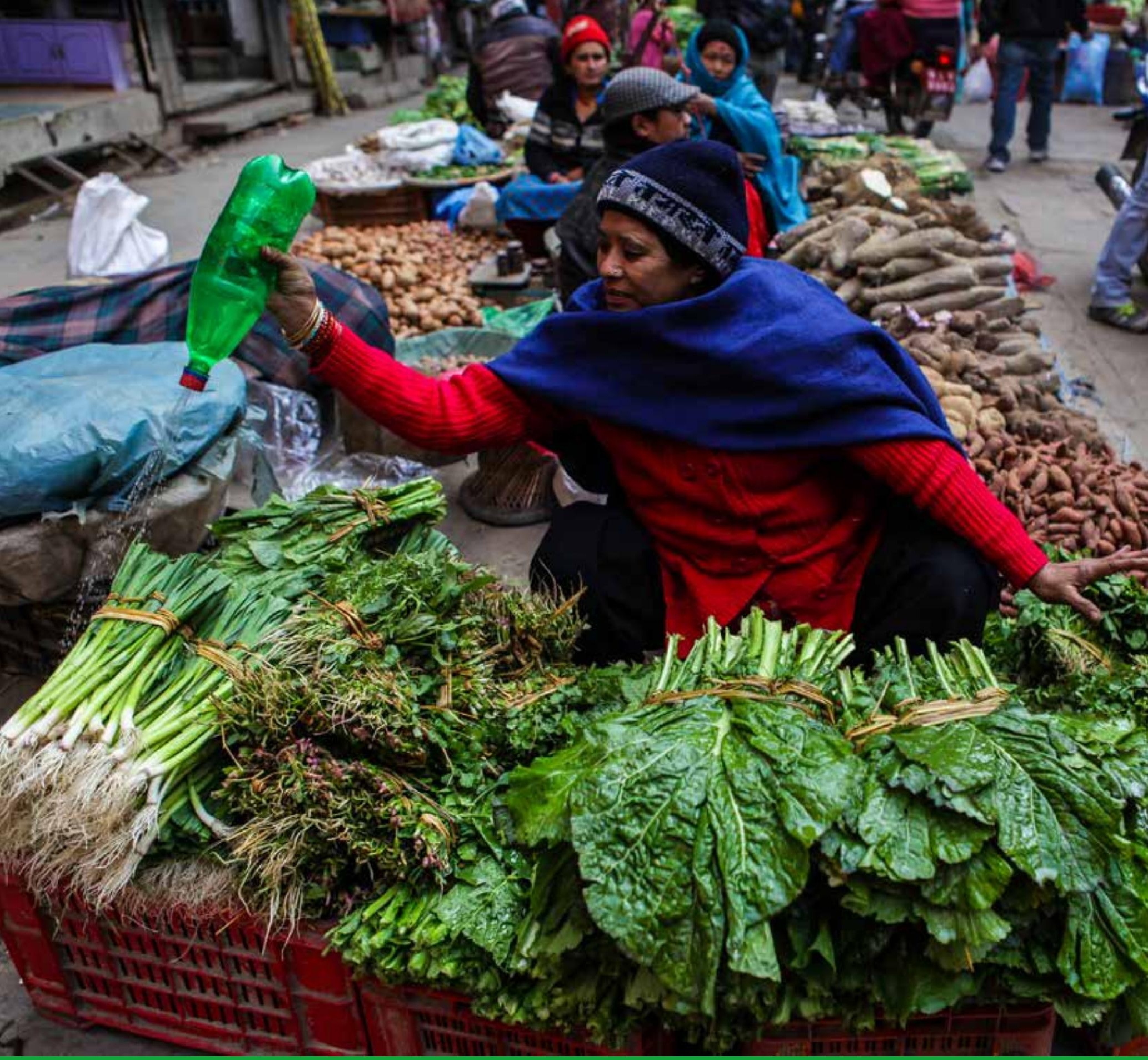

\title{
Scoping study on fruits and vegetables; results from Nepal
}

An assessment of investment opportunities for the Bill and Melinda Gates Foundation

Yeray Saavedra, Sichan Shrestha, Thomas Tichar

WAGENINGEN

UNIVERSITY \& RESEARCH 



\section{Scoping study on fruits and vegetables}

Results from Nepal

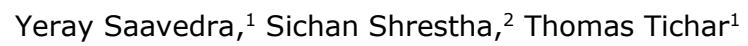

1 Wageningen Centre for Development Innovation

2 Freelancer

This study was carried out by Wageningen Economic Research and was financed by the Bill and Melinda Gates Foundation

Wageningen Economic Research

Wageningen, October 2021

REPORT

2021-109

ISBN 978-94-6395-075-6 
Yeray Saavedra, Sichan Shrestha, Thomas Tichar, 2021. Scoping study on fruits and vegetables;

Results from Nepal. Wageningen, Wageningen Economic Research, Report 2021-109. 62 pp.; 11 fig.;

12 tab.; 35 ref.

Wereldwijd lijdt een op de drie mensen aan een of meer vormen van ondervoeding. De teams van de Bill \& Melinda Gates Foundation die zich bezighouden met landbouw en voeding, in samenwerking met het Britse Department for International Development (FCDO), willen het potentieel van groente- en fruitketens onderzoeken om het aanbod van voedzame voedingsmiddelen te vergroten en te versterken, en om de lokale marktkansen voor meer inkomsten te vergroten, speciaal voor vrouwen. Dit rapport belicht de conclusies van een onderzoek in Nepal en identificeert verschillende oorzaken en mogelijke interventies om de fruit- en groentesectoren te verbeteren en daarmee de consumptie te verhogen.

Currently, one in three of the world's population suffer from one or more forms of malnutrition. The Agricultural Development and Nutrition teams at the Bill \& Melinda Gates Foundation, in collaboration with the UK's Department for International Development (FCDO), seek to investigate the potential of vegetable and fruit supply chains to increase the supply of and strengthen demand for nutritious foods, as well as increase local market opportunities for increased income, especially for women. This report highlights the conclusions from a study in Nepal, and identifies several root causes, as well as opportunities for interventions to further develop the fruit and vegetable sectors, and with that enhance consumption.

Key words: fruits, vegetables, food system, nutrition, supply chains

This report can be downloaded for free at https://doi.org/10.18174/554448 or at www.wur.eu/economic-research (under Wageningen Economic Research publications).

(C) 2021 Wageningen Economic Research

P.O. Box 29703, 2502 LS The Hague, The Netherlands, T +31 (0)70 3358330 ,

E communications.ssg@wur.nl, http://www.wur.eu/economic-research. Wageningen Economic Research is part of Wageningen University \& Research.

\section{(cc) BY-NC}

This work is licensed under a Creative Commons Attribution-Non Commercial 4.0 International License.

(c) Wageningen Economic Research, part of Stichting Wageningen Research, 2021

The user may reproduce, distribute and share this work and make derivative works from it. Material by third parties which is used in the work and which are subject to intellectual property rights may not be used without prior permission from the relevant third party. The user must attribute the work by stating the name indicated by the author or licensor but may not do this in such a way as to create the impression that the author/licensor endorses the use of the work or the work of the user. The user may not use the work for commercial purposes.

Wageningen Economic Research accepts no liability for any damage resulting from the use of the results of this study or the application of the advice contained in it.

Wageningen Economic Research is ISO 9001:2015 certified.

Confidential Wageningen Economic Research Report 2021-109 | Project code 2282500391

Cover photo: udeyismail / Shutterstock.com 


\section{Contents}

$\begin{array}{ll}\text { Preface } & 5\end{array}$

$\begin{array}{ll}\text { Summary } & 6\end{array}$

$\begin{array}{ll}\text { Background } & 6\end{array}$

$\begin{array}{ll}\text { Method } & 6\end{array}$

Key findings $\quad 6$

1

$\begin{array}{ll}\text { Introduction } & \mathbf{8}\end{array}$

$\begin{array}{lll}1.1 & \text { Background } & 8\end{array}$

$\begin{array}{lll}1.2 & \text { Objective } & 8\end{array}$

$\begin{array}{llr}1.3 & \text { Research questions } & 8\end{array}$

$\begin{array}{llr}1.4 & \text { Approach } & 10\end{array}$

$\begin{array}{lll}1.5 & \text { Reading guide } & 10\end{array}$

2.1 Country profile $\quad 11$

2.2 Overview and trends analysis for fruit and vegetable produce in Nepal 12

2.2.1 Area and volume of fruit and vegetable production 13

2.2.2 Production areas $\quad 15$

2.2.3 Consumption of fruits and vegetables 16

$\begin{array}{ll}2.2 .4 \text { Seed system } & 17\end{array}$

2.2.5 Gender and women's roles 18

$3 \quad$ Identified research questions $r$

$\begin{array}{lll}3.1 & \text { Introduction } & 19\end{array}$

3.2 Selection of fruits and vegetables $\quad 19$

$4 \quad$ Validation of research questions $\quad 21$

4.1 Introduction of the selected food supply systems $\quad 21$

$\begin{array}{ll}4.1 .1 & \text { Description of actors }\end{array}$

$\begin{array}{ll}4.1 .2 & \text { Number of actors }\end{array}$

4.1.3 Dominant type of value chain $\quad 23$

4.1.4 Enabling environment $\quad 23$

4.2 Increase in production leads to lower fruit and vegetable consumer

4.2.1 Seasonal variation $\quad 24$

$\begin{array}{ll}\text { 4.2.2 } & \text { Barriers for farmers to increase production }\end{array}$

4.2.3 Yield gaps and production losses $\quad 28$

4.2.4 Gender-specific barriers and opportunities to increase production $\quad 28$

4.3 Reduction in cost price will make production of fruit and vegetables more profitable $\quad 29$

4.3.1 Cost of producing fruit and vegetable $\quad 29$

4.3.2 Effects of cost reduction strategies $\quad 32$

Efficient value chains can lead to lower fruit and vegetable consumer
prices

4.4.1 Increase value chain efficiency $\quad 32$

4.4.2 Coordination in the value chain 33

4.4.3 Post-harvest losses $\quad 34$

4.4.4 Secured markets $\quad 35$ 
4.5 Communication between actors 36

4.5.1 Linkages between traders and consumers 36

$\begin{array}{ll}\text { 4.5.2 Information sharing } & 37\end{array}$

4.6 More and higher diversity in fruit and vegetable crops produced and traded leads to more diverse fruit and vegetable in the food environment $\quad 38$

4.6.1 Introduction of new fruit and vegetable varieties 38

4.6.2 Consumption trends $\quad 39$

4.7 Prices of fruit and vegetable are always higher compared to other food categories

4.7 .1 High prices 40

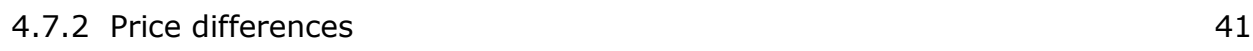

4.8 Women participation in fruit and vegetable production and value chain operations leads to higher income and empowerment by women $\quad 41$

4.8.1 Examples of women in fruit and vegetable production and value chains

4.8.2 Business models $\quad 43$

4.8.3 Public policy $\quad 44$

4.9 Public enforcement of standards will enhance food safety for consumers of fruit and vegetable $\quad 45$

4.9.1 Relevant standards $\quad 45$

4.9.2 Consumer trust in local standards $\quad 46$

4.10 Nudging and public extension will improve fruit and vegetable consumer awareness and consumption preferences $\quad 47$

$\begin{array}{ll}4.10 .1 \text { Policies and strategies } & 47\end{array}$

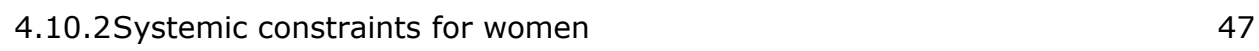

4.10.3Illustrative examples $\quad 48$

4.11 Increased food safety, consumer awareness and responses to consumer
preferences lead to higher acceptability of fruit and vegetable

4.11.1 Available, affordable, acceptable $\quad 49$

4.11.2Consumer motives and barriers $\quad 50$

$\begin{array}{ll}\text { Conclusion } & \mathbf{5 1}\end{array}$

5.1 Increase in production leads to lower fruit and vegetable consumer prices

5.2 Fruit and vegetable production is profitable for smallholders 51

5.3 More efficient value chains and consumer prices $\quad 51$

$\begin{array}{lll}5.4 & \text { Fruit and vegetable value chain efficiency } & 51\end{array}$

5.5 Direct farmer-consumer relations are limited $\quad 51$

5.6 Little evidence is found that diverse fruit and vegetables lead to an increase in consumption

5.7 Prices of fruit and vegetable are higher $\quad 52$

5.8 Women participation $\quad 52$

5.9 Higher income by women leads to higher consumption of fruit and vegetable

5.10 Public standards are not enforced $\quad 52$

5.11 Nudging and public extension directed at consumes is limited 53

5.12 Consumer behavior $\quad 53$

$\begin{array}{ll}\text { References and websites } & 54\end{array}$

$\begin{array}{lll}\text { Appendix } 1 & \text { Description of actors } & 56\end{array}$

Appendix 2 List of Focus Groups Discussions (FGDs) and Key Informant Interviews (KIIs) 58

$\begin{array}{lll}\text { Appendix } 3 & \text { Fruits and vegetables sentinel groups } & \mathbf{6 0}\end{array}$

$\begin{array}{lll}\text { Appendix } 4 & \text { List of projects in the fruit and vegetable sector } & 61\end{array}$ 


\section{Preface}

The world's population is expected to increase by 2 billion persons in the next 30 years, from 7.7 billion currently to 9.7 billion in 2050 . In spite of progress made in the past decades, the number of people being undernourished is on the increase again. Globally, 462 million are underweight, while 1.9 billion adults are overweight or obese. This contrast highlights well one of the most prominent global challenges imposed on our food systems, which is: how to make available, accessible and affordable healthy food to all.

To meet the growing demand for food and improved nutrition, food production and its nutritional value need to be enhanced. Compounding this issue is the pressure that existing agricultural systems place on the environment. Although there is scope to bring new land under cultivation, for example in Africa and Latin America, this has the knock-on effect of damaging the climate, biodiversity, natural habitats and more generally the integrity of the Earth's environmental system. The challenge of achieving global food and nutrition security is underscored by Sustainable Development Goal (SDG) 2: "End hunger, achieve food security and improved nutrition, and promote sustainable agriculture."

Fruits and vegetables play a key role in achieving above mentioned goals. This was acknowledged by the Bill and Melinda Gates Foundation (BMGF) and the Foreign, Commonwealth \& Development Office (FCDO) which realized that more knowledge on the current state of fruit and vegetable consumption, trade, processing and production worldwide, and notably in low- and middle-income countries, is needed. For that purpose, Wageningen University \& Research was contracted to conduct a global scoping study including deep dives into selected countries. After more than a year and a half of research, we are happy to present a number of research outputs that address comprehensively the state of art and main challenges associated with fruits and vegetables. The reports take us through all aspects of food systems in which fruits and vegetables play a role, from consumption to production, but also around the world, from Nigeria to Nepal. The study provides BMGF and FCDO with a clear set of recommendations as to priorities for philanthropical investments that have the goal of enhancing consumption of and economic benefits from fruits and vegetables.

Fruits and vegetables play a key role in meeting current and future food system challenges. With this research we know better where we are and what is needed to address these challenges. I hope our work contributes to setting in motion food system changes urgently needed.

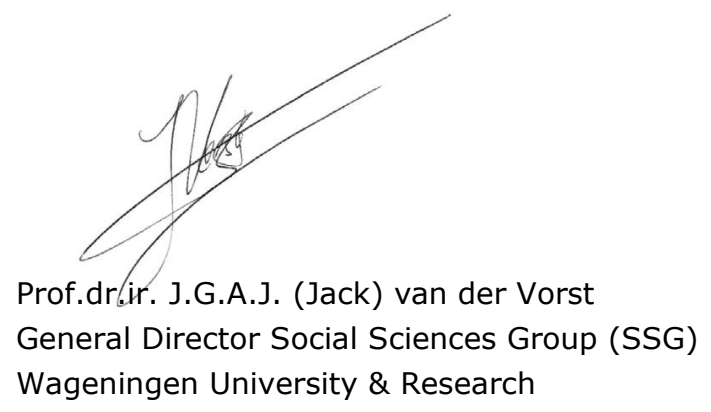




\section{Summary}

\section{Background}

The Bill and Melinda Gates Foundation (BMGF), in collaboration with the UK Foreign, Commonwealth \& Development Office (FCDO), seek to investigate the potential role of the horticultural sector for healthier diets and increased income generation, notably by women.

In Phase I, a global scoping study of the horticultural sector in West Africa, East Africa and South Asia was conducted. This Phase I study was based on available literature and secondary data. As a result, the research team identified leverage points for interventions in the food system to promote production, trade and consumption of fruits and vegetables. Phase II tested the validity and feasibility of the identified leverage points in seven countries - Bangladesh, Burkina Faso, Ethiopia, India, Nepal, Nigeria, and Tanzania. This report describes the findings of the Nepal country study.

The study ultimately identifies opportunities for action and investment in Nepal's fruit and vegetable sector, while guiding BMGF's potential role in accelerating systemic changes in food systems for healthier diets and women's economic empowerment.

\section{Method}

The current study seeks to validate possible leverage points for action and investments in the fruit and vegetable sector in Nepal. We undertook this validation by researching key questions that cover the entire spectrum of the sector - from production to value chains, markets, and consumption. The research team selected three fruits (kiwi, lapsi, mango) and three vegetables (bitter gourd, mustard green, pumpkin) to add focus to the wide scope of fruit and vegetables existing in Nepal.

The selection of crops was based on four criteria, namely: nutritional value, socio-economic importance and income generation for farmers (potential), opportunities for gender participation and empowerment, and market prospects of the crop. It is important to note that not all crops score high across all four criteria. Some have higher nutritional values than others or appear to be more gender inclusive. It is the totality of all six crops that meet the criteria, which serves as a proxy to answer the questions proposed below.

To answer our guiding research questions, the research team 1) reviewed dozens of reports, journals, articles, and government data; 2) facilitated five qualitative focus group discussions (FGDs); and 3) conducted 15 key informant interviews (KIIs). The variety of methods added depth to the analysis and allowed cross referencing and triangulation of data.

\section{Key findings}

The current consumption of fruit and vegetables in Nepal is limited, despite the diverse food environment that results from the meshing of different cultures and climates found across the country. Aspects such as seasonality, prices and influx of imported products play an important role when unpacking the low per capita consumption.

Seasonality and a varying demand in fruit and vegetables have a strong influence on prices as high fruit and vegetable prices drive up the costs of a healthy diet, which is calculated to exceed Nepali's yearly average income by $72 \%$. For example, prices of vegetable and fruits are considerably higher than for cereals; often, the difference is three or fourfold depending on the time of the year and 
season, and the influx of imported products. Higher prices for fruit and vegetable actors help offset the higher risks faced in the fruit and vegetable value chains.

Although fruit and vegetable consumption can be deemed as low, margins for smallholder farmers are high, especially for those who practice good crop management and have access to water through irrigation schemes - even on smaller plots of land. Margins could, in any case, be enhanced should the costs of labor be reduced. For example, introducing small-scale technologies in the sector would help farmers address the rising scarcity of labor (and cost), thus enhancing the profitability of fruit and vegetable production.

When considered as a whole, the fruit and vegetable sector is generally fragmented and not as efficient as other traditional sectors. Secured markets help value chains become more efficient and better coordinated, with low(er) transaction costs. A factor that influences value chain efficiency is direct relations between farmers and consumers. Only in a few instances do farmers engage with consumers directly, prompting consumer-based innovations such as pesticide-free products within the larger farmer-base. However, direct farmer-consumer market channels have a limitation in scalability due to the current market dynamics with many existing intermediary actors predominating.

Women have become increasingly involved in agricultural production, including for fruit and vegetables as, besides rural-to-urban migration, Nepal has a history of predominantly males working abroad for shorter or longer periods. Women have, to a lesser extent, been involved in value-addition (processing, marketing) and, where this occurs, there is greater evidence of women controlling the income they earn from sales. Where women have become more involved only in production, there is less evidence of a direct correlation between these efforts and their empowerment. Literature and field studies did find that increased income controlled by women increases overall food consumption but it is unclear whether this usually includes more fruit and vegetables.

With regards to the institutional environment, many actors in Nepal are becoming increasingly aware of the importance of safe food, self-sufficiency in food production and consumption of fruit and vegetables. These topics are high on the agenda of public institutions, as well as social networks and civil society organizations. However, ensuring (and enforcing) that food is safe, together with the creation of reliable and trusted markets and communication channels with consumers, remains a daunting challenge. This lack of clarity erodes consumers' acceptance of fruit and vegetables.

For all the gaps and challenges identified, there is a nevertheless a myriad of investment opportunities that can contribute to the transformation of food systems and its various outcomes, such as food and nutrition security. 


\section{Introduction}

\section{$1.1 \quad$ Background}

The Bill and Melinda Gates Foundation (BMGF), in collaboration with the Foreign, Commonwealth \& Development Office (FCDO) in the UK, seek to investigate the potential role of the horticultural sector for healthier diets and increased income generation, notably by women. Wageningen University and Research (WUR) conducted this study.

In Phase I, a global scoping study of the horticultural sector in West Africa, East Africa and South Asia was conducted. This Phase I study was based on available literature and secondary data. The research team identified as a result leverage points for interventions in the food system to promote production, trade and consumption of fruits and vegetables. Phase II tested the validity and feasibility of the identified leverage points in seven countries - Bangladesh, Burkina Faso, Ethiopia, India, Nepal, Nigeria, and Tanzania. This report describes the findings of Nepal country study.

\subsection{Objective}

The objective of the study is to identify opportunities for action and investment in Nepal's fruit and vegetable sector to guide future engagement by the BMGF. The potential leverage points, identified in in the global Phase I scoping study, are operationalized through eleven research questions and presented in Section Error! Reference source not found..3 of this report.

\subsection{Research questions}

The leverage points identified in Phase I, together with the research questions chosen to test their validity and feasibility, are shown in Table 1.1.

Table 1.1 Leverage points and research questions

\begin{tabular}{|c|c|}
\hline Leverage point & Research question Phase II \\
\hline \multirow{3}{*}{$\begin{array}{l}\text { 1. Increase in production leads } \\
\text { to lower fruit and vegetable } \\
\text { consumer prices }\end{array}$} & $\begin{array}{l}\text { How does seasonal variation in weather influence fruit and vegetable production, } \\
\text { yields and market prices (disaggregated by fruit and vegetable category)? }\end{array}$ \\
\hline & $\begin{array}{l}\text { What are the main barriers for farmers to increase the production of fruits and } \\
\text { vegetables? }\end{array}$ \\
\hline & $\begin{array}{l}\text { What keeps farmers from intensification? Do female producers face greater barriers } \\
\text { than male producers, and are there examples that have lowered these? } \\
\text { Are quality inputs and services accessible and is the enabling environment supportive } \\
\text { to intensification? }\end{array}$ \\
\hline \multirow{3}{*}{$\begin{array}{l}\text { 2. Reduction in cost price will } \\
\text { make production of fruit and } \\
\text { vegetable more profitable to } \\
\text { smallholders }\end{array}$} & $\begin{array}{l}\text { How much are the production costs and can we compare them across the seven } \\
\text { countries? }\end{array}$ \\
\hline & What happens to the farm gate price when costs are reduced? \\
\hline & What happens to the income of farmers when farm gate prices are lower? \\
\hline
\end{tabular}


Leverage point

3. More efficient value chains

can lead to lower fruit and

vegetable consumer prices

4. More secured fruit and vegetable markets increase value chain efficiency, farmer income and reduce wastage

\section{Intermediary actors}

communicate consumer needs to producers and (jointly) develop innovative food products
Research question Phase II

Does value chain efficiency result in lower farm gate prices and/or consumer prices? Data on prices: farm gate and consumer prices. What are the risks, costs and types of coordination for the key fruit and vegetable categories? How can more efficiency be achieved and are there examples of such enhanced efficiencies?

Are there examples that more secured markets (more formal) are beneficial to smallholder farmers?

How should farmers benefit from such arrangements?

How do traders and processors (male and female) connect to consumers? Are they organized to support each other?

Do they impose standards on producers?

What examples are there of women succeeding? Are these exceptions or at scale in the different levels of the food value chain?

Are there examples of traders and processors (male and female) that are capable of responding to consumer needs by developing innovative food products?

What are conducive conditions for information sharing and what is the role of trust (as social construction of exclusivity)?

\section{More and higher diversity in} fruit and vegetable crops produced and traded leads to more and more diverse fruit and vegetable in the food environment

7. Prices of fruit and vegetable are always higher compared to other food categories

Has the introduction of new fruit and vegetable varieties contributed to more fruit and vegetable consumed?

What are the trends in fruits and vegetable consumption in the seven countries, are these dependent on season, geographical location (production/non-production areas), and can these trends be disaggregated by different types of fruits and vegetables? Why are prices to consumers of fruit and vegetable higher compared to other domestically produced food crops? Are there differences between categories of fruit and vegetable and what explains these differences?

8. Women participation in fruit and vegetable production and value chain operations leads to higher income and empowerment by women

\section{Higher income by women} leads to higher consumption of fruit and vegetable

\section{Public enforcement of} standards will enhance food safety for consumers of fruit and vegetable

\section{Nudging and public} extension will improve fruit and vegetable consumer awareness and consumption preferences
Are there examples of successful integration of women in profitable production and value chain operations? What explains these successes and is there evidence of them being scaled up?

What business models work best for women's inclusion and leadership?
If fruit and vegetable become more commercial (or scaled up) will the income be controlled by women?

Inventory of relevant standards (public/private).

How are they enforced?

Do consumers trust standards? How is it appreciated by other stakeholders in the food system?

Are there specific policies and strategies formulated and implemented for improving diet quality among different consumer categories and do they include strategies on fruits and vegetables? Is there evidence of their impact?

How have policies enabled women to address systemic constraints that they face, and to successfully access sufficient nutrition?

Inventory of innovative examples implemented, who is implementing it? Are consumers' motives taken into account?

12. Increased food safety, consumer awareness and What are consumers' motives and barriers to (not) consume (specific) fruits and vegetables, such as indigenous vegetables, for different household members?

preferences lead to higher acceptability of fruit and vegetable

13. Improved availability, affordability and acceptability leads to intake of fruit and vegetable that meets the recommendations
If everything is as planned (available, affordable, acceptable), will consumers increase fruit and vegetable intake in their diet, according to the recommendations? 


\subsection{Approach}

The approach used to answer the research questions includes:

1. An extensive review of more than 60 reports, journals, articles, and government data published on fruits and vegetables in Nepal;

2. A selection of three vegetable and three fruit crops for better operationalization of the research questions;

3. Facilitation of five (qualitative) focus group discussions (FGDs) and fifteen interviews with key informants (KII) in the fruit and vegetable sector in Nepal, which were held between March and April 2021. Representatives from different stakeholder groups in the fruit and vegetable sector were invited: farmers, traders, associations, policymakers, processors or wholesalers, to name a few. An equitable gender balance was sought.

Given the wide diversity of the fruit and vegetable sector in Nepal, we selected three vegetable crops - Mustard green, bitter gourd, and pumpkin, and three fruit crops - lapsi, mango and kiwi, so that research questions and leverage points remained central and focused. The crop selection was based on four criteria: nutrition, socio-economic (potential), gender participation and empowerment, and market prospects (see Section 3.2 for more information). Once the selection was complete, producing areas and actors involved in these subsectors were identified. The facilitation of five FGDs in different districts (Pokhara, 2x Lalitpur, Kavre and Kathmandu), and key informant interviews followed. Appendix 1 provides an overview of the FGDs and KIIs, and their location.

Focus group discussions and interviews with key informants shed light on topics that have been hardly studied to date (i.e. consumption, costs of production). In addition, FGD participants and key informants shared interesting experiences and novel cases in the fruit and vegetable sector. These experiences and cases are described in boxes throughout the report.

Chapter 4 discusses the results of the various data and information collected by answering the research questions identified in Phase I.

\subsection{Reading guide}

Chapter 2 gives a general overview of the fruit and vegetable sector in Nepal, including current domestic area and production figures, consumption, prevailing seed system and the role of gender and women in the fruit and vegetable sector. Chapter 3 describes the criteria followed for the selection of the six priority fruits and vegetables, with a description of the significance of those selected crops in the country. Chapter 4 and its sub-sections analyses the leverage points and associated research questions as described in Table 1.1. The final Chapter compiles the major findings of the study by reflecting on the leverage points. 


\section{State of play}

\section{$2.1 \quad$ Country profile}

Nepal is a landlocked country located in South Asia, which shares a border with India border that stretches $1,770 \mathrm{~km}$. In the North, the Tibet Autonomous Region of China and Nepal border runs for $1,389 \mathrm{~km}$. The country occupies $147,516 \mathrm{sq}$. km of land, with the distance from East to West of $800 \mathrm{~km}$ while the South-to-North transect covers $250 \mathrm{~km}$. Nepal encompasses three main geographical regions: Mountain region, Hilly region, or mid hills and the Terai region. Figure 2.1 shows the geographical map of Nepal. The country's distinctive geography includes fertile plains, forests and marshy grasslands. The Himalayan Mountains range between 4,877 m to 8,848 m, including eight of the world's ten highest peaks including Mount Everest. The mountain region accounts for about $64 \%$ of total land area.

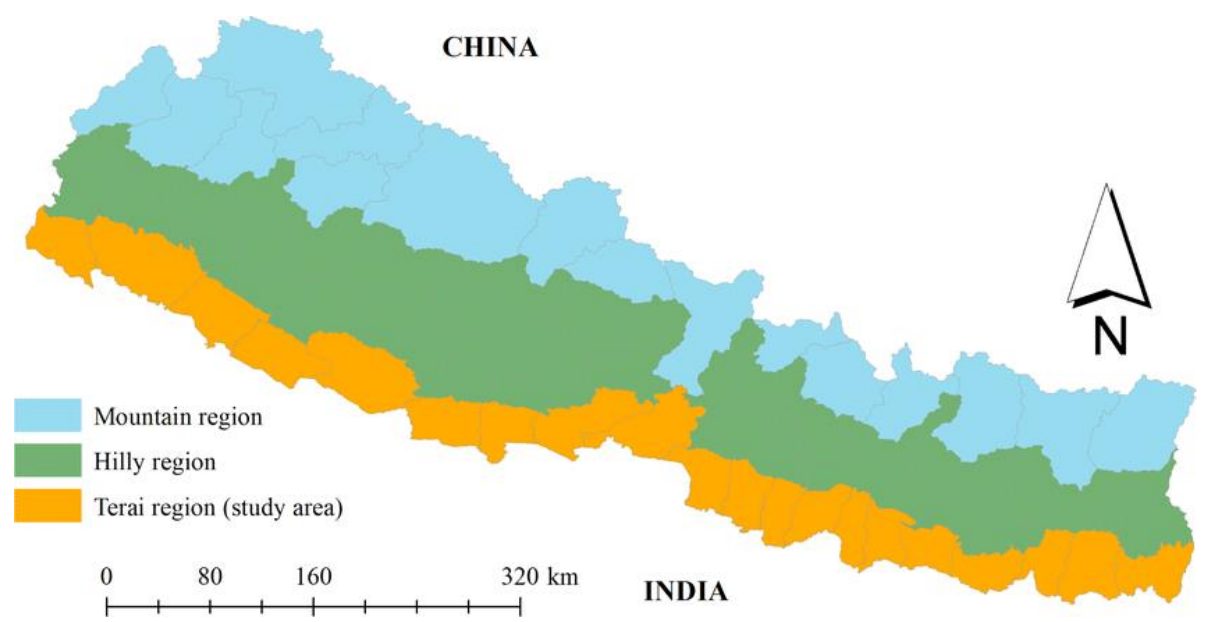

Figure 2.1 Geographical map of Nepal Retrieved from Joshi et al. (2018).

Nepal's current population has reached 30 million, with a population density of 203 inhabitants per $\mathrm{km}^{2}$. Population continues to increase steadily, with an average growth of about 3 million people every 5 years. In $2020,21 \%$ of the total population resided in urban areas with Kathmandu as the capital city ${ }^{1}$.

According to the new federal constitution, there are three spheres of government: central government, provincial government consisting of seven provinces, and local government including the municipal government (Nagarpalika). There are about 276 municipalities, including 460 rural municipalities (Gaunpalika).

The United Nations lists Nepal as one of the least developed countries in terms of low gross national income, weak human assets and having a high degree of economic vulnerability. In 2020, the Nepal Development Update produced by the World Bank stated that $18.7 \%$ of the Nepali population are living under the poverty line currently (US\$1.9/day), and 30\% live close to the poverty line. Nepal ranked 142 out of 189 countries attending to the Human Development Index value in 2020.

Nepal is primarily an agricultural-based economy, which employs $78 \%$ of the economically-active population, and generates over one fourth of gross domestic product (GDP) $(27.6 \%$ in 2019 , down

1 https://censusnepal.cbs.gov.np/ 
from $29.2 \%$ in 2016/17). Within the agricultural sector, vegetables contribute $9.71 \%$ and fruits and spices contribute $7.04 \%$. In 2019, total annual exports were valued at US\$74,000 for fruits, and US\$9.22 million for vegetables. India remains the main country receiving Nepali fruit and vegetable exports. Remittance inflow in Nepal is estimated to contribute $25.4 \%$ to national GDP worth Rs3.4 trillion (US\$29.8 billion) (Nepal Economic Forum, 2019).

\subsection{Overview and trends analysis for fruit and vegetable produce in Nepal}

In the 'Agricultural Development Strategy (ADS 2015-2035)', the foundation for growth is laid out for the agriculture sector (MoAD, 2016). In this document, farming households are clustered according to their socio-economic characteristics in three groups:

1. Group 1: Small commercial households owning land size between 1.0 to 5 ha, which represent around $25 \%$ of rural families;

2. Group 2: Subsistence farmers owning land size from 0.5 to 1 ha, which represent $27 \%$;

3. Group 3: Landless or near landless farmers, which represent nearly $50 \%$ of rural population (1.6 million families).

Table 2.1 breaks down the three groups by size, number and area of holdings.

Table 2.1 Landholding distribution 2011/2012

\begin{tabular}{|c|c|c|c|c|c|c|}
\hline \multirow[t]{2}{*}{ Size of holding } & \multicolumn{3}{|c|}{ Holdings } & \multicolumn{3}{|c|}{ Area of Holdings } \\
\hline & $\begin{array}{r}\text { Number } \\
(' 000)\end{array}$ & Percent & $\begin{array}{r}\text { Cumulative } \\
\text { percent }\end{array}$ & $\begin{array}{r}\text { Area } \\
(\text { '000 ha })\end{array}$ & Percent & $\begin{array}{r}\text { Cumulative } \\
\text { percent }\end{array}$ \\
\hline 0.5 ha and under 1 ha & 984.0 & 26.5 & 80.0 & 695.1 & 27.6 & 46.8 \\
\hline 1 ha and under 5 ha & 732.7 & 19.7 & 99.7 & $1,258.1$ & 49.9 & 96.7 \\
\hline Total & $3,715.6$ & 100.0 & & $2,522.5$ & 100.0 & \\
\hline
\end{tabular}

Source: MoAD 2016 (adopted from Census 2011/12).

About $78 \%$ of all households cultivate on less than 1 ha of land, with a higher proportion (53\%) cultivating on land ranging in size from 0.2 to 0.5 ha. The remaining $25 \%$ cultivate on $0.5-1.0$ ha land $($ MoAD, 2016)\. Farmers owning less than 0.5 ha, face real challenges in making farming profitable (GoN, 2015).

With regards to farming systems, smallholder or subsistence farmers practicing mixed farming without irrigation prevail in the agricultural sector in Nepal, with about $70 \%$ of the total land. Smallholder mixed farming with irrigation remains small at 15\%. Figure 2.2 shows the distribution of total land per farming systemin percentage as per data compiled, and FGDs and KIIs. 


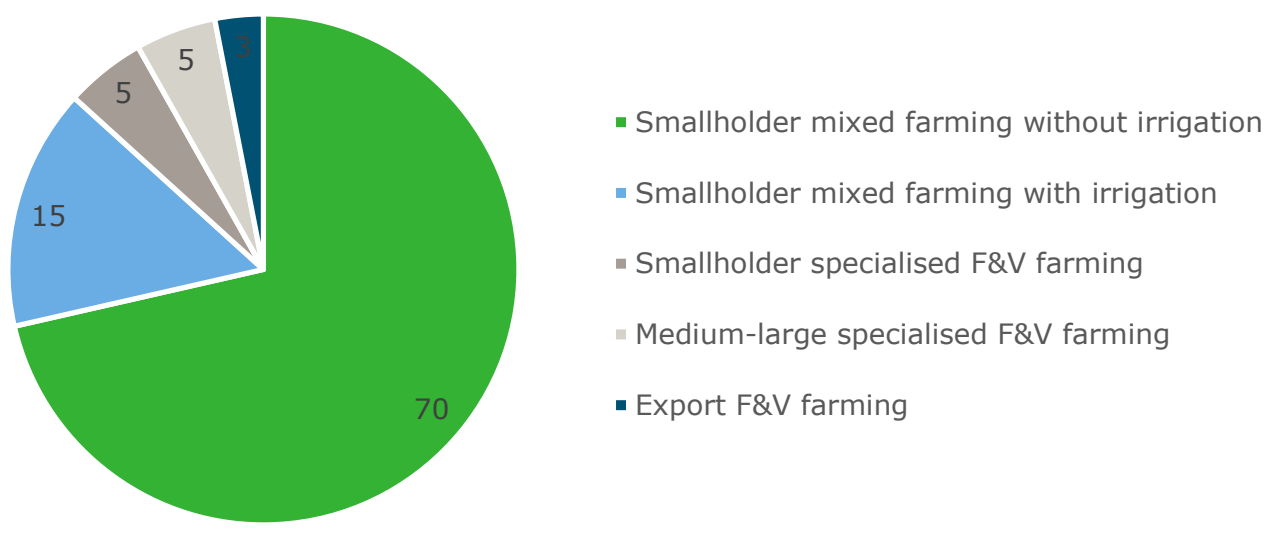

Figure 2.2 Percentage of total F\&V area under different farming systems Source: FGDs and KIIs.

Smallholder specialized fruit and vegetable farming and medium-large specialized fruit and vegetable farming compromise 5 and 7\%, respectively; the remaining 3\% of total land is dedicated to exports.

To help implement the ADS, the 'Prime Minister Agriculture Modernization Project (PMAMP)' was designed to boost productivity and commercialization of major cereals, fish, fruits and vegetables over a 10 -year span. Launched in 2016, the ambitious plan aims to convert agricultural areas in Nepal into well-defined and crop-specific areas that receive government support to intensively produce crops. The new structure comprises of super-zones (commercial areas of more than 1,000 ha), zones (over 500 ha), blocks (over 50 ha), and pockets (over 10 ha).

In 2020, Agritech Nepal ${ }^{2}$ reported that a total of 16 super zones (from the initial target of 21), 106 zones (total target: 300 ), 336 blocks (total target: 1,500) and 2,776 pockets (total target: 10,000 pockets) have been created. Interestingly, vegetable production is to be promoted across the different areas - from the super zone (Kaski district, focusing on vegetable production) to zones (more than 15 districts), blocks and pockets. Special attention is given to vegetable production in zones given the opportunity to consolidate produce and improve the income of farmers and other actors in the sector. Similarly, the fruit crops mandarin, sweet orange and apples are to be promoted in super zones and zones. Banana and mangos are also included in zones. Districts assigned to fruit production are Sindhuli, Jumla, and Syangja.

\subsubsection{Area and volume of fruit and vegetable production}

The production of fruits (excluding bananas) has not grown over the last 10 years. Fruit yield productivity dropped between 2013 and 2017. Inadequate manure and fertilization management, emergence of pest and diseases and low renovation of old trees were some of the factors identified in data consulted and causing a yield drop in 2013 and 2014. The productivity trend seems to be reversing as shown in Table 2.2.

Vegetable production takes place across the Terai $(<600 \mathrm{~m}$ ) and mid-hill regions (between 600 $1,500 \mathrm{~m}$ ), with $55 \%$ and $40 \%$ of the total vegetable production area, respectively. The remaining $5 \%$ is grown in the high-hill region (above $1,500 \mathrm{~m}$ ). Overall, national production (in tons) of vegetables has grown significantly - 39\% over the last 10 years (see Table 2.2). The combination of more land dedicated to vegetables, as well as a spike in productivity explains this increase. Productivity of vegetables (yield in t/ha) has increased by over 10\% - from $12.4 \mathrm{t} / \mathrm{ha}$ in 2010 to about $14.4 \mathrm{t} / \mathrm{ha}$ in 2018. Data from the Kalimati market, in Kathmandu, also illustrates the increase in vegetable production. Over the period $2014 / 15$ to $2018 / 19$, there was a $33 \%$ increment in vegetable supply with an average yearly growth of $8 \%$.

2 http://nepalagritech.com.np/ 
Table 2.2 Area (ha) and production (t) of fruits in Nepal

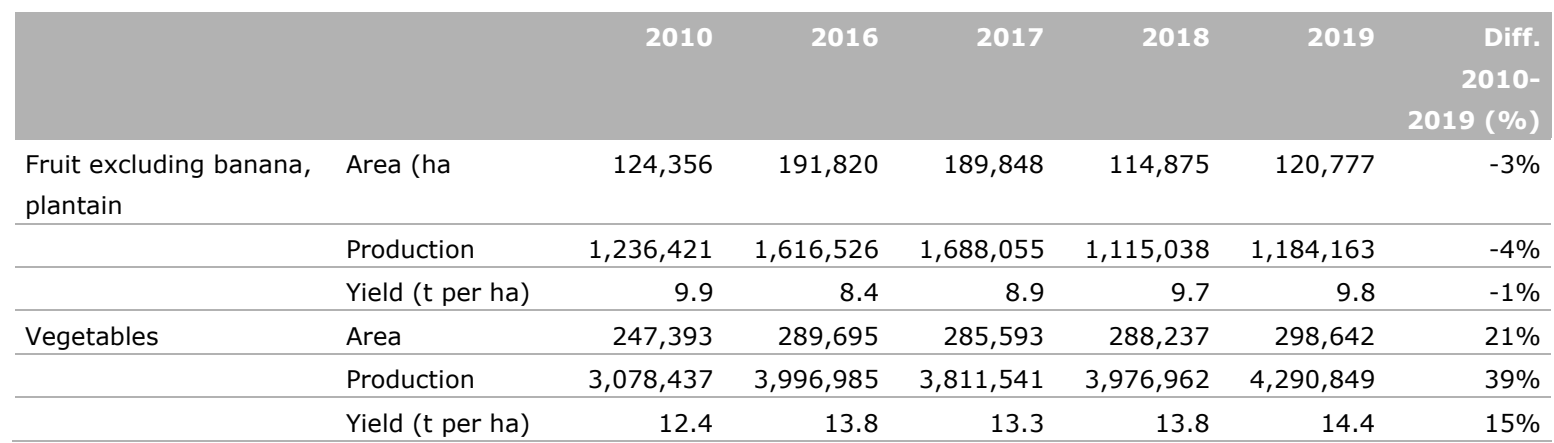

Source: FAOSTAT.

According to the Ministry of Agriculture and Livestock Development (MoALD), the most produced vegetable crops in descending order are cauliflower, cabbage, tomato, onion, radish, broadleaf mustard, cucumber, bitter gourd, bottle gourd and brinjal (MOALD, 2020). Figure 2.3 provides an overview of the production figures and yields for these vegetables. Amongst these vegetable crops, tomatoes provide the highest yields, and onions provide the lowest.

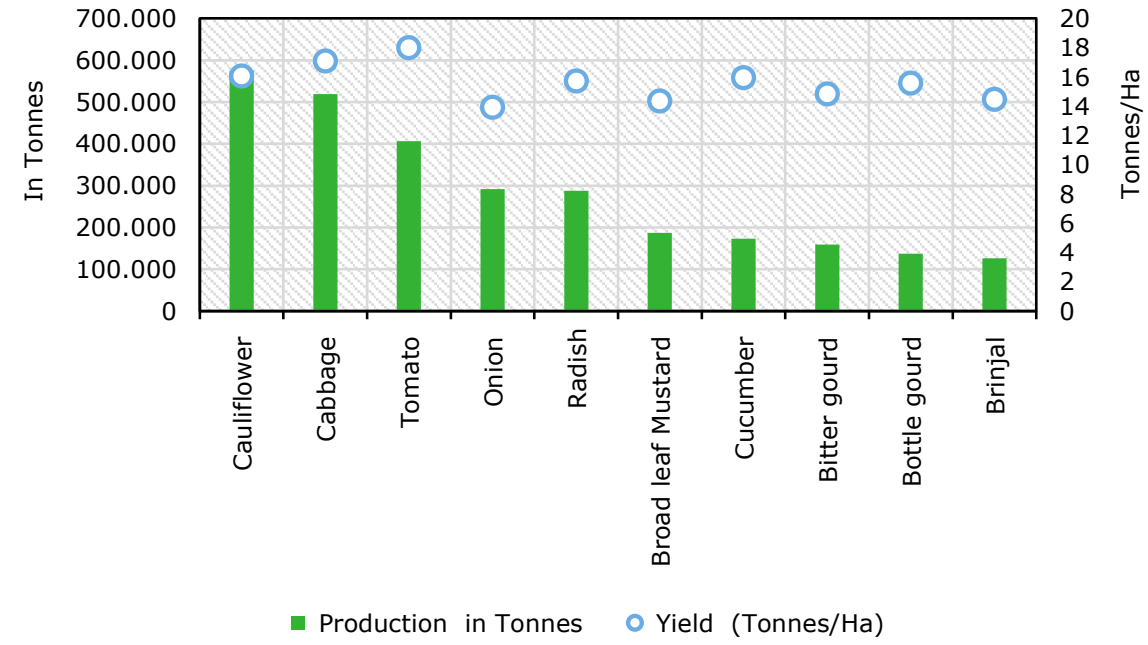

Figure 2.3 Top 10 vegetables by production

Source: MOALD (2020).

Figure 2.4 shows the top ten production of fruits in descending order: mango, banana, mandarin, litchi, sweet orange, lime, pear, apple, guava, and jackfruit. Amongst these crops, bananas are the highest yielding, and limes are the lowest. 


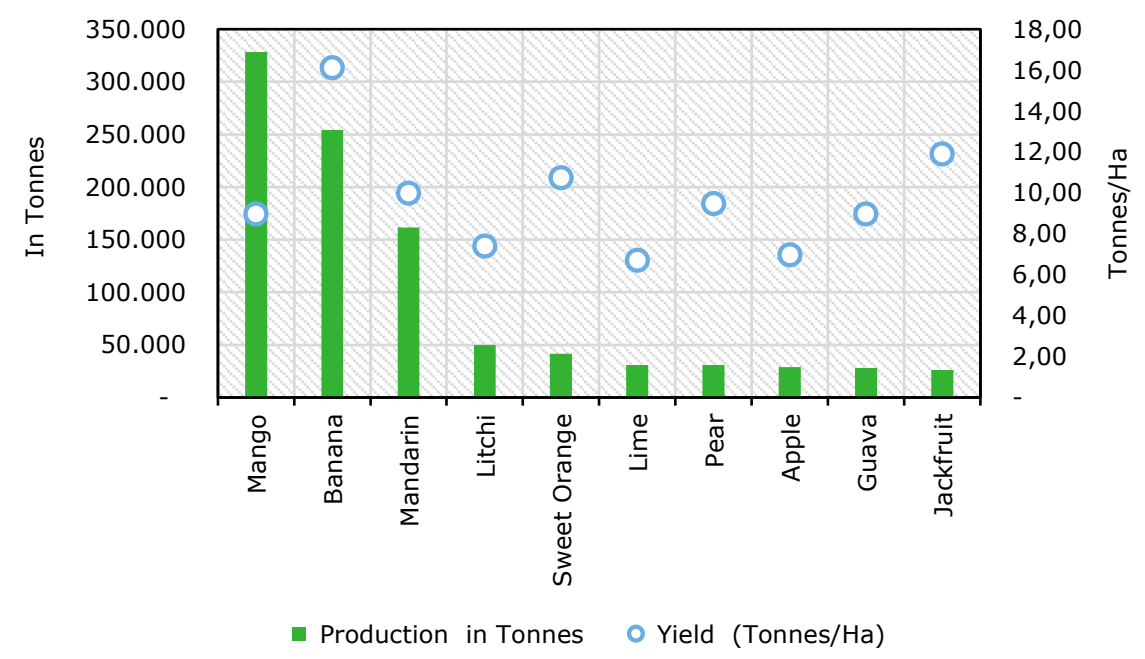

Figure 2.4 Top 10 vegetables by production

Source: MoALD (2020).

\subsubsection{Production areas}

As mentioned previously, the land used for vegetable cultivation has increased by $20 \%$ in the last 10 years, equivalent to more than $7 \%$ of Nepal's total agricultural land. It is estimated that $40 \%$ of vegetable production is used for household consumption and $60 \%$ is sold in the markets (CBS, MoALD, 2009/10). An increased awareness among farmers around the high profitability of vegetables, as well as the government's active promotion and the rise in vegetable markets have led to this growth. Meanwhile, the cultivation area of fruits has increased by $42 \%$ in the last 10 years. Figure 2.4 showed the evolution of cultivation areas for both fruit and vegetables over the period 2009-2019.

Figure 2.5 shows the area in ha per district. Most of the pocket areas for vegetable production are located in the Terai (South) belt, and some districts in the central region adjoining to Kathmandu district.

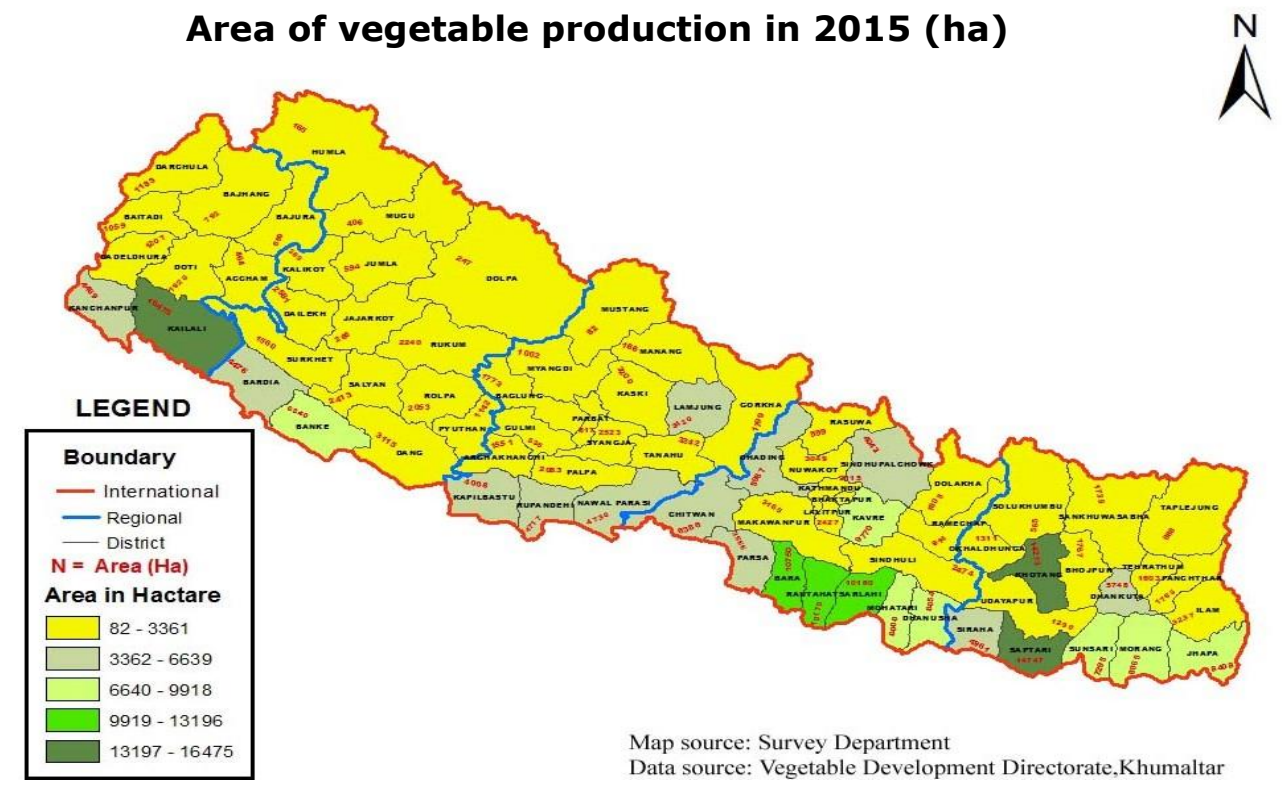

Figure 2.5 Area of vegetables production

Retrieved from the National Centre for Potato, Vegetable and Spice Crops Development. 
Fruits crops are typically grown in the mid-hills, or hilly region. Unfortunately, a similar map with the distribution of most fruits crops in the country was not found. However, Figure 2.6 shows the distribution of lapsi, which stretches along the mid-hill areas. Most fruit crops follow a similar distribution pattern.

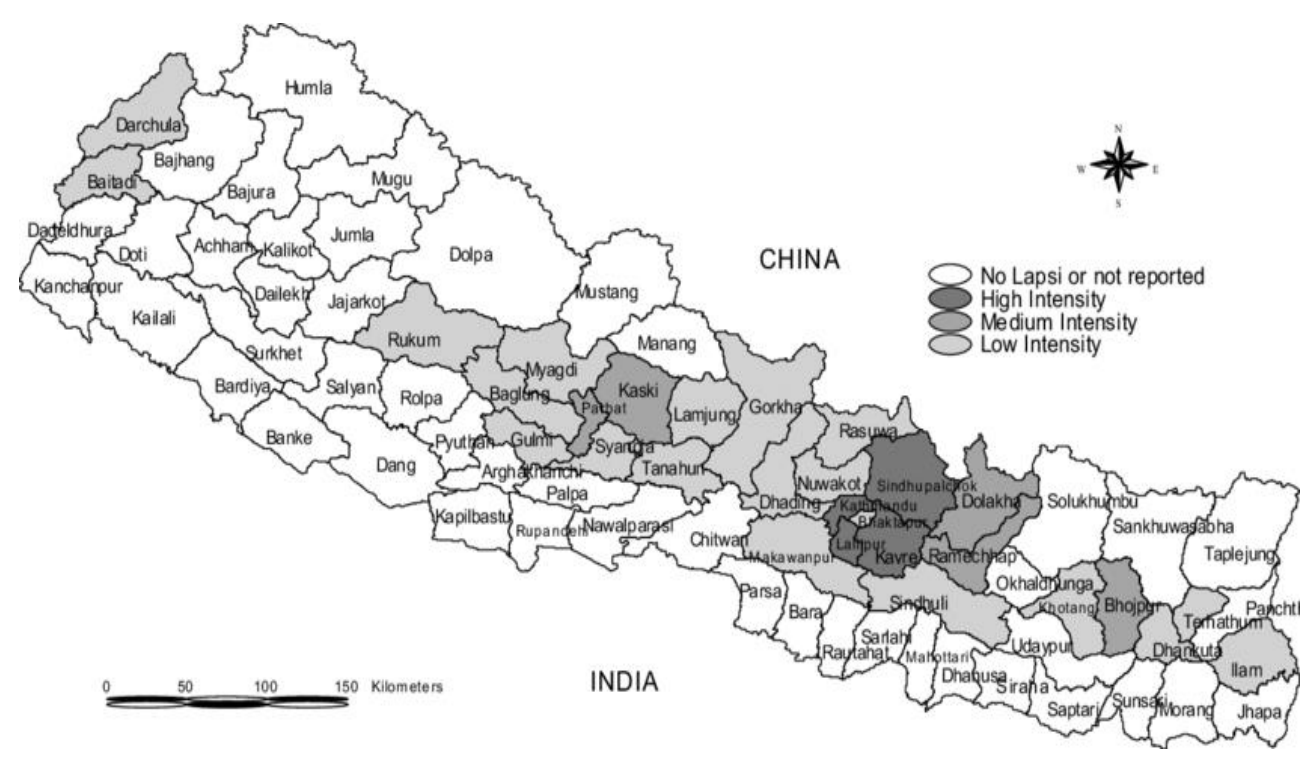

Figure 2.6 Production areas for a fruit crop: lapsi Retrieved from Paudel et al. (2003).

\subsubsection{Consumption of fruits and vegetables}

Comprehensive national data on the intake of fruits and vegetables is lacking. However, a selection of surveys indicate that only $3-4 \%$ of the population meets the requirements of a healthy diet.

Nationwide studies reported very low fruit and vegetable consumption rates among the Nepali population. To date, very few studies have been able to provide factual data on the fruit and vegetable intake in the country (Nepali, 2020). Nevertheless, we provide a detailed account of the studies conducted thus far, and their findings. The following results are described on amount of servings consumed. The World Health Organization recommends at least $400 \mathrm{~g}$ of vegetables and fruits per day - or five servings of $80 \mathrm{~g}$ each.

In 2013, a group of researchers conducted a nationwide study on the fruit and vegetable consumption within a group of 777 adults, of which $70 \%$ were female. This study concluded that $98.3 \%$ of the males and $97.8 \%$ of the females did not consume the recommended five servings per day (Vaidya et al., 2014). Similarly, another nationwide research conducted in 2015 on the burden and determinants of non-communicable disease risk factors in Nepal found that $99 \%$ of the 4,200 respondents consumed less than five servings per day (Aryal et al., 2015). Findings from a STEPS survey Nepal 2019 report published by Nepal Health Research Council also reports very low fruit and vegetable consumption. More than 5,500 adults participated in the survey. Findings showed that $96.3 \%$ women and $97 \%$ men had insufficient intake of fruits and vegetables. Moreover, only $10.1 \%$ of the adults knew about the correct servings of fruits and vegetables intake per day (Ministry of Health, 2019). The most recent study on fruit and vegetable consumption in Nepal dates back to September, 2020. In this cross-sectional study, 2,815 participants were interviewed, of which 1,843 were female and 972 were male. The study found that $10.2 \%$ of respondents consumed equal or more than five servings a day, and $89.8 \%$ consumed less than five servings of fruits and vegetables a day (Nepali et al, 2020). Data collected during the FGDs and KIIs ${ }^{3}$ also support the perception that fruit and vegetable consumption in Nepal is underwhelming.

\footnotetext{
3 For the complete list of FGDs and KIIs, consult Appendix 2.
} 
It is worthwhile referring to the global burden of disease (GBC) as an indication of current national consumption. Through the food system dashboard (foodsystemsdashboard.org), modelled estimates based on data from multiple sources can be consulted. As the dashboard also indicates, estimates vary greatly nationally and sub-nationally and 'thus may under or overestimate dietary intake'. In Nepal, per capita intake of fruits was estimated to be $68 \mathrm{~g} /$ day in 2017, and that of vegetables, $214 \mathrm{~g} /$ day in the same year, for a combined intake of $282 \mathrm{~g} /$ day. This represents a gap of $30 \%$ with respect to the minimum recommended intake of $400 \mathrm{~g}$ of fruit and vegetables per day. According to FAOSTAT Food Balance Sheets, the average supply of vegetables, in grams per person per day, was 317 in 2017, and 128 for fruits. When combined, it results in $445 \mathrm{~g} /$ person/day, above the minimum intake recommended.

From the above, we can state that while studies conducted to date confirmed that, overall, the local population consumes less fruit and vegetables than the minimum recommended (GBC calculated the gap to be about 30\%), FAO's data suggests that there is about enough grams per person per day of vegetables and fruits available in the country's food supply to meet the minimum requirements. Importantly, FAO's indicator does not consider the affordability, access of fruit and vegetables among the population or food losses along the value chains.

\subsubsection{Seed system}

Overall, the seed sector in Nepal is unregulated and, at times, operated in a haphazard manner. Most seeds are produced by farmers themselves and re-used and/or exchanged without involving markets. Vegetable seeds are recognized as a lucrative enterprise for improving farmers' livelihoods and addressing issues of self-sufficiency, food security and economic development of rural communities (CEPREAD Annual report, 2009; and HVAP report, 2011). In 2009, vegetable seed production in Nepal contributed to about $16 \%$ of total vegetable seed demand in the country.

As reported by the government, only around 1,000 t of vegetable seeds were produced in 2010, from a total seed production of $35,000 \mathrm{t}$. The demand for vegetable seeds is projected to grow to $2,400 \mathrm{t}$ in 2025. About one-fifth of the total demand of vegetable seeds was imported in 2009 .

Figure 2.7 describes the current vegetable seed value chain. The four different colors denote the distinct market channels for seed growers (farmers). Data on the characterization of these farmers were not found. The formal seed system in Nepal includes public organizations such as the Nepal Agricultural Research Council (NARC) and the National Seed Company Limited, NGOs, seed growers, cooperatives, seed companies and seed retailers. Very few companies integrate grading, standard packaging and labelling of vegetable seeds in a horizontally-integrated business. In this regard, there is an absence of well-established seed marketing companies in Nepal and inadequate quality control infrastructure. Currently, the major areas for vegetable seed production are located in the mid and high-hills. The hilly area of Nepal offers a micro-climatic diversity suitable for producing vegetable seeds.

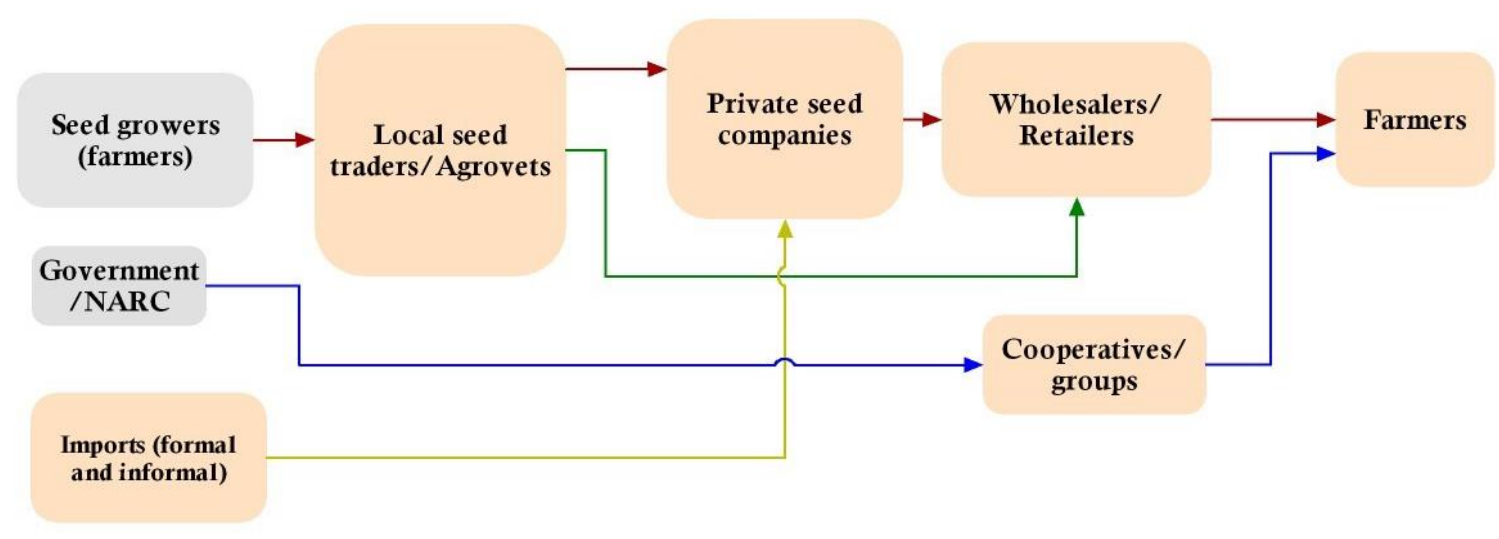

Figure 2.7 The vegetable seed value chain

Source: Authors' compilations. 
The seed vision of Nepal (2013-2025) is the guiding document available for overall development of the seed sector, which focuses on marketing of high yield and quality seeds across the country through strengthening of seed networks and seed supply channels with public and private partnership modalities. As some authors argue, a more organized vegetable seed production and distribution systems is deemed necessary in the context of the growing demand for quality vegetable seeds.

\subsubsection{Gender and women's roles}

As in other countries, gender roles and relations are undergoing a transition in Nepal, which is reflected in the agricultural space, as well as more broadly. The combination of household and agricultural work that women contribute to in rural areas is still not recognized as constraining to women's overall opportunities. However, a number of factors are contributing to the change in the role of women in Nepali society; higher rates of overall education for women and men allow women to take on more income opportunities, be it through small-scale initiatives, such as kitchen gardens, or starting and scaling agribusinesses. Under the constitution introduced in 2015, a third of federal and provincial parliamentary seats are reserved for women, and local-level elections across the country have resulted in over 14,000 female elected officials in public offices, which is literally changing the face of politics. Finally, many Nepalis go abroad to work as migrant labor, sometimes for years; while some women go abroad, the vast majority are men, which leaves the household and farmstead (for those that have it) to be cared for by their wives. This situation, in combination with the rising cost of living, has driven many women, by necessity, into agribusiness of some sort - supported in part by donor- and public-funded programs. Evidence of women contributing to household income through produce sold via aggregators is becoming more widespread. Cooperatives are a key driver, both for women's economic as well as social change in agriculture. Some women become business leaders in their own right, providing inspiration to others. Much of this is supported through sub-national, handson programs (see 4.8 .3 for policy examples). 


\section{Identified research questions}

\subsection{Introduction}

The present study seeks to validate possible leverage points for action and investments in the fruit and vegetable sector in Nepal. We undertake this validation by researching key questions that cover the entire spectrum of the sector - from production to value chains, markets, and consumption to name a few items. Table 2 outlines the leverage points and the questions selected.

The fruit and vegetable sector constitutes a wide array of crops. For this reason, and to be able to focus interactions with the FGDs and KIIs, the research team selected a number of crops as a proxy to better understand sector dynamics, and with the ultimate goal of answering the research questions proposed. Section 3.2 details the crop selection made.

\subsection{Selection of fruits and vegetables}

The selection of crops, three fruits and three vegetables, was based on four criteria: nutrition, socioeconomic (potential), gender participation and empowerment, and market prospects.

- Nutrition: what current crops in Nepal contribute to healthier diets given their nutritional value? Nutritious crops may or may not be widely consumed yet.

- Socio-economic (potential): do the selected crops have the potential to become an important source of income for smallholder farmers and women?

- Gender participation and empowerment: Do women participate in the various activities along the value chain of the said crop, and do women have opportunities to be empowered at any stage of the said value chain?

- Market prospects: what is the potential for growth of the selected crops, either in terms of productivity, and income generation for farmers and actors involved in the value chain?

It is important to note that not all crops score high across all four criteria. Some have higher nutritional values than others, for example, or appear to be more gender inclusive. It is the totality of all six crops that meet the criteria, which serves as a proxy to answer the questions proposed below.

Based on the above criteria and consultations with experts, the selected crops included:

- Mustard green: A common and popular vegetable crop in Nepal, available throughout the year. It contributes to iron, vitamin C, vitamin A and folate intake. It is also considered a sentinel crop ${ }^{4}$ and representative of the green leafy vegetables sub-group. For a list of sentinel food groups, see Appendix 3. Women are commonly engaged in production due to ease of cultivation, and through cooperatives or farmers' groups. Mustard green, which can be processed into pickles and is demand year-round, offers opportunities for off-season production.

- Bitter gourd: Among the top 10 vegetable crops by volume, bitter gourd is widely consumed, with women being engaged in production and sales, and with potential for off-season production. It is also linked to numerous health benefits, including blood sugar control and cholesterol levels. At present, many development organizations (iDE, JICA, or FAO) and projects (KISAN) working in the vegetable sector have identified Bitter gourd as a potential cash crop to improve the livelihood of rural smallholder farmers.

- Pumpkin: Provides a good source of vitamin A and is regularly consumed in the country. It is often cultivated by farmers with only minimal land. Pumpkins can be stored for up to 6 months. Women grow and sell pumpkin in rural villages.

\footnotetext{
${ }^{4}$ Crops consumed widely and exemplar for the different food groups.
} 
- Lapsi: Available in Kathmandu and nearby districts. Consumers generally prefer this fruit due to its sour taste. Nowadays, Nepalis living abroad demand processed products made from this fruit, for example pickles, fruit tarts, and sour candy. To date, a number of female entrepreneurs process and sell lapsi.

- Mango: Highly consumed in raw and processed forms. Mangos are supplied in large quantities (top 1 fruit produced by volume), with high demand during June through August. Women are involved in production, processing and trade especially in Terai districts. Importations from India to meet demand are also common. The consumption of mangos contributes to vitamin $\mathrm{C}$ and improves iron/zinc bioavailability).

- Kiwi: Cultivated in more than 22 districts of Nepal and gradually expanding in more districts (MoALD, 2020), Kiwi is becoming a popular fruit crop among Nepali farmers and have seen an increasing demand from hotels and restaurants. Within a short period, the production has increased from $719 \mathrm{t}$ in 2016/17 to 3,372 $\mathrm{t}$ in 2019/20. Kiwis. Successful cases of women engaging in kiwi farming have been reported (see Section 4.8.1 for an example). Kiwis are rich in vitamin C.

With this crop selection in mind, a number of producing areas and actors involved in these subsectors were identified. Next, the team held five FGDs in different districts (Pokhara, Lalitpur, Kavre and Kalimati) with representative actors, using the research questions to guide the process. Each FGD addressed 2-4 research questions. Key informant interviews followed shortly after the completion of FGDs. Appendix 1 provides an overview of the FGDs and KIIs, and their location. 


\section{$4 \quad$ Validation of research questions}

\subsection{Introduction of the selected food supply systems}

\subsubsection{Description of actors}

The fruit and vegetable sector in Nepal broadly comprises of input suppliers, farmers, traders, wholesalers and retailers. Actors who provide various services such as extension and those working in the enabling environment, both public (i.e. government bodies) and (semi)-private (i.e. NGOS, projects) are included in the large constellation of actors in the fruit and vegetable sector. Section 4.1.4, enabling environment, focuses on these actors.

Sector activities in both vegetable and fruits are similar - for example, traders dealing with only fruits only, or only vegetables, or a combination of both are found. As explained in Chapter 2, smallholder farmers generally grow a mix of crops, with only commercial smallholder farmers or the larger subsistence farmers specializing in one or more fruit and vegetable crops. In our crop selection, we observe that smallholder farmers that move into crops that require certain (initial) investment, be it irrigation schemes, land preparation, or higher quality inputs, for example, tend to specialize in a few vegetable crops, or one, as their primary source of income. Kiwi farming, which is becoming popular among female entrepreneurs, offers an example of crop specialization given the higher costs initially involved and knowledge required. Moreover, the larger the landholding, the more specialized fruit and vegetable farmers become. On the market end, specialized wholesalers and retailers for fruits and vegetables are present in regional and national markets, as well as fruit and vegetable shops and Local Haat Bazars.

Table 4.1 shows the large diversity of actors in the fruit and vegetable sector per sector activity or function. For a detailed description of the actors below, consult Appendix 3.

Table 4.1 Actors/structures in the fruit and vegetable sector, per sector activity

\begin{tabular}{ll} 
Sector activity & Actors/structures fulfilling the activity \\
Input supply & $\begin{array}{l}\text { Agrovets; Government (through their province and municipal level offices Krishi Gyan } \\
\text { Kendra and Gaunpalika, respectively); cooperatives, NGOs }\end{array}$ \\
\hline Production & Landless or near landless farmers; smallholder farmers, or subsistence farmers; commercial \\
smallholder farmers
\end{tabular}

\section{Input supply}

All input suppliers are included - agrovets, governments, NGOs, and cooperatives. In the fruit and vegetable sector, input suppliers provide all essential inputs and services to farmers. The government of Nepal, ${ }^{5}$ through their provincial and municipal level offices, is active in the provision of inputs and services to farmers through a subsidy program, facilitating loans which are supposed to be repaid shortly after harvest. During the FGDs, farmers reported that, although the program is in place, more efforts should be made to transfer modern production techniques and technologies to farmers.

Cooperatives can provide services such as capacity building, access to finance, or aggregation through collection centers and collective marketing of produce. More information on cooperatives can be found in Sections 4.4.2 and 4.5.2. In addition, farmers have also observed growing engagement with NGOs in the access to inputs, improved market linkages and capacity building activities.

5 The role of the government in shaping the regulatory environment in the fruit and vegetable sector can be consulted in Section 4.9. 


\section{Production}

Section 2.2 explains the current supply base in the fruit and vegetable sector per landholding and farming system.

\section{Trading}

Often referred to as middlemen, traders, or commission agents, many actors may act as traders in different regions, or value chains, or times of the year. The proliferation in traders and the many forms that trading can take may be caused by factors such as the perishability and seasonality nature of fruit and vegetables, the lack of proper storage and cooling facilities, or the transportation challenges that Nepal poses as a country. For example, remote rural areas with difficult road access see very few local traders with modest means of transportation available (i.e. small pickups). For those living in rural areas, produce is collected at farm level and transported to major market centers, where urban traders and wholesalers operate. On the other hand, in areas better connected to road infrastructure, cooperatives and farmers' groups may often act as traders to farmers, overseeing the flow of produce from farm to markets. Section 4.5.1 elaborate on the linkages between farmers and (female) traders. It is important to note that traders often specialize in either vegetables or fruits, or even a single commodity within the fruit group e.g. mango traders or lapsi traders. Specialized fruit traders focus on handling, transport requirements, and quality.

\section{Marketing/selling}

Fruit and vegetable shops are a common sight in Nepal, with an estimated percentage of the dominant fruit and vegetable urban retail markets of about $50 \%$. Regional (i.e. Haat Bazars) and retail national markets of about $20 \%$, with smaller street vendors dealing with $10-15 \%$. Supermarkets and direct supply to consumers range from a combined $5-10 \% .{ }^{6}$ Retail markets are move diverse in urban areas, both in term of market places and assortment of fruits and vegetables offered. In urban centers, the effect of seasonality in fruit and vegetables is cushioned by the availability of imported products throughout the year, whereas rural areas are more bound to seasonal flows of fruit and vegetables.

The next section offers an account of the number of actors in a seemingly crowded fruit and vegetable sector.

\subsubsection{Number of actors}

As Table 4.2 shows, data on the number of actors become less available as we move further in the generic fruit and vegetable value chain.

Table 4.2 Number of actors

\begin{tabular}{|c|c|c|c|}
\hline Sector activity & Actors fulfilling the activity & Number of actors & Source \\
\hline Input supply & $\begin{array}{l}\text { Agrovets; } \\
\text { Government (through Agriculture Centre office); } \\
\text { fruit and vegetable cooperatives }\end{array}$ & $\begin{array}{l}4,900 \\
- \\
200\end{array}$ & Economic survey, 2019/20 \\
\hline Production* & $\begin{array}{l}\text { Landless or near landless farmers; } \\
\text { Smallholder farmers, or subsistence farmers; } \\
\text { Commercial farmers }\end{array}$ & $\begin{array}{l}\text { Fruits: N/A } \\
\text { Vegetable farmers: } \\
3,243,500\end{array}$ & CASA, 2020 \\
\hline Trading & $\begin{array}{l}\text { Farmers' groups; } \\
\text { Traders, or middlemen; } \\
\text { Wholesalers; } \\
\text { Retailers }\end{array}$ & $\begin{array}{l}81,400 \\
\text { N/A } \\
\text { N/A } \\
\text { N/A }\end{array}$ & $\begin{array}{l}\text { National Sample Census of } \\
\text { Agriculture, CBS, } 2013\end{array}$ \\
\hline Marketing/selling & $\begin{array}{l}\text { Fruit and vegetable stores } \\
\text { Local Haat Bazar; } \\
\text { Regional markets; } \\
\text { National markets; } \\
\text { Urban Haat Bazaars } \\
\text { Supermarkets; } \\
\text { Online e-commerce }\end{array}$ & $\begin{array}{l}\text { N/A } \\
\text { N/A } \\
\text { N/A } \\
>4 \\
>5 \\
>10 \\
>10\end{array}$ & Own estimation \\
\hline
\end{tabular}

\footnotetext{
6 Note the reader that these estimates are based on consultations with different actors and own experience.
} 
The exact data on number of actors per sector activity, available from trusted sources, is lacking for the most part.

\subsubsection{Dominant type of value chain}

In reality, no one type of fruit and vegetable value chain prevails. Rather, many different types of value chains co-exist in the fruit and vegetable sector. Figure 4.1 show the common flows of fruit and vegetables, from production to markets.

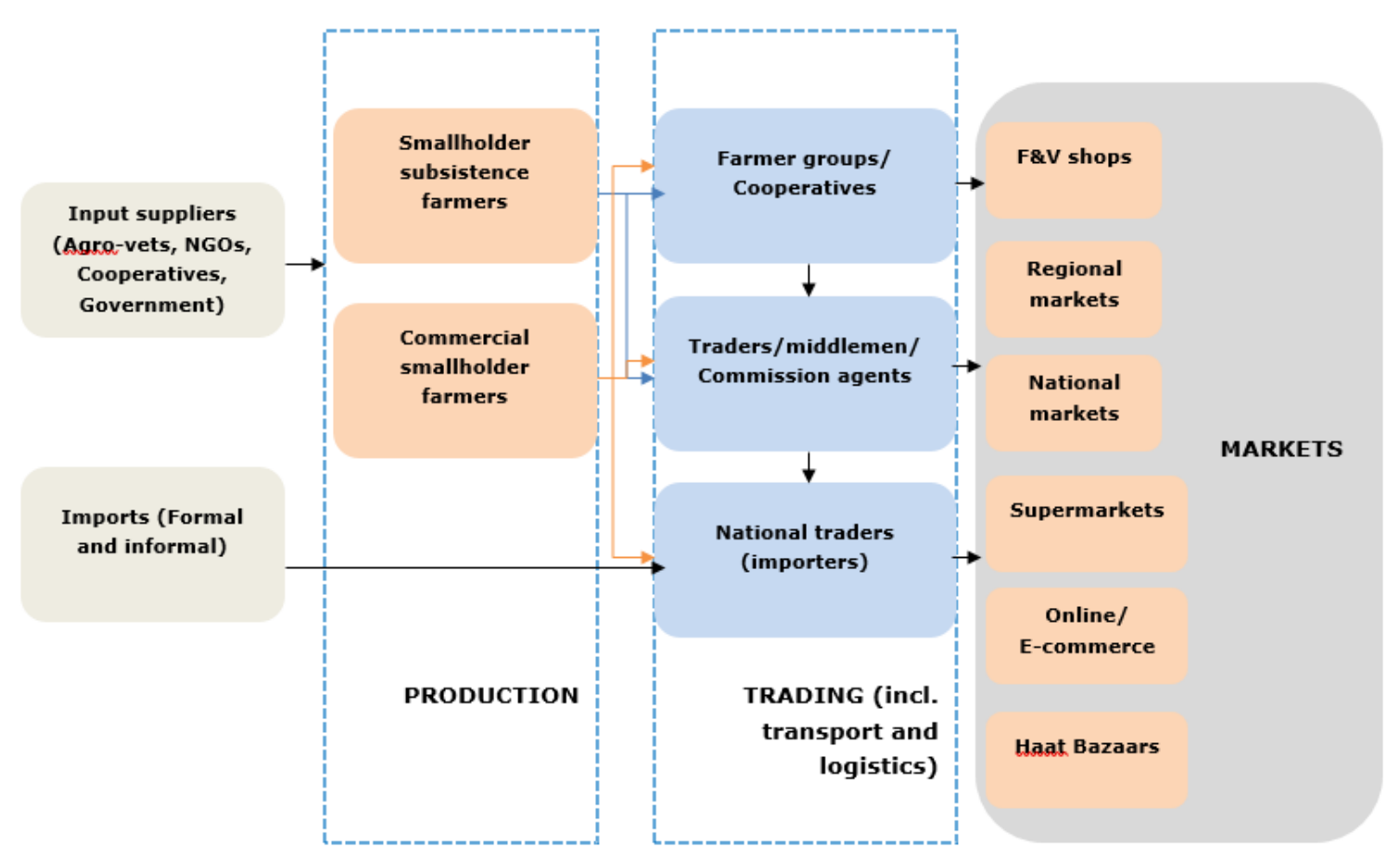

Figure 4.1 A generic representation of the fruit and vegetables value chains in Nepal Source: Authors' compilations.

As Figure 4.1 indicates, both smallholder subsistence and commercial smallholder farmers typically sell their produce either to collection centers (service offered by some cooperatives), farmer groups or local/national traders. These, in turn, sell to district or market wholesalers operating in national and regional markets. Retailers purchase the produce from this type of actor for later sales in regional or national markets, fruit \& vegetable shops or Haat Bazaars. The latter will be addressed in Section 4.5.1. Supermarkets and online/e-commerce have begun to market increasing volumes of fruit and vegetables. A list of supermarkets can be found in Appendix 3.

Another value chain channel that supplies fruits and vegetables to national traders revolves around imports from India and China. Nepal imported vegetables worth Rs14.61 billion/US\$125 million in 2018/19, and fruits valued at Rs10.44 billion/US\$89 million from India (Government of Nepal, 2020). Often, the flow of imported fruit and vegetables comes to bridge the supply gap caused by the acute seasonal availability of local fruit and vegetables. In some other instances, the importation of fruits $\&$ vegetable still takes place during the local harvest season. For more information on imports, consult Section 4.2.2.

\subsubsection{Enabling environment}

Nepal's enabling environment in the fruit and vegetable sector is intricate. Since 2008, with the federal system in Nepal, many government institutions at various levels have some type of mandate in the fruit and vegetable sector. Similarly, many development organizations, NGOs and international NGOS (INGOs) are active in the fruit and vegetable sector. Table 4.3 lists all the institutions that 
operate in the enabling environment, and Appendix 4 outlines the large number of ongoing projects in the fruit and vegetable sector.

Table 4.3 Institutions in the enabling environment

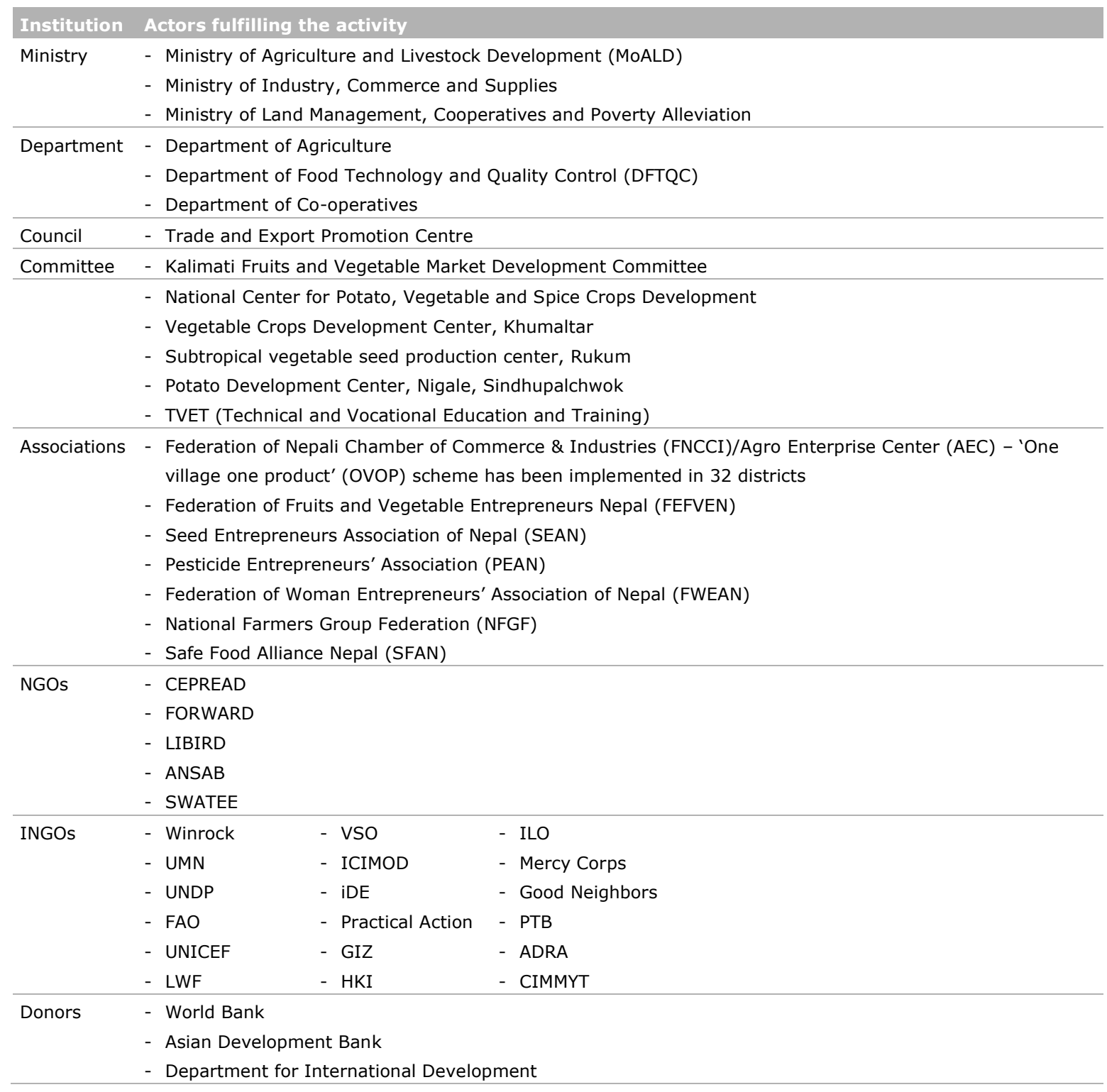

A crowded enabling environment can be deemed both as a positive development given the wide interest in promoting fruit and vegetables, but also negative: many farmers and direct actors involved in the fruit and vegetable value chains remain very unclear as to what rules and regulations apply, and what institutions are to provide actual support. FGDs confirmed the belief that most farmers are not aware of the fruit and vegetable's enabling environment and the respective institutions.

\subsection{Increase in production leads to lower fruit and vegetable consumer prices}

\subsubsection{Seasonal variation}

The selected fruit and vegetables are grown in different parts of the country and are thus available year-round to consumers. At the same time, greenhouse technology is becoming more popular among commercial smallholder farmers to tap into the off-season market. 
Fruit and vegetables are largely seasonal and grown depending on the topography, altitude, temperature and rainfall of the production regions. Fruits and vegetables can be clustered into three major production seasons (winter, summer and monsoon). See Figure 4.2 for a summary of the crops selected, per season.

\begin{tabular}{|c|c|c|c|c|c|c|c|c|c|c|c|c|c|}
\hline \multirow[b]{2}{*}{ Altitude } & \multirow[b]{2}{*}{ Description } & \multicolumn{4}{|c|}{ Winter } & \multicolumn{4}{|c|}{ Summer } & \multicolumn{4}{|c|}{ Monsoon/Rainy } \\
\hline & & Nov & Dec & Jan & Feb & Mar & Apr & May & Jun & Jul & Aug & Sep & Oct \\
\hline & \multicolumn{13}{|l|}{ Vegetables: } \\
\hline \multirow{4}{*}{$\begin{array}{l}\text { Mid-hills (1500 } \\
\text { to } 600 \mathrm{~m} \text { ) }\end{array}$} & \multicolumn{4}{|l|}{ Bitter Gourd } & $\mathrm{P}$ & $\mathrm{P}$ & $\mathrm{PH}$ & $\mathrm{PH}$ & $\mathrm{H}$ & $\mathrm{H}$ & $\mathrm{H}$ & & \\
\hline & \multicolumn{2}{|l|}{ Bitter Gourd (Off-season) } & $\mathrm{P}$ & $\mathrm{P}$ & $\mathrm{PH}$ & $\mathrm{H}$ & $\mathrm{H}$ & $\mathrm{H}$ & & & & & \\
\hline & Pumpkin & $\mathrm{H}$ & $\mathrm{H}$ & $\mathrm{H}$ & $\mathrm{HP}$ & $\mathrm{HP}$ & $\mathrm{P}$ & & & & & & $\mathrm{H}$ \\
\hline & \multicolumn{4}{|l|}{ Broad Leaf Mustard } & $P$ & $P$ & $\mathrm{P}$ & $\mathrm{PH}$ & $\mathrm{H}$ & $\mathrm{H}$ & $\mathrm{H}$ & $\mathrm{H}$ & \\
\hline \multirow{5}{*}{$\begin{array}{l}\text { Terai and river } \\
\text { basin }(<600 \mathrm{~m})\end{array}$} & \multicolumn{2}{|l|}{ Bitter Gourd } & $P$ & $P$ & $\mathrm{P}$ & $\mathrm{PH}$ & $\mathrm{H}$ & $\mathrm{H}$ & $\mathrm{H}$ & & & & \\
\hline & Bitter Gourd (Off-season) & $P$ & $P$ & $\mathrm{P}$ & $\mathrm{H}$ & $\mathrm{H}$ & $\mathrm{H}$ & & & & & & \\
\hline & \multicolumn{2}{|l|}{ Pumpkin } & $P$ & $\mathrm{P}$ & $\mathrm{P}$ & $\mathrm{H}$ & $\mathrm{H}$ & $\mathrm{H}$ & $\mathrm{H}$ & & & & \\
\hline & Broad Leaf Mustard & $\mathrm{PH}$ & $\mathrm{PH}$ & $\mathrm{H}$ & $\mathrm{H}$ & & & & & & & $P$ & $\mathrm{P}$ \\
\hline & \multicolumn{13}{|l|}{ Fruit: } \\
\hline $1,000-2,500 m$ & Kiwi & $\mathrm{H}$ & $\mathrm{H}$ & & & & & & & & & $\mathrm{H}$ & $\mathrm{H}$ \\
\hline $600 \mathrm{~m}$ & \multicolumn{6}{|l|}{ Lapsi } & $\mathrm{F}$ & $\mathrm{F}$ & $\mathrm{F}$ & $\mathrm{H}$ & $\mathrm{H}$ & $\mathrm{H}$ & \\
\hline$<600 \mathrm{~m}$ & \multicolumn{6}{|l|}{ Mango-Maldaha } & $\mathrm{H}$ & $\mathrm{H}$ & $\mathrm{H}$ & & & & \\
\hline
\end{tabular}

Figure 4.2 Seasons for the selected fruit and vegetables Key: P=planting; $H=$ harvesting.

Nepal has a diverse range of micro-climates. Across the mid-hills and Terai regions, the three selected vegetable crops are grown between 6 to 8 months in the year. The vegetables are harvested in the mid-hills during the rainy season (July to Oct), which is off-season in the Terai area. In contrast, the winter season (November to February) is favorable for vegetable production in the Terai areas, such as Chitwan, Lalbandhi and others. As an example, bitter gourd can be cultivated in the Terai and midhills, as well as an off-season crop inside a greenhouse (polyhouse or plastic house) so farmers can supply during the low season, and thus obtain higher prices. Figure 4.2 also shows the seasonality aspect for all three selected fruit crops. Section 4.2.3 details the changes observed in the seasons due to erratic weather patterns, which are causing significant losses to farmers.

Commercial farmers grow off-season vegetables in a controlled environment, such as greenhouses. After initial piloting, commercial and lead farmers (both types between 1 and 2 ha) in Nepal (some supported by the government and/or projects) have begun to adopt greenhouse technology thus far, after a piloting phase. Plastic tunnels, polythene houses and glasshouses, all known locally as greenhouse farming techniques, help avoid frost, excessive winter cold and strong wind, and raise the temperature even during the winter season (USAID, 2011). Critically, greenhouse technology also requires an irrigation scheme, efficient use of inputs and good crop management.

Typically, farmers use polythene tunnels to raise seedlings of tomato, brinjal, sweet pepper, beans, and cucumber before planting out. However, in the winter season, the whole cropping period takes place in greenhouses e.g. Bitter gourd. However, estimating the actual production per year coming from these type of technologies for the selected crops requires further study.

Figure 4.3 illustrates the average wholesale price fluctuations for five of the six selected crops. Note that prices for some crops, like mangos or lapsi, are not available for all months. Data have been retrieved from the Kalimati market website. 


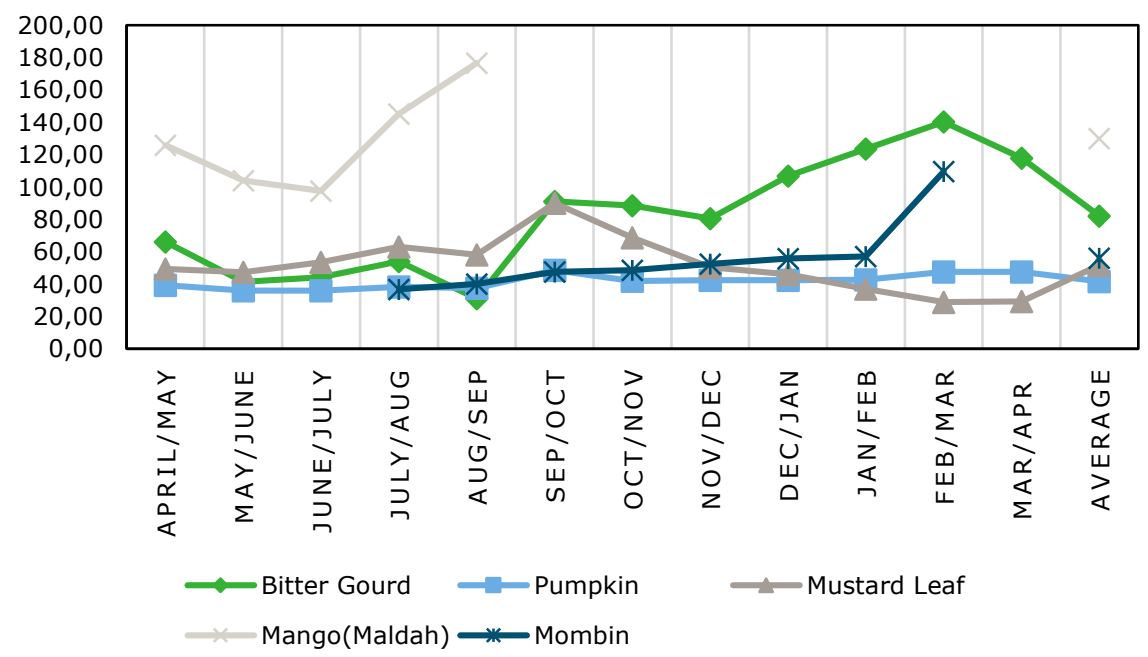

Figure 4.3 Average wholesale price $(N P R / \mathrm{kg})$ retrieved from the Kalimati website (2019) ${ }^{7}$ *Mombi - also known as lapsi.

Figure 4.3 shows high price fluctuation in all crops (more so in fruits than vegetables), showing a fourfold increase for bitter gourd from the lowest to the highest price throughout the year. Pumpkins show a more stable trend. It is important to note that imports, already discussed in Section 4.1.3 adds additional stress to prices for local fruits and vegetables (Kavre, FGD; Kalimati, FGD; Ghusel, FGD). Both India and China, as economies of scale, produce highly mechanized fruit and vegetables making use of government subsidies and incentives. This phenomena is observed with bitter gourd and pumpkin, widely imported from India. Mango and Kiwi are also imported from both China and India.

Based on our data, FGDs and KIIs, we conclude that seasonality in fruit and vegetables has an influence on prices, which undergo fluctuations, compounded by the relative large influence of imports on the price of locally produced fruit and vegetables. Seasonal variability of fruits, and therefore price fluctuation, is more pronounced than that of vegetables given their nature (one harvest per year) and remote locations.

\subsubsection{Barriers for farmers to increase production}

Limited quality inputs, in terms of affordability and availability, greatly constrain fruit and vegetable production. It is not easy for farmers to acquire inputs such as fertilizers, chemicals and seeds, which agrovets source from countries like India. Most farmers mentioned this challenge during FGDs: inputs, for most fruit and vegetables, are often unavailable at the right time of the season. In farmers' eyes, 'input prices do feel prohibitive more often than not'.

Another hurdle to overcome for aspiring fruit and vegetable farmers, who wish to grow and specialize in fruit and vegetable production, is the limited access to water through irrigation schemes, as well as access to finance. Lastly, the instability of farm gate prices, which stems from the seasonal character of fruits and vegetables also erodes farmers' confidence to increase production. Market traders, in their role as intermediaries, tend to remain unclear with regards to price setting and price fluctuation throughout the year. More information on prices is detailed in Sections 4.2.1 and 4.7. In terms of gender, female farmers face the same barriers, as well as gender-specific ones as listed in Section 4.2.4.

With small landholdings, farmers face proportionately more barriers to increasing production. As mentioned in Section 2.2, near landless smallholder farmers represent about $48 \%$ of the total rural population. In recent years, landholdings have become more and more fragmented, particularly in the mountains compared to the Terai. It was reported by key informants that many farmers in this size range, 0.5 ha or less, own different portions of land spread across multiple locations due to the

7 https://kalimatimarket.gov.np/ 
continuous division among family members over the years, making it difficult to reach a scale of production where some modern technologies and machinery can be considered a viable investment.

Vegetable production is highly intensive, much more so than fruit production. Vegetables are deemed as short duration crops with quick returns. Conversely, fruit production is less intensive and provide returns once a year, after harvest. According to FGDs, intensifying fruit and vegetable production appears difficult due to:

1. Lack of access to water for irrigation, an essential element for improving the productivity of fruit and vegetable production. Most farmers are dependent on seasonal rainfall and lack access to modern irrigation technologies, such as pumps or drip irrigation. This need is especially felt by vegetable farmers. Vegetables crops, such as bitter gourd, are not tolerant to drought and pumpkin and leafy vegetables also require a regular supply of water. Fruit crops are typically rainfed.

2. Poor road networks to transport goods to market in a cost-effective manner. Fruit and vegetable production tends to be located in remote areas and tend to be less well-connected with main road networks.

3. Insufficient consolidation of produce, which makes transportation expensive. Despite the proliferation of collection centers, vegetable farmers generally do not produce large quantities, which incurs high freight costs per unit. To protect margins, vegetable farmers (subsistence) sell their produce to traders, who can arrange transportation from farm to market venues. Fruit farmers, like those producing mango and lapsi, connect to traders directly.

4. Limited access to (new) knowledge and information. Farmers from more traditional and wellestablished crops, such as mango and lapsi, have received little or no new knowledge on crop practices or new varieties. Kiwi, on the other hand, is seen as an emerging crop and has hence been introduced in communities through either development projects or government programs (see Section 4.8.1 for a case study on introduction of kiwi). Learning how to implement pest and disease management strategies is an example of the limitation of farmers to access various knowledge. Pest and disease incidence remains a constant pressure, although interviewed farmers often downplayed the importance of controlling pest and diseases when compared to other challenges detailed above.

The points above illustrate that farmers growing 'priority' crops $^{8}$ have, in general, better access to knowledge and technological solutions, as well as strong(er) connection to markets. For these farmers, intensifying crop production becomes a question of market opportunities and prices more than increasing production itself. In our crop selection, kiwi farmers are more likely to undertake crop intensification, compared to mango or lapsi farmers for example.

According to farmers' opinions, increasing fruit and vegetable production is possible should farm gate prices for fruits and vegetables remain stable and fair at the time of harvest. Nevertheless, FGDs show that, in secured markets, when prices follow a more 'stable' pattern, only the more skilled and financially-able farmers are able to take part in these value chains given the higher requirements and investments involved. See Section 4.4.4 for more information on secured markets.

Box 1: For farmers, (un)fair and (un)stable pricing hampers fruit and vegetable production the most

During the FGD held in Kavre, farmers provided their views on increasing production: 'Fair pricing for fruit and vegetable is the major driving factor for increasing production. Once there is fair pricing in place then farmers will be motivated to improve produce quality and quantity, and hence invest in quality inputs and practices such as grading and packaging.' Another example of the continuous 'price gap' is the competition with imported commodities. 'Importing the same commodity from India and China at harvesting time has largely affected producers of Nepal as they do not get a fair price and have to sell making a loss.'

We conclude from literature and our FGDs that smallholder fruit and vegetable farmers face multiple barriers to intensification, most notably input pricing and quality, land fragmentation, which the smallest scale farmers suffer from the most, and fluctuation in farm gate prices. Counterintuitively,

8 Authors understand priority crops as those promoted by the Government and/or development partners for reasons of nutrition, economic value or (gender) inclusion. 
crops that are more viable are not automatically better for smallholders as minimum skills and finance provide a barrier to entry that only larger-scale farmers are able to overcome. Smallholders need additional support in order to benefit from priority crops.

\subsubsection{Yield gaps and production losses}

\section{Yield gaps}

Yield gaps in fruit and vegetable production remain considerable and, to some extent, avoidable. Inputs such as seeds or fertilizers are often not available on time, disrupting the entire crop planning and harvest. Input dealers source their goods from other countries, especially India, leading to logistical challenges that result in the disruption of the input supply chain. As a result, delayed planting may lead to various problems - poor crop emergence, high incidence of pest and diseases, or overlap with either dry or rainy periods, to cite a few examples (Kavre, FGD). As a cash crop, bitter gourd farmers incur lower yields notably due to the lack of pesticides and the high incidence of pest and diseases as a consequence. Fruit crops are usually less intensively produced, and therefore less subject to reduced yields due to unavailable inputs.

A few authors have attempted to estimate the yields gaps for a number of fruit and vegetables. Among the selected crops, a yield gap of $60 \%$ in kiwi was estimated, based on an actual yield of $4 \mathrm{t}$ per ha, and a potential yield of $10 \mathrm{t}$ per ha (Gautam and Gotame, 2020). It should be noted that this figure should be subjected to further study given that kiwi production is still relatively new in Nepal, and little intelligence has yet been collected on its agronomy. In mangos, the Nepal Horticulture Promotion Centre reported a potential yield of about $10 \mathrm{t}$ per ha, which is about a $15 \%$ gap between potential and actual yield. In vegetables, Pandey et al. (2017) calculated a gap in bitter gourd yield of $33 \%$.

\section{Production losses}

Fruit and vegetable losses occur at various stages - production, aggregation and (post)harvest (USAID, 2011). Amongst these, losses due to deficient postharvest handling are deemed as the most significant. Section 4.4.3 addresses post-harvest losses in detail.

Farmers observe production losses caused by natural disasters such as hailstorms, which seem to have increased in incidence and lead to a considerable reduction in fruit crop yields (Pokhra, FGD). Green leafy vegetables, bitter ground and pumpkin crops can also be completely destroyed as a result of hailstorms (Pokhra, FGD). In the case of mangos, strong wind and hailstones caused in 2018 more than 3,000 t to be lost in Saptari district, the major mango producing district of Nepal. More estimates of production losses for the selected crops were unfortunately not found. For the purpose of this study, the research team has estimated losses accrued during production at 5-10\% fruit and vegetable, based on own the team's experience and consultations with sector actors.

We conclude from data and our FGDs that the yield gap for both fruits and vegetables can be between $15 \%$ and as high as $60 \%$. Fruits present a higher yield gap than vegetables. On-farm losses are less documented than those that occur from postharvest up to retail. Section 4.4.3 is dedicated to postharvest losses.

\subsubsection{Gender-specific barriers and opportunities to increase production}

\section{Household responsibilities}

As in other countries in this study, women's double burden in Nepal between household responsibilities and agricultural labor prohibits them from investing more time to gain more knowledge and skills in order to approach agriculture as a micro-business. Evidence of where women have managed to generate greater income has, in part, come from a supportive household environment wherein the husband has recognized his wife's interest to pursue an income-generating activity, and the household provided support by partly taking over other chores (Ghusel FGD).

Although the double burden of household responsibilities and agricultural labor was described as the most common impediment to those looking to scale up from micro-scale production, ownership of 
land $^{9}$ (IOM, 2013) and, related to this, access to finance, are two additional constraints. While credit provision is a challenge more broadly, women's lack of collateral puts them at an additional disadvantage - this even more so as, even though their husbands may be abroad, they are still not recognized as the head of household or able to make a claim to the land that is owned by their husband.

Although women's leadership in agricultural businesses is still low (FAO, 2019), there was a common sentiment in FGD feedback that women have started to raise their voices and stand up for their rights. One anecdotal piece of evidence came from Ms Dipika Adhikari who produces, transports and sells vegetables in different markets around Pokhara. One day when unloading vegetables at a local market, the municipal police told her this was illegal (it wasn't), and started to confiscate her produce. After she argued with them, the police eventually dropped her vegetables and left, and she was able to sell her produce. Without her standing up for her rights, she would not have retrieved her produce.

More generally, as men predominantly go abroad to work, women are left behind to manage the household and land, which has led to agricultural programs mainly working with women and women's groups. Evidence from the Center for Environmental and Agricultural Policy Research, Extension and Development (CEAPRED), which supports various programs in Nepal, illustrated a change both in women's income and confidence. For example, in a project in Udayapur District (SE Nepal), women started earning between Rs800,000-2,200,000 (US\$6,780-18,700), which was higher than their husbands' earnings abroad. As a result, many wives invited their husbands to come home and support them in their business. Mr Keshav Dutta Joshi, from CAEPRED, observed that, more recently when the Swedish ambassador visited a similar project, it was the women who were there to welcome her, not their husbands, as they were recognized as the leads in the project.

The collected evidence illustrates that while women still face systemic constraints to being recognized as entrepreneurs in the fruit and vegetable sectors, attitudinal, policy and programmatic changes have shifted in this direction, along with evidence that this positively impacts on women's lives and livelihoods. This shift, along with an increasing amount of women involved in fruit and vegetable production due to male migration, forms a base from which to scale up.

\subsection{Reduction in cost price will make production of fruit and vegetables more profitable}

\subsubsection{Cost of producing fruit and vegetable}

Labor accounts for the largest cost of production in fruit and vegetables. The problem of hiring labor becomes more acute with the increasing rate of migration from rural to urban and urban to overseas employment (IOM, 2019). Better wages in off-farm employment becomes a problem for farmers. As a result, many farmers that depend on labor are gradually ceasing farming. Overall, smallholder fruit and vegetable farmers fail to track the total cost of labor over the crop season (Ghusel FGD, Pokhara FGD, and Kavre FGD). Another reason for labor shortage is the rapid urbanization of cities and, even in rural villages, agricultural lands are converted into buildings and other infrastructure. Land prices are increasing virtually every day. Those who own land in urban and semi-urban areas are often tempted to sell and invest in buildings, to earn rental income or fixed income from banks.

Various farmers expressed that family members are providing labor especially during production and may also use a 'barter system' in place where labor at the time of cultivation is exchanged between families. Laborers only tend to be hired by commercial-scale farmers.

Smallholder fruit and vegetable farmers growing more traditional crops, such as mango or leafy vegetables, do not tend to use book-keeping. In contrast, few commercial smallholder farmers

\footnotetext{
9 International Organization for Migration (IOM). (2013). Barriers To Women'S Land and Property Access and Ownership in Nepal.
} 
growing more priority crops (i.e. kiwi) do see the value of book-keeping. For those commercial, detailoriented farmers, practices to reduce costs of production have the potential to be adopted more easily.

Despite farmers' overall lack of records, we detail below a breakdown of the current production costs for four of the fruit and vegetables selected. Examples have been drawn from reliable sources and authors' own calculations.

Table 4.4 Cost of production for 1 ha land - bitter gourd

\begin{tabular}{|c|c|c|c|}
\hline$\#$ & Description & Amount in NPR/USD & $\%$ \\
\hline 1 & Seedling & & \\
\hline a & Seeds & $6,000 / 51$ & 3 \\
\hline$b$ & Manure and fertilizer & $10,000 / 85$ & 5 \\
\hline c & Nursery plantation - Labor & $18,000 / 153$ & 8 \\
\hline 2 & Labor & $114,000 / 970$ & 51 \\
\hline 3 & Manure, fertilizer, and micronutrient & $50,000 / 424$ & 22 \\
\hline 4 & Plant protection inputs & $6,000 / 51$ & 2 \\
\hline 5 & Irrigation & $8,000 / 68$ & 4 \\
\hline \multirow[t]{6}{*}{6} & Packaging and transportation & $10,000 / 85$ & 5 \\
\hline & Total cost & $222,000 / 1,884$ & \\
\hline & Production of $20,000 \mathrm{~kg}$ from 1 ha - Cost per $\mathbf{k g}$ & $11 / 0.1$ & \\
\hline & Average selling price Rs50 per $\mathrm{kg}$ - Sales in NPR (Price $\mathrm{x}$ production) & $1,000,000 / 8,475$ & \\
\hline & $\begin{array}{ll}\text { Profit in NPR } \\
\end{array}$ & $778,000 / 6,600$ & \\
\hline & Profit margin in $\%$ & $78 \%$ & \\
\hline
\end{tabular}

Source: Pandey, Raj et al. (2017).

Table 4.5 Cost of production for 1 ha land - pumpkin

\begin{tabular}{|c|c|c|c|}
\hline \# & Description & Amount in NPR/USD & $\%$ \\
\hline 1 & Seedling & & \\
\hline a & Seedling production & $2,000 / 17$ & 1 \\
\hline 2 & Crop production & - & - \\
\hline a & Labor - Nursery & $18,000 / 153$ & 8 \\
\hline c & Manure, fertilizer and micronutrient & $50,000 / 424$ & 24 \\
\hline $\mathrm{d}$ & Plant protection inputs & $6,000 / 51$ & 3 \\
\hline e & Irrigation & $8,000 / 68$ & 4 \\
\hline \multirow[t]{2}{*}{$f$} & Packaging and transportation & $10,000 / 85$ & 5 \\
\hline & Profit in NPR & $788,000 / 6,700$ & \\
\hline
\end{tabular}

Source: Pandey, Raj et al. (2017). 
Table 4.6 Cost of production for 1 ha land - kiwi

\begin{tabular}{|c|c|c|c|}
\hline \# & Description & Amount in NPR/USD & $\%$ \\
\hline 1 & Labor & $115,000 / 976$ & 25 \\
\hline 2 & Sapling & $101,600 / 862$ & 22 \\
\hline 4 & Irrigation & $64,000 / 543$ & 14 \\
\hline 5 & Structure & $60,000 / 510$ & 13 \\
\hline 7 & Packaging & $8,000 / 68$ & 2 \\
\hline \multicolumn{4}{|l|}{ Remark } \\
\hline \multirow[t]{2}{*}{$\mathrm{s}$} & Total cost & $460,600 / 3,910$ & \\
\hline & Production of $4,000 \mathrm{~kg}$ from 1 Hectare - Cost per kg & $115 / 1$ & \\
\hline
\end{tabular}

Source: Tiwari and Bhandari (2020).

Table 4.7 Cost of production for 1 ha land - mango

\begin{tabular}{|c|c|c|c|}
\hline$\#$ & Description & Amount in NPR/USD & $\%$ \\
\hline A & Variable cost: & & \\
\hline 1 & Labor - Permanent & $101,000 / 856$ & $85 \%$ \\
\hline a & Urea & $2,100 / 17.8$ & $2 \%$ \\
\hline b & DAP & $4,050 / 34$ & $3 \%$ \\
\hline \multirow[t]{2}{*}{ d } & Materials & $8,000 / 68$ & $7 \%$ \\
\hline & Total variable cost & $118,450 / 1,000$ & \\
\hline B & Fixed cost: & & \\
\hline 1 & Land rent & $26,000 / 220$ & $63 \%$ \\
\hline \multirow{7}{*}{4} & Total fixed cost & $41,000 / 347$ & \\
\hline & Total cost & $159,450 / 1,350$ & \\
\hline & Cost per $\mathrm{kg}$ in NPR & $13 / 0.11$ & \\
\hline & For 1 hectare land, Productivity is $12,000 \mathrm{~kg} / \mathrm{ha}$ & & \\
\hline & Total sales (25 NPR/kg) & $297,840 / 2,520$ & \\
\hline & Profit margin & $138,390 / 1,200$ & \\
\hline & Profit margin in $\%$ & $46 \%$ & \\
\hline
\end{tabular}

Source: Shrestha et al. (2021).

But are these costs of production higher or lower than other food groups? The Agribusiness Promotion \& Marketing Directorate calculated that the production costs for cereals (i.e. rice, maize, wheat) vary between 13-17 NPR/kg, or 0.11-0.14 USD $/ \mathrm{kg}$, which is slightly higher than vegetables, such as bitter gourd, or pumpkin, with 5-11 NPR/kg. Cereal production incurs higher production costs than vegetables, and is lower than fruits, but with more stable prices year-round (Bhandari and Aryal, 2015). In Section 4.11.1, we address the effects of prices on healthier diets in Nepal.

As Tables 4.4, 4.5, 4.6 and 4.7 and our FGDs show, labor costs for fruit and vegetables commonly vary between $25-65 \%$ and is slightly higher for vegetables than fruits. On the other hand, strong profit margins for both fruits and vegetables, despite high labor costs, suggest the potential of fruit and vegetable production to generate high income for farmers provided that farm-gate prices are within an acceptable range (above minimum prices during peak seasons). See Section 4.7 for more detail on prices. Despite this promising outlook, it is important to note that commercial smallholder farmers who were interviewed stated an important dependency on fetching high prices given the fact that production costs are difficult to reduce on small landholdings (between 1 and 5 ha) with no use of 
small-scale technologies. Furthermore, farmers have to compete with better wages offered in off-farm employment.

\subsubsection{Effects of cost reduction strategies}

Small-scale technologies and modern farming tools and equipment are often considered as the most efficient cost-reduction strategies for vegetables (Kavre FGD, Pokhara FGD). For traditional fruit crops, such as mango and lapsi, limited use of small-scale technologies are also observed. These include irrigation kits, tools for land preparation, harvesting kits or mulching to name a few; these may reduce production costs in the medium-long term by lowering labor costs of and relieving the work burden for female farmers especially. ${ }^{10}$ However, the adoption rate of these new technologies is slow due to the limited financial resources available to farmers. In the past, many projects as well as some ongoing initiatives have attempted to demonstrate new technologies, but adoption rates remain low (Iyob and Witte, 2017). A driver for adoption, according to farmers, is (upward) trends in farm-gate prices as farmers do feel more compelled to invest in small-scale technologies as farm-gate prices increase.

Based on our data and FGDs, reduction in costs can lead to revenue increase at farm level in the medium-term provided that small-scale technologies are introduced which, despite the (little) initial investment, lowers labor costs and relieves the work burden especially for female farmers.

\subsection{Efficient value chains can lead to lower fruit and vegetable consumer prices}

\subsubsection{Increase value chain efficiency}

The seasonal character of most fruit and vegetables and the disconnect between farmers and market actors hamper the efficiency in value chains. In other words, a high product seasonality, in combination with inefficient transport systems and little trust among actors, prevent fruit and vegetable value chains from becoming more efficient.

Fruits and vegetable value chains in Nepal are highly fragmented, populated with many actors sometimes in faraway areas and limited information flowing up and down the chains. Transaction costs are typically high, with varying margins along the chains. Based on personal communications with sector actors, as well as salient data from the FGDs, margins for fruit and vegetable farmers oscillate between $40-50 \%$. Traders' margin set at 5-10\%, which goes up to $15-20 \%$ for fruit and vegetable retailers. For our selection, vegetable value chains tend to be more efficient than fruit value chains (except for kiwi) given farmers' commercial orientation and short crop cycles. Local traders source fresh vegetables from the farm, all the way to the markets. For crops such as mustard leaves, where transportation is not as taxing as with fruits like mangos, the produce flows from growing areas to markets are constant. Sourcing these traditional vegetables throughout the year has brought an efficiency level to actors involved in the value chain, given the fact that income is likely to be more dependent on (high and constant) volume than prices (lower during peak harvest periods).

To date, only a few projects have attempted to increase value chain efficiency, and very indirectly for example, by focusing on building farmers' capacities to produce, and linking them with market traders (i.e. Kisan II project). Transitioning to commercial fruit and vegetable value chains is believed to improve efficiency in the medium term by ensuring a fair income amongst actors. Risks and benefits are often better understood, featuring more formal and long-lasting relationships.

A scheme that is gaining traction in Nepal and appears to contribute towards efficient value chains is contract farming. In this regard, the Government introduced an 'Agribusiness Promotion Act, 2017' (http://nnfsp.gov.np) for the promotion and professionalization of agriculture by strengthening relations between farmers and agribusiness persons or entities. It includes a legal framework for

10 https://thehimalayantimes.com/opinion/commercial-agriculture-some-positive-signs 
contract farming. In this scheme, private sector actors provide a variety of technical inputs and services to farmers, which can include verbal or contractual buyback guarantee agreements. However, in practice, there are reported difficulties in the implementation and monitoring of such a regulation (Ghusel FGD). Section 4.9 addresses the current policies in the fruit and vegetable sector.

Based on our data and FGDs we conclude that no direct relation between efficient value chains and lower fruit and vegetable consumer prices can be found. The seasonal variability of fruit and vegetables preventing value chains from becoming more efficient, compounded with high fragmentation, adds upward pressure to fruit and vegetable prices for consumers. Contract farming can enhance value chain efficiencies. Further studies on shorter and direct-to-consumer value chains could well shed light on a possible reduction in fruit and vegetable prices on well-established and efficient value chains.

\subsubsection{Coordination in the value chain}

\section{Farmers largely operate in supply-driven, loosely coordinated schemes}

In general, fruit and vegetable value chains are supply driven and seem to miss the market windows that offer high(er) prices. Data and our FGDs suggest that push-based strategies, where produce are pushed through the value chain channels, feature very few coordinated actions along the chains. Farmers produce first and think about the market later. Coordination does improve as farmers move into more commercial schemes. In a demand-driven environment, actors tend to organize themselves better and exchange information up and down the chain. In our selection, commercial kiwi and some lapsi farmers, which are crops in demand and are supplied by few farmers, operate in more coordinated value chains as they strive to reach agreements with a few number of traders.

Losses due to extreme weather increase the risks along the chains, and hamper coordination. The likelihood of fruit and vegetables being lost before they reach the markets due to extreme weather is high (Section 4.2.3 describes this issue in more detail) and resulting losses increases the risks for farmers and traders, while decreasing their ability to coordinate activities. The question about who bears the costs of these losses, or even quality-related losses, prevents actors becoming more organized and coordinated.

Crop insurance in the fruit and vegetable sector remains unclear for fruit and vegetable farmers, and is only used scarcely (Pokhara FGD, Kavre FGD). In their view, insurance companies are not yet fully comprehending the nature of smallholder fruit and vegetable business. The insurance system also requires detailed paperwork. Our FGDs show that farmers are either not aware of the insurance system as currently conceived or disagree with the valuation of the crops based on the cost of production (and not on market prices).

Some cooperatives, through collection centers and collective marketing, improve the coordination among actors, especially in vegetable value chains. Cooperatives target smallholder fruit and vegetable farmers in particular, and provide services like capacity building, access to finance, or aggregation through collection centers and collective marketing of produce. The rise of collection centers ${ }^{11}$ and collective marketing in Nepal is thought to improve the coordination of actors along value chains.

At the moment, Government as well as development institutions are providing incentives for farmers to improve their market prospects. In our crop selection, farmers growing green leafy vegetables, pumpkin or bitter gourd are often part of cooperatives. Collection centers are established by cooperatives, and guarantee the purchase of products from farmers on a regular basis. Despite their proliferation, many rural areas still do not have cooperatives and collection centers. Moreover, some existing cooperatives need further strengthening especially in providing marketing support. For more information on how cooperatives support women, see Section 4.8.

\footnotetext{
${ }^{11}$ There are more than 1,030 agriculture cooperatives in Nepal, of which 500 are commodity-focused. More than 200 cooperatives focus on fruits and vegetables (fruit development project, 2017). More than 800,000 farmers are associated with cooperatives (Ministry of Finance, 2019).
} 
Based on our data and FGDs, we conclude that value chain actors in fruit and vegetables operate under limited coordination strategies. Risks along the value chains such as extreme weather events hamper coordination. Nevertheless, as fruit and vegetable chains transition from subsistence to commercially-oriented, more coordination mechanisms amongst players are observed. Cooperatives with collection centers enhance supply chain coordination.

\subsubsection{Post-harvest losses}

Post-harvest losses occur largely due to improper handling, packaging, lack of available technology, poor facilities at collection centers, as well as during the transport of the produce (FGDs). Lack of careful handling includes harvesting of fruit and vegetable without care (throwing fruit and vegetables into sacks or bags for example), deficient temperature management and storage. Generally, there is no use of mechanical tools/equipment. Different studies show that postharvest losses are anywhere between $15-25 \%$ in fruit value chains, and $25-50 \%$ in vegetable value chains (Gautam and Bhattarai, 2012). Conversely, the food systems dashboard, which uses data from FAO, Euromonitor International, World Bank, and other global and regional data sources, reports postharvest losses of about $8 \%$ for both fruits and vegetables. Note that these losses do not take into account losses at retail. Tiwari and Bhandari, (2020) point toa loss of about $10 \%$ in the final value of kiwi. Unfortunately, no more data are available for the selected crops.

As a proxy, losses in the mandarin crop were found to be $46 \%$ (Bhattarai et al., 2013). Similarly, USAID (USAID, 2011) reported postharvest loss in off-season vegetables of 25 to $50 \%$ The reason behind losses was due to improper handling, packaging, technology, and poor facilities at the collection centers. Recently, and for some vegetable value chains, losses seem to have been reduced due to better handling and transport materials. Tiwari et al., 2020, on his recent study on postharvest loss in tomatoes, reported $10 \%$ loss from harvesting to marketing, $2 \%$ loss during harvesting and packing, $4 \%$ loss during transportation, and $2 \%$ loss during storage. The impression of losses being at least contained was shared by most farmers (FGDs), although they reported not to fully know what happens with the produce after harvest, and away from their farms. Further research on both production and postharvest losses can help understand the levels of losses that the fruit and vegetable sector is currently facing.

\section{Reducing transport losses: introducing plastic crates}

Some key actors in the fruit and vegetable sector have attempted to reduce losses during transport by introducing plastic crates. Today, most vegetables and fruits are still transported in 'Dokos' or sacks, ( $10 \%$ loss). Losses with plastic crates are believed to be less than $10 \%$. Our FGDs confirmed a gradual conversion to plastic crates. The adoption level of this new technology remains slow for most fruit and vegetables, however. A costly price tag appears to be the main reason. Mr Khom Pd. Adhikari, President of the Federation of Fruits and Vegetable Entrepreneurs Nepal (FEFVEN) spoke on this issue, 'Introducing crates in Nepal has been challenging. In collaboration with FAO, we imported crates from Thailand and distributed them to farmers. Unfortunately, the project was not suitable in the long term due to the high costs of importing and distributing plastic crates'.

Lastly, some fruit and vegetable projects are tackling post-harvest losses. Notably, UNDP is currently implementing a 5-year project (2018-22) on postharvest management to minimize losses and achieving the best possible prices for farmers in province 3 and 4 . The project works with cooperatives and groups in collaboration with NARC, and invests in physical facilities, organization management, price information system and linkages. ${ }^{12}$ Main strategies to reduce losses include varietal screening, management practices, harvest methods, timing, cleaning, grading, sorting, packaging, and improvements in the functioning of collection centers.

Based on our data and FGDs, we conclude that postharvest losses limits the potential of fruit and vegetables becoming more efficient, and consumers receiving lower fruit and vegetable prices. Whether an improved efficiency automatically translates into lower consumer prices remains unclear, although evidence suggests there is not a direct link.

12 https://www.np.undp.org/content/nepal/en/home/projects/vcdp.html 


\subsubsection{Secured markets}

Collection centers help smallholder farmers secure their markets through aggregation Collection centerr ${ }^{13}$ play an important role in securing markets for those smaller farmers, as per data and FGDs. Smallholder farmers, in turn, reap benefits from product aggregation, which is achieved with some level of grading and sorting. The market support that follows includes finding buyers and transportation. Some collection centers also provide agricultural inputs to farmers on credit. This business model has proved to work for smallholder fruit and vegetable farmers in rural areas given their known challenges. In urban areas, collection centers are less common. Here, fruit and vegetable farmers appear to face less dificulties with product sales given their proximity to markets and the surrounding (business) infrastructure.

\section{Importation of fruits and vegetables have an impact on smallholder fruit and vegetable farmers}

'Securing markets is not only a matter of putting efficient structures in place (i.e. collection centers), but also addressing the price instability.' This is the sentiment of most farmers and actors who took part in the FGDs. An important distorting factor regarding price instability, and therefore securing markets in the country, is the import of agricultural commodities from India and China. Traders often turn to import of fruits and vegetables due to improved logistics, packaging and stability of supply. This was confirmed during Gushel, FGD and Lalitpur, FGD. Kiwi, mango and bitter gourd crops are examples of crops imported throughout the year. Fruit and vegetables imported from India continue to rise. In this scenario, the common fruit and vegetable crops grown by smallholder farmers inevitably collide with imports during peak season. Moreover, smallholder fruit and vegetable farmers believe that secured markets are based on trust and reliable relations among actors. Often, the standards to access secured markets is slightly higher than what smallholder fruit and vegetable farmers can meet, for example stability of supply. Fruit and vegetable farmers who sell in informal markets (around $80 \%$ ), often observe a lack of trust between them and traders (Kalimati, FGD).

\section{Niche markets have the potential to provide opportunities for (some) smallholder fruit and vegetable farmers}

Some of Nepalese fruits and vegetables find their footing in niche markets. Apple, oranges and kiwi, for example, feature a competitive advantage based on their taste and origin. More and more largescale supermarket stores such as Bhatbhati ${ }^{14}$, Bigmart or Salesberry provide separated shelves to display niche products grown in Nepal. Bhatbhati supermarket is promoting Nepalese products with 'Made in Nepal'. Similarly, the growth of a 'pesticide-free' market segment offer a good outlook for fruit and vegetable farmers. Section 4.10.3 includes an example of this trend.

Based on our data and FGDs, we conclude that markets for fruit and vegetables tend to become more secure as actors agree on product quantities and prices beforehand, and on a regular basis. This is observed in more commercial fruit and vegetable chains, for example kiwi and bitter gourd. Business transactions are usually conducted under mutual trust, and agreed upon verbally. This is true especially for farmers that supply off-peak, or outside of glut periods. For smallholder farmers who sell in informal markets (around $80 \%$ ), a 'breach of trust' is often observed between farmers and traders. These smallholder farmers face difficulties to transition into more secure or commercial markets, such as Kalimati and regional markets, due to lack of stable supply and quality. Lastly, data and FGDs suggest that specializing in niche markets represent a viable alternative for a 'niche' amount of both smallholder and commercial fruit and vegetable farmers, away from seasonal harvest periods.

\footnotetext{
${ }^{13}$ Actual data of total collection centres established including vegetable is not available in Nepal. USAID through SIMI, and Ujyalo project have established 100 collection centres for vegetable marketing. In addition, a new on-going project from UNDP/KOKIA (2018-22) is investing in 20 new collection centres, 18 being under construction (https://www.np.undp.org/content/nepal/en/home/projects/cmdp.html).

${ }^{14}$ Bhatbhati supermarket is the largest store in Nepal with more than 30 stores throughout the country.
} 


\subsection{Communication between actors}

\subsubsection{Linkages between traders and consumers}

Fully-fledged, consumer-driven fruit and vegetable value chains in Nepal are very rare. In most value chains, farmers and traders push the produce that reaches consumers in the market. Consumers therefore have limited choices that cater directly to their needs.

\section{Consumers and retailers engage in quick transactions in local and regional markets}

The relationship between farmers, market actors and consumers has evolved over recent years. Today, fruit and vegetable markets feature wholesalers and retailers, with separate stalls that deal with different product quantities. As a result, consumers seem to better understand prices, and purchase the products that best meet their needs. The interaction retailer-consumer remains largely a swift transaction with little attention given to (particular) product attributes except for price and volume (Kalimati, FGD). For these products, no set of standards are imposed on farmers with the exception of basic grading based on size (Ghusel, FGD). Nowadays, only a few consumers can afford available and pesticide-free, and graded, quality products available in departmental supermarkets and specialty food stores. Vegetables like tomatoes, cauliflower, and cabbage require high use of pesticides, which creates a market for pesticide-free products. For the selected crops, this issue is less pressing given the limited use of pesticide.

\section{Some market venues enable consumers to directly purchase fruit and vegetables from farmers}

Interestingly, an innovative model that focuses on the interaction between consumer-producers, without traders or intermediaries, is gaining traction. Consumers purchase directly from farmers in socalled farmers' market, or Haat Bazaars. As mentioned above, a small fraction of consumers, especially in large urban markets like Kathmandu or Pokhara, highly value quality, pesticide-free fruits and vegetables. Currently, consumers buy these fruit and vegetables on the basis of trust. However, different actors are now working towards labelling safe fruit and vegetables. See Box 2 for more information. Consumers can choose from a wide array of fruit and vegetable, cereals, beans, spices which better caterto their needs. The drawback of this model so far seems to be the low frequency (once market day a week). Box 2 describes Haat Bazaar in detail.

Box 2: Haat Bazaar, the trading place for local people in both the Terai and hills regions, including Kathmandu markets

Haat-bazaar is a physical space for selling fruit and vegetable and other commodities where consumers and sellers meet, which only operates on a specific day of the week. Haat Bazar therefore serves as a trading venue for local farmers in rural areas to sell their products while promoting local foods and it generally takes place on a weekly or bi-weekly basis in a playground or any available open space, which is accessible to most families. Haat Bazar provides avenues for those farmers who lack access to markets due to transportation. Foods sold in the Haat Bazar are usually locally produced with high nutrition and medicinal values. About $20 \%$ of vegetables from farmers are sold in the local Haat Bazar (USAID, 2013). Such markets are selling pesticide-free fruits and vegetables (grown under IPM or organic practices). Government, local organizations and development partners have supported the establishment of HaatBazaars for promoting domestic fruit and vegetables to consumers and easy access at a fair price (Kartli, 2005). Urban Haat Bazar markets are operating within the premises of hotels and restaurants within the Kathmandu valley that open on specific days and are managed by the private sector.

\section{Linkages between farmers and (female) fruit and vegetable traders}

Typically, most fruit and vegetable farmers in Nepal sell their produce to either local traders, farmer organizations or cooperatives. See Section 4.1.3 for a description of the generic fruit and vegetable value chain in Nepal. As mentioned in Section 4.1.1, fruit and vegetable traders specialize in either fruits or vegetables. Within the fruit group, traders are further specialized in one fruit, for example mangos or lapsi. Vegetable traders deal with a larger product assortment. In the negotiation between farmer and trader, the farmer's bargaining capacity can influence the crop price. Female fruit and 
vegetable traders are said to be more transparent, and loyal in business, while male traders are cunning in nature and sometimes they show 'chicanery practices' (Ghusel, FGD). Female fruit and vegetable traders are nevertheless a minority in the male-dominated sector. Data that confirms the role, and number of female fruit and vegetable traders are unfortunately lacking. Data consulted suggests that women have, for example, a far higher track (about 90\%) record of repayment (and on time) than men (ADB, 2012). Further research on the role of female traders could add much value to the trading dynamics of fruit and vegetables in Nepal. Lastly, trust between actors increases with kin relationships (Box 3).

Box 3: When trading fruit and vegetables, kin relationships matter

In many rural villages of Nepal, kin relationships between (female) farmers and (female) traders seem to improve farmers' bargaining power and negotiation skills. Ms Radha Sapkota (Ghusel, FGD), a women farmer who sells vegetables put it this way, 'Some traders were not offering a fair price, so I was not ready to sell.' One of the many traders that went by happened to be blood-related. 'I could sell my produce at a good price when my relative trader came by, a good bargaining for both of us was possible given our long-term relationship.' Ms Sapkote went on to note that good negotiation skills and bargaining power with buyers are key for a successful transaction.

Based on our data and FGDs, we conclude that most fruit and vegetable traders have limited linkages with consumers, who typically engage in quick transactions with retailers in market places, such as fruit and vegetable shops. At the moment, few market places cater for consumers' needs around quality; supermarkets being a growing segment for fruit and vegetable purchase. No major differences were observed between fruits and vegetables, despite traders' specialization on either sub-sector. Haat Bazaar, or farmers' markets, prove to be an exception by connecting farmers and consumers directly.

\subsubsection{Information sharing}

Fruit and vegetable farmers have seen an increase in the (digital) information available in the sector over the years. The emergence of mobile communication, as well as internet service, online media or television has led to a rapid improvement in information sharing (Ministry of Finance, 2019). Today, women, as well as other household members, can also access and retrieve market information on fruit and vegetables ${ }^{15}$. Fruit and vegetable farmers have currently more means to investigate prices, or even sale trends. For example, commercial smallholder fruit and vegetable farmers inquire about prices to traders over the phone on a regular basis. Information sharing in the vegetable sector has advanced at a faster pace than that of fruits given the introduction of new varieties, intensification and promotion of growing areas in super zones, and zones (see Section 2.2).

When it comes to digital information, the Kalimati market - the leading market venue in Nepal, provides daily wholesale prices of 12 listed commodities and is accessible through its website. The Kalimati market covers 60 to $70 \%$ of the Kathmandu valley consumers' demand (CASA, 2020). At the moment, it is believed that only a small fraction of commercial fruit and vegetable farmers make use of this platform.

\section{Smallholder fruit and vegetable farmers continue to rely on cooperatives and local government wards for market information}

Despite the rise in (digital) information, cooperatives and local government offices are often the primary source of reliable information for less-connected farmers, which are still the majority in the sector. With the transition to federalism, municipalities (rural and urban) provide many services to farmers. As of late, municipalities are gradually educating more and more (especially) women's groups and cooperatives about their roles. Interviewees noted that the political transition and subsequent transfer of functions are not yet clear for many farmers.

15 https://www.cgiar.org/food-security-impact/photo_stories/connecting-farmers-to-better-information-in-nepal/ 
An example of municipal service for fruit and vegetable is the rural municipality of Bagmati Gaunpalika, Lalitpur district, which has developed a mobile application that allows users to access market information from their phones. ${ }^{16}$ Using the application, farmers can also understand the budget al located to the agriculture sector under several activities.

Cooperatives, on the other hand, are often seen as the contact point for networking with the Government and other organizations in the fruit and vegetable sector. According to data and FGDs, fruit and vegetable cooperatives improve farmers' access to information, such as prices and demand for products throughout the year. This structure proves especially useful for farmers which have limited access to digital information. Cooperatives are popular in vegetable crops grown typically by smallholder farmers, such as green leafy vegetables, and are less important for fruits crops given their more pronounced seasonal character.

Based on our data and FGDs, we conclude that information sharing in the fruit and vegetable sector has increased rapidly in the last 10 years thanks to the emergence of digital information; the rise of models that contribute to information flow, such as cooperatives at the level of farmers; or national markets on the consumption side. Information sharing has advanced faster in the vegetable sector due to the level of intensification, introduction of new varieties and promotion of growing areas by the Government. Consumers now have more venues and means to become informed about fruit and vegetables.

\title{
4.6 More and higher diversity in fruit and vegetable crops produced and traded leads to more diverse fruit and vegetable in the food environment
}

\author{
4.6.1 Introduction of new fruit and vegetable varieties
}

Nepal has traditionally embraced new foods, culinary traditions and ingredients. Nepali cuisine blends its cultural diversity and geography with elements from India, China, and Tibet. The diverse food culture results in an abundance of vegetables dishes and accompaniments. Fruits like kiwi, mangoes and lapsis are featured in locally prepared sweets.

Despite consumer demand for new crops, growing new varieties takes time and investment New crops and varieties are grown more and more to appeal to the diverse consumer pool. The life of a new crop is bound to be short if it fails to align with consumers' preferences. Introducing new fruit and vegetable crops takes time. Farmers need to find a new or niche market, where consumers are willing to pay comparatively higher prices for the said crop than for other established fruit and vegetables. In markets that have direct interaction between farmers and consumers, such as Haat Bazaars, farmers become familiar with consumers' preferences over time. Supermarkets and national markets often have a better sense of consumers' preferences, although it is unclear whether this information reaches downstream actors in the value chain. Consumers' purchasing power has increased over the years mainly due to remittances and other income sources (Ministry of Finance, 2020).

From a production standpoint, introducing new fruit and vegetable crops and varieties is risky, and costly. Investments in new farm equipment and infrastructure are often needed, while production costs are also likely to soar due to higher quality inputs and (specialized) labor. Fruit and vegetable farmers that do venture into new crops and varieties tend to be less risk-adverse and more prone to expanding their knowledge. High market prices are often the main driver for this transition. The kiwi crop is an example of a successful yet slow introduction of a new crop.

16 https://bagmati.susasan.org/ 


\section{Farmers consider the best crops to grow within a wide selection}

Having more crops available to grow makes fruit and vegetable farmers consider the 'right' selection of crops. For some, this can lead to frustrations within the household. Green leafy vegetables, for example, fetch quick returns within 25 to 30 days, compared with bitter gourd's 3-month cycle, or a year for kiwi and other fruits. Often, fruit and vegetable farmers choose the crop for which inputs are available. As mentioned earlier, many seeds and fertilizers tend not to be available on time.

The newest fruit and vegetables introduced in the Nepali market and grown by Nepali farmers include kiwis, avocados, gourds beetroot, asparagus, or drumstick, to cite a few. These crops are still produced in small quantities. In the case of kiwi, production has increased by $369 \%$ from 719 t to 3,372 t (2016/17 to 2018/19). Area has also increased from 186 ha to 1,362 ha.

Based on our data and FGDs, we conclude that the high diversity of fruit and vegetables in Nepal respond, in part, to the needs of the wide consumer pool, and is rooted in the motivation of some fruit and vegetable farmers to continue introducing new varieties from neighboring countries and thus access premium markets. A diverse food environment continues to grow in Nepal as a result.

\subsubsection{Consumption trends}

Little has been reported regarding consumer trends in the fruit and vegetable sector in Nepal. Following consultations held with sector actors and personal experience, trends in fruit and vegetables consumption vary depending on crop seasons (on season vs offseason), origin and flow of the produce (local vs imported), and consumer location (urban vs rural). These factors are seen to play a role. Consumption of fruit and vegetables follows seasonal patterns in rural areas, with limited proximity to fruit and vegetable stores, and Haat Bazaars. Nevertheless, imports often reach even rural areas. In the Terai, consumption of seasonal vegetables such as bitter gourd and pumpkin increases during March to June, harvest season. In the mid-hills, the harvest of these vegetables does not overlap as strongly, contributing to a more regular year-round vegetable consumption. Mustard green is typically produced in high altitudes from June to September, constraining consumption in rural areas.

Consumption of selected fruits is higher in the harvest season, especially as rural areas become more distant from urban centers and the (im)possibility to consume imported products.

Trends differ in urban areas. Overall, consumers with disposable income, especially in the Kathmandu valley, have numerous venues to purchase all types of fruit and vegetables, many more compared to rural consumers. In the same vein, a growing understanding of the nutritional value and healthy claims of fruit and vegetables can be observed among rural and urban consumers, in part as result of government and project interventions in the field of health and nutrition in the country. Lastly, it is important to note that no analysis of the effect of product seasonality on consumer behavior has been found.

Section 2.2.3 further addressed fruit and vegetable consumption and the large gap still existing between recommendation intake and actual intake by most Nepali consumers.

\section{The impact of the Covid-19 pandemic on fruit and vegetable consumption trends}

Reportedly, the pandemic seems to be causing a reverse migration; people began to migrate from urban to rural areas due to the fear of limited food availability and the spread of the virus happening quickly due to population density. Wholesalers and retailers observed a surplus of fruit and vegetables available in the market. In addition, the demand for fruit and vegetable reduced due to limited mobility. The consumption of fruit and vegetable in hotels, restaurants and others came to a halt as there were no tourists in the country. As of late, businesses dependent on local consumption has seen a rebound in demand. The tourism sector has, on the other hand, been hit the hardest and its recovery remains unclear.

Based on our data and FGDs, we conclude that consumption of fruit and vegetables follows seasonal trends in rural areas - consumption increases as fruit and vegetables become available in the market, and decreases at the end of the harvest seasons. In the Terai, multiple vegetables become available at the same time, which impacts on year-round vegetable consumption. Consumption in the mid-hills is 
believed to remain more stable since vegetables are harvested at different times of the year. By contrast, the effects of seasonality in urban areas is less felt given the more diverse foods available, with access to imported products and proximity to food stores.

\subsection{Prices of fruit and vegetable are always higher compared to other food categories}

\subsubsection{High prices}

In general, fresh fruit and vegetables are more expensive to farm than staples crops. Fruit and vegetables have a short shelf life, rely heavily on labor, inputs, and they are prone to suffer losses due to extreme weather or during transportation, and are subject to (seasonal) supply-demand dynamics.

Staple foods like cereals are, in comparison, less expensive for consumers than most vegetables, not all, and certainly lower than fruit prices. Importantly, most cereal prices remain largely stable throughout the year, whereas fruit and vegetables present a wider fluctuation due to the above. Table 4.8 shows the differences in farm-gate prices, and retail/consumption for fruit and vegetables and some cereal crops. The latter group are typically connected to processing industries, which demand stable flows of produce, and make more use of mechanization on larger holdings.

Table 4.8 shows an overview of the average costs (in USD) per person per day for a healthy diet defined based on food-based dietary guidelines. In Nepal, a healthy diet will cost on average US $\$ 4.13$ per person out of which $42 \%$ (US $\$ 1.72$ ) is spent on fruit and vegetable, which is comparable to the global percentage (39\%) spend on fruit and vegetables (Herfort et al., 2020).

Table 4.8 Cost of fruits and vegetables and proportion of cost of a healthy diet in several countries, 2017

\begin{tabular}{|c|c|c|c|}
\hline Country & $\begin{array}{l}\text { Cost of healthy diet in USD } \\
\text { per person per day (mean } \\
\text { across } 10 \text { guidelines) }\end{array}$ & $\begin{array}{l}\text { Cost of least costly fruit } \\
\text { and vegetable in USD per } \\
\text { person per day (mean } \\
\text { across } 10 \text { guidelines) }\end{array}$ & $\begin{array}{r}\text { Share of the cost of a } \\
\text { healthy diet accounted } \\
\text { for by fruit and } \\
\text { vegetable }\end{array}$ \\
\hline Bangladesh & 3.41 & 1.17 & $34 \%$ \\
\hline Burkina Faso & 3.66 & 1.08 & $30 \%$ \\
\hline India & 3.27 & 1.26 & $39 \%$ \\
\hline Nepal & 4.13 & 1.72 & $42 \%$ \\
\hline Nigeria & 3.57 & 1.21 & $34 \%$ \\
\hline Tanzania & 2.62 & 0.86 & $33 \%$ \\
\hline
\end{tabular}

Note: These results are based on analysis of the 2017 ICP dataset to find the lowest cost foods in each country. National datasets may have additional foods that may be lower or higher cost at different times and places in the country. The proportion of the cost of a healthy diet is based on the mean cost of ten different national food-based dietary guidelines. The mean cost may differ from the median cost, which was reported in the SOFI 2020.

Source: Anna Herforth and Aishwarya Venkat, personal communication. Based on the analysis in Herforth et al (2020).

With the above in mind, can consumers in Nepal afford a (costly) healthy diet? Per capita income numbers suggest that wide consumption of fruit and vegetables for healthy diets in Nepal is difficult. The GDP per capita for 2019 was US\$1,071, a 3.12\% increase from 2018 (Economic survey 2019/20, MoF). On a monthly basis, the costs of a healthy diets (US\$124) seem to largely exceed the average income per capita (US\$89) by $72 \%$. 


\subsubsection{Price differences}

Price differences within fruit and vegetables is considerably higher than that of cereal crops as mentioned previously. Table 4.9 shows price differences at farm-gate and retail (consumer) for fruit and vegetables and some cereal crops. Moreover, consumer prices for fruit and vegetables surpass that of cereals.

Table 4.9 Price differences of selected fruits and vegetables at farm gate and retail/consumer

\begin{tabular}{|c|c|c|c|c|}
\hline$\#$ & Commodities & $\begin{array}{l}\text { Farm gate price * } \\
(\mathrm{NPR} / \mathbf{k g}-\mathrm{USD} / \mathbf{k g})\end{array}$ & $\begin{array}{l}\text { Retail/ Consumer price* } \\
\text { (NPR/kg - USD/kg) }\end{array}$ & Source \\
\hline \multicolumn{5}{|c|}{ Fruits: } \\
\hline 2 & Lapsi & $15-25 / 0.1-0.2$ & $80-100 / 0.7-0.8$ & Noora (2020) \\
\hline 3 & Mango & $20-40$ & $80-150 / 0.7-1.3$ & Shrestha et al. (2021) \\
\hline \multirow[t]{2}{*}{1} & Green leafy & $8-12 / 0.1$ & $60-80 / 0.5-0.7$ & FGD \\
\hline & & & & Kalimati market, 2021 \\
\hline \multirow[t]{2}{*}{2} & Bitter gourd & $12-18 / 0.1-0.2$ & $100-150 / 0.8-1.3$ & FGD \\
\hline & & & & Kalimati market, 2021 \\
\hline 3 & Pumpkin & $10-20 / 0.1-0.2$ & $80-100 / 0.7-0.8$ & Own estimation \\
\hline 3 & Maize & $22-30 / 0.2-0.3$ & $40-60 / 0.3-0.5$ & Own estimation \\
\hline
\end{tabular}

* Whole year average price.

Table 4.8 shows how prices for vegetables, despite their high fluctuation, are higher than fruits. Prices of fruits indicate even a higher year variation, and year average.

Drawing on $\mathrm{kg}$ average pricing of selected crops for consumers, vegetable and fruits are considerably higher in price than cereals; vegetables are just over $70 \%$ higher while fruits (excluding kiwi) are almost double in price (including kiwi would makes fruits over seven times as expensive as cereals). From the data above, we can also conclude that the costs of a healthy diet including consumption of fruit and vegetables in Nepal exceed population's average income by a margin of $72 \%$.

\subsection{Women participation in fruit and vegetable production and value chain operations leads to higher income and empowerment by women}

Women still face various barriers to taking leadership roles in agribusiness. But, despite these, there are examples of women succeeding as entrepreneurs and becoming recognized in their own right. More broadly, public policy and donor-funded programs are helping to shift public sentiment to recognizing what is already a reality, namely that women play a key role in producing the country's fruits and vegetables and need support to help do this better. While women's involvement in production and valueaddition does not, by definition, lead to their empowerment, ample evidence of existing support programs illustrates that addressing their specific needs can help bring about this change.

\subsubsection{Examples of women in fruit and vegetable production and value chains}

The following two case studies provide complementary insights into women's roles and opportunities. Although every case is different, some lessons learned can be drawn from them; first, at household level cooperation with the husband can only help to provide women with the opportunity to pursue their business interests. Second, technical support followed by ongoing organizational support is key 
to facilitating the ambitions of female agri-entrepreneurs. Third, ambitions vary; some want to achieve more than others, and in different ways. Providing support for women to pursue their socio-economic interests (not just purely economic) will improve opportunities not just for those directly involved, but have knock-on effects for others.

\section{Ghusel village: women's empowerment and crop innovation ${ }^{17}$}

Ghusel village is in Lalitpur district, only $25 \mathrm{~km}$ from Kathmandu but still fairly isolated with only an earthen road connecting the area to the outside world. Agriculture, including vegetables, and livestock are the staple income sources. Unlike other villages, and despite limited connectivity, Ghusel's population has not seen a major outflow, having been able to support itself through the adoption of kiwi as a relatively new product for the domestic Nepali market, and through organizing of a women'sonly cooperative with support from the Women's Development Office. These two aspects of Ghusel village are interrelated through Mr. and Mrs. Gautam, as explained below.

\section{Organizing women through a cooperative}

When getting married, Mrs. Sarita Gautam moved to Ghusel to live with her husband. At the time, subsistence crops were the main source of sustenance in the village, with no income generated through sale of produce. A community-owned women's group was formed and, in 2011, converted into a cooperative with support from the Women's Development Office, FWEAN (see Annex 1 for description), SOLVE Nepal and the local municipality. Initiated by 26 women, Sisautar Women's Saving and Credit Cooperative started with small saving amounts of Rs20 (US\$0.20) per month to encourage the habit of saving, and later increased to Rs200 (US\$1.70) per month. SOLVE provided support to construct the cooperative's own building, as well as for capacity building trainings and basic assets. Similarly, FWEAN provided livelihood technical support, skills and entrepreneurship development. The cooperative has computer-based bookkeeping, a strategic plan and six internal policies to guide internal controls. The cooperative provides serves various services; these include forming a stronger social network between the women members in the community to learn from one another, and supporting savings and credit which have allowed women to invest in vegetables, fruits and other small-scale businesses. The 346 members are all women and have a collective savings of about Rs7 million (US\$59,300). It has become a crucial forum for the women to build their leadership. As a result, they are not hesitant to come forward to speak at public events. 'We have come together and work for social causes,' says Mrs. Sarita Gautam, President. Alongside this role, Mrs. Gautam has also held the Female Community Health Volunteer (FCHV) position for the previous nine years, and so is well-respected as a key influencer.

\section{Kiwi: bringing a new crop to the village}

In 2018, Mrs. Gautam's husband learned about kiwi, which was not grown much in Nepal at the time. After participating in a government-funded six-day training program run on a model farm, and visiting a demonstration plot run by ICIMOD (an intergovernmental learning center which supports sustainable mountain communities), Mr. Gautam purchased and planted 17 kiwi plants. These require 3 years to reach maturity and produce enough kiwis to become commercially viable. Mr. Gautam had to convince his own (perhaps justifiably) sceptical household members whether this was a good use of resources, which caused some friction in the household. However, after the trees matured they began harvesting $25-30 \mathrm{~kg}$ of kiwis (selling at around Rs400/kg or US\$3.40). The first sales barely generated a profit but they reinvested what they had into infrastructure (saplings, metal frames, tunnel, and drip irrigation facilities) and in 2021 they produced around $60 \mathrm{~kg}$. They are satisfied that, even with a fluctuating price per kg, they can sell kiwi at a profit. Besides kiwi trees, they intercrop the land, also growing seasonal vegetables (also sold to market); $50 \%$ of the investments made after they started came from a government subsidy (Krishi Gyan Kendra) and provisions of drip irrigation and plastic tunnels through FWEAN. The family realized that they could benefit if they could convince others to also grow kiwi and so improve their collective negotiating power vs buyers. With the help of a cooperative, todate 30 kiwi farmers now exist in the community, who purchase kiwi saplings from Mr Gautam. Alongside FWEAN, SAHAS Nepal have supported this initiative (and other crop types) by providing irrigation facilities to all households in the community.

\footnotetext{
${ }^{17}$ Derived from multiple sources: - https://myrepublica.nagariknetwork.com/news/the-kitchen-queen/; https://www.facebook.com/KitchenRecipe2016/?ref=page_internal; Own interview.
} 


\section{Gender relations and business in the household and the community}

The introduction of drip irrigation massively reduced the time it took Mrs. Gautam to fetch water, so serving as a labor-saving device. And, while the couple maintain a more 'traditional' division of labor (he goes to market, she does the household work), Mrs. Gautam indicated that they work as a team whereby trust is key. Within the community, she holds a great deal of respect due to her role, and the couple are regarded as innovators. More broadly, the women's cooperative has helped other women save and start to invest in their own small-scale agribusinesses which has contributed to the women's household income.

\section{Women in business - pickled lapsi (plum)}

Ms. Hajuri Bista is an example of a women who has managed to set up her own business and build a solid brand over the years in pickled lapsi. In 1993, she received training from the DFTQC (Department of Food Technology \& Quality Control) through the Wean Multi-purpose Cooperative which she had recently joined. The focus of the training was on how to preserve food products without the use of chemicals, which she started doing together with two other women from the training. Though one other left, and another lady passed away, she persevered by herself. At first she produced and processed the pickles and sold them through the cooperative, which had set up its own outlet and registered its own brand to distinguish itself in the market as a Nepali traditional taste free from chemicals. The brand 'Navaras' (meaning 'new taste') was officially registered with DFTQC and received quality certification. At the time, the whole market for pickled plums came from Indian imports and so rather than competing directly, the cooperative focused on creating a market for organic pickled plums. With rising popularity, the cooperative started sourcing from other women entrepreneurs who could supply pickles alongside Ms. Hajuri Bista.

Ms. Bista is also a brand ambassador as consumers relate to Navaras as Bista's pickle. Besides being a supplier to the cooperative, she also established her own business, Hajuri Khadya Udhyog; under this name, she started experimenting with various types of pickling recipes and gradually introduced them into the market, collecting feedback and adapting them. She now produces 46 pickle varieties and has an annual turnover of over Rs10 million (US\$85,000). According to Ms Hajuri Bista, 'Due to lack of proper information about government policies, women entrepreneurs have to spend extra money. If you understand the government policies, you will save money.' She is now popularly known as a 'pickle lady'.

\subsubsection{Business models}

Small-scale female entrepreneurship is beginning to emerge in Nepal although there remains an absence of women in leadership positions in the agribusiness sector - despite women holding senior positions in other sectors and in politics. Similarly, female participation in capacity building programs are increasing, and women are more commonly represented in most cooperatives and associations. This is starting to shift the sentiment that there is a role for both men and women in the agricultural business with their strength and weaknesses (Ghusel, FGD). But, while women are capable of managing fruit and vegetable production, they have less access to training in accounting and experience in business negotiation, which has limited their ability to take control of the business. The following areas illustrate where women are being supported to address these constraints.

\section{Aggregation and collective marketing}

Connecting smallholder women farmers to aggregation centers can particularly benefit those located in remote areas and with greater mobility constraints. Collection centers already exist across the country and vary in size and capacity. Government and development projects have been supporting such collection centers across the country in building their management capacity and infrastructure with weighing machines, storage facilities and record-keeping. There are collection centers also providing inputs and services to farmers. The role of the collection centers could be expanded along with valueadded services, such as processing, packaging, cold storage, etc., in the future and it will be important for women to be proactively involved in this upscaling to ensure they benefit from this as producers. 


\section{Cooperatives}

Cooperatives with a collection center, as already highlighted, can also function as a place for women to receive much-needed capacity support, build up savings and develop a greater degree of confidence. The cooperative structure is a widely-used model across Nepal for multiple sectors, and are already being used to support women specifically, though there are not any at scale focused only on fruits and vegetables, or specifically on gender and nutrition.

\section{Access to finance and risk spreading}

Women face challenges on accessing and managing credit. Alongside smallholder systems, as shown by the cooperative in Ghusel village (see case study above), there are also larger-scale programs to support women; a joint government-USAID program supporting educating women on business literacy (USAID, 2014), and Nepal Rastra Bank focuses on women as a specific target group in their Financial Literacy Framework (OECD, 2013). The federal government has also directed all banks to set up branches at local level, which can especially help women with mobility constraints to open accounts, as well as facilitate monitoring of financial education programs (see also 'access to credit' in the following section). In some cases, traders also pre-finance the production of seasonal fruits, such as mango, oranges, apples where the buyers from the markets provide advance money on an agreed quantity and price before the harvesting season. Traders usually pay advance money for the whole garden owned by the farmers and, at the time of harvesting, visit the fruit garden, harvest fruits and transport them to the market with their own resources. In this business model, all risks are born by the traders and producers enjoy market assurance before the harvesting period. This can work for women farmers who otherwise do not want to take the risk of producing too much of one crop.

\subsubsection{Public policy}

There are a number of policies at local to national level that support women's inclusion in agriculture.

\section{Gender-sensitive service provision}

At the provincial level and local municipalities, there is a guideline for gender-responsive budget allocation for gender equality. The aim of the guideline covers: capacity building of women; participation of women in planning and implementation; share of income and benefits; increase in employment and income generation of women; and reduction in women's workload and quality of time. As a result, women can access agricultural inputs and services in the yearly program budget. 'In the past, budgets were spent on vocational skill development training in various sectors, such as tailoring, targeting women in the villages, whereas most of women's involvement was in agriculture. Now the budgets are allocated for agricultural activities targeting women,' says Ms. Ranjana Ghimire, Deputy Mayor, Bagmati Gaunpalika, Lalitpur.

\section{Entrepreneurial support}

There are also several policies in Nepal for promoting women as entrepreneurs, such as business registration (only having to pay Rs100 for registration and free renewal up to 5 years), government subsidies on agricultural production, and businesses and lower government fees for land ownership in the name of women.

\section{Access to credit}

Women Entrepreneurship Development Fund was implemented by the Government of Nepal in 2015 to support women entrepreneurs to access loans between Rs100,000-500,000 at 6\% interest rate for 3 years without collateral. The total size of the fund is about Rs220 million (http://dcsi.gov.np/en).

Under another initiative, an integrated interest subsidy guideline was published in 2018 by the Ministry of Finance to provide loans to, amongst others, women with the provision being that, if the loan is paid back on time, the government will reimburse $5-6 \%$ of the amount. The scheme has been implemented through all commercial banks. Female entrepreneurs can take loans of up to Rs1,500,000 without collateral for 5 years at $6 \%$ subsidy on bank interest (https://www.nrb.org.np/). 


\section{Property rights}

Women in Nepal have property ownership rights. With the new land act, the Government has marked a policy that allows girls and daughters-in law to have equal right in parental property. In 2015, the Government changed the law and, today, there is a $25-50 \%$ discount on the registration fee when the land is registered under a woman's name. After the new civil code in 2018, daughters are entitled to keep their share of their parents' property after getting married, which means equal rights for sons and daughters. After a divorce, women are also entitled to their husband's share of property, if the divorce is the husband's fault. Land rights bring security, independence and confidence, which together enable women to become active in all social and political arenas. Women's land ownership encourages men to view women as equals, which is shown to give women more decision-making power in their households and decrease domestic violence (USAID, 2013).

The scale of impact of these policies varies in practice: service provision has shown positive results, while land inheritance has been limited. This is due, in part, to the federalization process taking place over the past few years, which has transitioned budget implementation from national to state-level. With this budget transition, sub-state implemented policies have functioned better than national level ones. Nevertheless, the policies illustrate a clear governmental understanding of the constraints that women specifically face as smallholder producers look to start or scale a rural micro-business.

\subsection{Public enforcement of standards will enhance food safety for consumers of fruit and vegetable}

\subsubsection{Relevant standards}

Standards on product safety prevail in the fruit and vegetable sector. Among these, standards on pesticide use apply to all actors operating in fresh fruit and vegetable chains, including farmers. The government has set a threshold level on pesticide use, which are measured in laboratory facilities available in 12 regional markets. However, no inspection takes place in the production areas. Attending to this limited scale, only a nominal amount of fruit and vegetables are checked during the year and monitoring pesticide residues across all fruit and vegetable value chains remains an important point of attention for the government. Actors in fruit and vegetable value chains are particularly troubled by the influx of produce with seemingly high pesticide levels which are imported from neighboring countries (Pokhra, FGD; Gashel, FGD).

\section{Various governmental bodies regulate and enforce food (safety) standards}

Actors in the fruit and vegetable sector in Nepal must meet the standards developed by the National Council for Standards (NCS), the government body responsible for approving and endorsing Nepalese standards. The Nepal Bureau of Standards and Metrology acts as the NCS secretariat and prepares the country standards for food products and methods of food processing.

Safety during food processing is the main focus of the current food act, which was established in 1966. Gaining more importance after 1990s, food safety is being operationalized following the farmto-fork approach - food must be safe throughout all phases: production, processing, transportation and trading. Today, the DFTQC under the Ministry of Agriculture Development is the government agency responsible for enforcement of the food and feed act in the country.

\section{Monitoring Maximum Residue Levels (MRLs) in the market place}

Every year, more than 635 t of 170 types of pesticides are imported in Nepal (Plant Protection Directorate, MoALD). The Central Agriculture Laboratory regularly monitors MRLs on fruit and vegetables brought into Kathmandu valley. Samples that exceed the maximum residue level are disposed of (The Kathmandu Post, 2019).

Apart from the pesticide threshold, the agro market development and management bill, drafted by MoALD, regulates the elements that agro markets should feature: sheds (separate for organic and those harvested from IPM areas), displays of price information, road access, parking facilities, water 
and sanitation, a timely inspection of weighing machine and pest control of the agro products.

Unfortunately, many retail stores and open markets throughout the country still offer products that do not meet basic quality and hygiene standards (CASA, 2020).

\subsubsection{Consumer trust in local standards}

Food product labels in Nepal do not generally exist. Consumers, aware of this absence, rely on trusted urban retail markets and supermarkets to purchase safe fruit and vegetables. Here, consumers show higher levels of trust given the regular (quality) checks that take place. Trust in this case revolves around the perception that food must be safe, more than the assurance that the food is undoubtedly safe. Meanwhile, fresh produce available in rural markets is seen as less trustworthy. Factors such as deficient hygienic practices in the market place, limited traceability and little transparency only further decrease public trust. Public data around consumers' perception and notions of safe foods are unfortunately lacking.

A growing consumer segment that demands safer fruit and vegetables has been long reported (Aryal et al., 2009). Unfortunately, it remains unclear the current extent or composition of this consumer group. An important driver for this consumer group is the health claims that fruit and vegetables offer. Certain social media echoes and even amplifies this message. However, most consumers are still believed to focus on price and less on safety/quality. For the vast majority, safe food and safety standards are not well-known concepts. As a result, private sector as well as government have dedicated little investments into processing facilities and quality infrastructure (NABIC, 2019).

'Mainstreaming organic and pesticide-free safe products could improve consumer's trust in local standards'. This general sentiment was shared by a number of participants in the FGDs. In this light, Bhattarai, (2019) studied consumers' willingness to pay for organic vegetables in the Kathmandu Valley. He found that, from a sample of 120 respondents chosen randomly from four vegetable markets, $94 \%$ of respondents were found to be interested in organic vegetables, whereas $86 \%$ were willing to pay a premium price. The majority of respondents did not believe that vegetables available in the urban markers are grown organically.

This staggering initial evidence on willingness to pay for safe vegetables contrasts with the perceived willingness of farmers to adopt organic farming, a long-standing debate. According to Banjara (2016), the prospects for future growth are not promising (Banjara, 2016). At the moment, the farming community visited expressed mixed feelings about organic fruit and vegetable farming and prohibition of the use of chemicals, manures, IPM measures to name a few.

Box 4: Bridging the trust gap: Blockchain food traceability in fruit and vegetable

The blockchain system has been recently introduced in Nepal by Esatya in collaboration with Agriclear and Green Growth. The pilot project is being implemented in sweet orange (Junar). (Source:

https://esatya.io/). Consumers can access information such as origin, farm name, pesticide use or harvest date through their smartphone via a QR code.

Consumers pay a premium for these quality-first products. Those involved expect this approach to become more mainstream in the near future, should the pilot project succeed.

Based on our data and FGDs, we conclude that actors in the fruit and vegetable sector are no strangers to food safety standards, a topic that continues to be in the spotlight. Evidence of imports of products from India containing high MRLs levels have caused actors to focus on the enforcement of standards across the fruit and vegetable sector in Nepal, and the need to consolidate efforts so safe food becomes more normalized. 


\subsection{Nudging and public extension will improve fruit and vegetable consumer awareness and consumption preferences}

\subsubsection{Policies and strategies}

Nepal has recognized the central role of nutrition in achieving overall socio-economic development. The Multi-Sectoral Nutrition Plan (MNSP) (2108 - 2022) (NPC, 2017) aims to achieve three outcome levels, one of which addresses healthy diets: 'improved access to and the equitable use of nutritionsensitive services and improved healthy dietary habits'. A key intervention of this outcome is to promote the production of fruit and vegetables, nutritious roots, cereals and pulses to improve the consumption of diversified foods at household level. As a separate intervention, the government intends to promote the production and consumption of fruits and green leafy vegetables.

\section{Improving fruit and vegetable consumption through production and area increase}

Strategies to improve the consumption of fruit and vegetables revolve around providing technical support (i.e. training, demonstration) and making available inputs (i.e. seeds, fertilizers, varieties) at household and community levels. Result indicators include both fruit and vegetable production and area increase. An implicit assumption that increasing the supply of fruit and vegetables leads to increase consumptions is observed; neither strategies on awareness of fruit and vegetable consumption for healthy diets nor consumer-centered activities were found in the plan. At national level, FAO's food-based dietary guidelines for Nepal serve as a good basis to improve diets.

In the Nutrition Plan, consumers or consumer categories are mentioned nowhere as a group. The plan focuses on women of reproductive age, adolescent girls and under-3-year old, together with mothers, adolescents, infants' grandmothers and husbands of pregnant women. Although quality of diets is not yet a known concept, the Nutrition Plan also intends to reduce chronic energy deficiency among women and increase availability and consumption of safe and nutritious food. Recent data show in Nepal, the average cost of fruit and vegetables per person per day is US\$1.72, about $42 \%$ of a healthy diet as defined by the food-based dietary guidelines (Herforth and Venkat, personal communication.)

\section{A multi-sectoral approach to enhance nutrition security}

Conceived as a multi-sectoral (and multi-stakeholder) trajectory, the Nutrition Plan (a US\$470 million undertaking) aims to bring together national and international NGOs, private sector agencies, community and civil society organizations to take part in Nepal's strategy for achieving food and nutrition security. The Plan is being implemented at all three government levels including seven relevant ministries. The MNSP describes the problem of undernutrition as caused by inadequate access to nutritious and diverse food, the poor use of available foods, infectious diseases, unsafe water, and poor hygiene, untimely treatment of diseases, poor use of health services, heavy workload and poor awareness (MNSP report).

Several organizations, including the private sector, strive for nutrition security in Nepal. Scaling Up Nutrition (SUN), the global nutrition movement, realized the importance of the private sector in the food-based nutrition intervention movement. Similarly, the Baliyo Nepal program, supported by the Bill and Melinda Gates Foundation and under the MNSP and SUN framework for changing behavior in food consumption habits, is another example. The program focuses on developing fortified products and other nutritious edibles, such as eggs, and porridge making them accessible and affordable to lower income populations.

\subsubsection{Systemic constraints for women}

Though undernutrition is high across the overall population, women face additional constraints to improving this. Most traditional food in the rural parts of Nepal is heavy in carbohydrates and lacks many of the necessary micronutrients, affecting all household members. According to one study, fruit and vegetable consumption by adolescent girls in rural communities of Southern Nepal is only $11.8 \%$ of the recommended amounts and, of the 407 surveyed, $53.8 \%$ were aware of the need to eat 
adequate amounts of fruit and vegetables (Singh et al., 2019). Traditional beliefs also constrain women during pregnancy, lactating and illness, whereby elder generations discourage consumption of certain food types, such as papaya or spinach, as it is believed to have a negative effect on the body (https://mccintersections.wordpress.com).

Who eats first is also gender biased, whereby males are served first (starting with the head of household), followed by women according to age. Menstruating girls and adolescent women will be served separately and are not allowed to enter the kitchen (Madjdian and Bras, 2016). Women and people in lower castes face similar barriers to improving their food security (USAID 2017a).

However, when women earn more income and retain control of it, they spend more on food (as well as education) for their family. Women that have set up a small-scale business also gain more confidence to negotiate household spending (https://reliefweb.int/report/nepal/empowering-women-farmersnepal-make-changes-bring-progress-all). Further to this, an impact evaluation of a 2004 program that worked on homestead food production, nutritional improvement and gender equality noted an increase in uptake of fruit and vegetables - though whether this came from production from the household or increased control of income by women is unclear (IFPRI, 2013).

There are two notable publicly-funded nutrition programs related to gender: Nepal joined the SUN Movement in May 2011, and with the MSNP Phase I (2012-2017) followed by MNSP Phase II (20172022, linking to the nutrition Sustainable Development Goal targets around women's empowerment, first 1,000 days of children) have promoted more awareness around these issues. This is being enacted through the new federalized system, linking to 753 local authorities and includes a monitoring system (https://scalingupnutrition.org).

Suaahara II is an integrated nutrition program aimed at improving the nutritional status of women and children in the first 1,000 days of life, which is focused on households in 40 districts. The program mobilizes FCHVs and other community extension workers to disseminate critical health messages, services and commodities at the household level through mothers' group discussion forums. The project is promoting homestead food production and village-model farm techniques to promote better access to nutritious food.

\subsubsection{Illustrative examples}

Healthy conscious consumers begin to find new alternative models to purchase safer, and more traceable, fruit and vegetables in Nepal. Current marketing models appear to be experimenting with direct linkages between farmer and consumers and the facilitation of market space for pesticide-free and local, niche Nepali (fruit and vegetables) foods. We provide a number of examples below.

\section{'Pesticide-free' outlets, and markets}

The Safe Food Alliance Nepal (SFAN), in partnership with more than 50 partners, are promoting pesticidefree fruits and vegetables in their partners' physical and online outlets and online outlets scattered across the country. Partners also organize weekly Haat bazaar (for more information see Section 4.5.1) on specific days in several places in the Kathmandu valley. Figure 4.4 shows a promotional banner for an Haat bazaar in Jawalakhel, Lalitpur, which operates every Saturday from 2 to 7 PM.

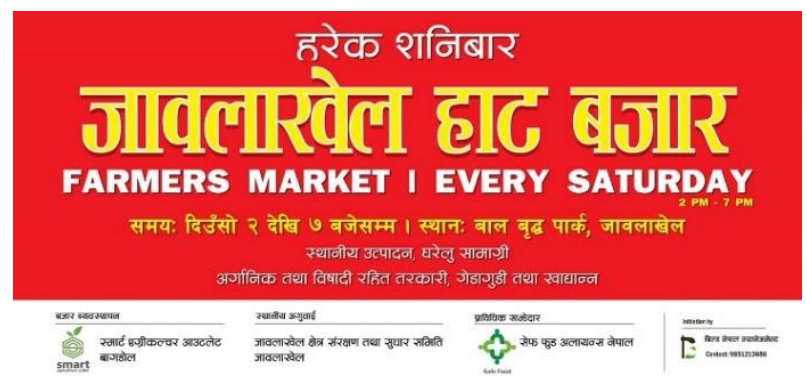

Figure 4.4 Banner of Hat Bazaar at Jwalakhel, Lalitpur 
A wide array of farmers come to sell their agricultural produce at the Haat Bazaar. This market has been managed in collaboration with Build Nepal, SFAN, and the Smart Agricultural Outlet company and Jawalakhel local club. SFAN is a not-for-profit sharing private company working on facilitating Safe Food Market System Management along their supply chain (farm to market). As of late, SFAN is also working towards labeling safe fruit and vegetables.

\section{Local fruit and vegetables make their way into large retail chains}

Bhatbhati supermarket, a leading retail outlet with 16 stores across the country, has been promoting Nepali products, including fresh fruit and vegetables. This supermarket chain sources from national traders who, in turn, purchase from commercial-scale fruit and vegetable producers (between 2 to 5 ha). Fruit and vegetables are pesticide-free, with a stable supply throughout the year. Consumer prices are often $50-100 \%$ higher than the regional/wet market retail price.

\section{Experimenting with no intermediaries - from the farm to the consumer}

Kalimati vegetable market just recently (from March 18, 2021) created 12 specified stalls especially for farmers to sell their products as a trial to remove the additional margins set by traders. This action comes as a direct response from farmers demanding a separate space to sell their products for some time now. During the trial period, farmers do not need to pay rent. After the trial, farmers (only 12 included in the pilot) will likely pay minimum rental amounts. In the market, there are 500 stalls from 27 cooperatives with a contract period of 15 years selling fruits and vegetables with a daily transaction of about $700 \mathrm{t}$ where $45 \%$ is from imports. The Kalimati market covers $70 \%$ of the total demand of Katmandu valley. ${ }^{18}$ In addition, Section 4.5.1 provides another example of the direct farmer-toconsumer link.

Based on our data and FGDs, we conclude that innovative models that capitalize on foods that are safe (pesticide-free), are locally grown (superior taste), or are convenient (supermarket), have the potential to be scalable and better connect with a wider consumer base. Nevertheless, these models do have to demonstrate that foods are true to their origin and production methods used.

\subsection{Increased food safety, consumer awareness and responses to consumer preferences lead to higher acceptability of fruit and vegetable}

\subsubsection{Available, affordable, acceptable}

'The majority of consumers would increase their intake of fruit and vegetables only when available at affordable prices'. This is the general sentiment observed during the KIIs and FGDs. No data supporting or opposing this are available.

As Section 4.7.1 indicated, making fruit and vegetables affordable is a huge challenge in Nepal. Transport-related costs are considerable, and the geography and remoteness of fruit and vegetable producing areas, as well as lack of access to good roads, limit the availability of fruit and vegetables, and aggravates their (un)affordability.

As defined by the food-based dietary guidelines and as introduced earlier, the costs of healthy diet per person and day in Nepal is US\$4.13, amounting to US\$124 per month. Around $42 \%$ of the costs of a healthy diet come from fruit and vegetables. For a global comparison, cost of a healthy diet per day and per person is US\$3.84 for Sub-Saharan Africa; US\$4.03 for Western Africa; US\$3.67 for Eastern Africa; US $\$ 4.20$ for South-Eastern Asia; US $\$ 4.07$ for Southern Asia; US $\$ 3.82$ for low-income countries and US\$3.98 for lower-middle income countries (see Section 3.7.1). As data suggest, the costs of a healthy diet in Nepal is higher than neighboring countries.

18 https://rajdhanidaily.com visited April 2, 2020. 


\section{A healthy diet cannot be afforded}

Section 4.7.1 concludes that affording a healthy diet remains far-fetched for the larger Nepali population. Our FGDs supported the perception that currently most (rural) families only occasionally consume vegetables, and fruits only when they fall sick. It is customary to offer fruits to healing household members or friends.

Vegetables locally produced are widely accepted by most consumers, especially as a condiment in traditional dishes. Fruits, on the other hand, are widely accepted for their unique taste. Mangos, or apples from the Mustang district, are an example. The case below illustrates the high cultural acceptability for fruit and vegetables in Nepal.

\section{Acceptability of fruit and vegetables in Nepal - the case of indigenous fruits}

Rural families often grow and/or consume fruits and vegetables given their adaptability to adverse biophysical conditions (i.e. poor soil, water scarcity), perceived nutritional value and, importantly, their sweet taste. After all, consuming sweets is a well-established concept in Nepali cuisine. Indigenous fruits are consumed mostly in the form of pickles and candies from lapsi (one of the six selected crops), amala or tamarind as they can be preserved for a long time. There are other indigenous fruits, such as Kafal, Aiselu, Bael, Jamun which are freshly consumed as they ripen. All of these fruits, whether consumed fresh or processed, are known to rural households. It is important to note that most fruit crops are grown in very remote, and difficult to access, areas. Different authors continue to argue for the commercial use of valuable indigenous fruits (Gautam and Gotame, 2020).

In some instances, indigenous fruits are also part of the social construction - for example, Bael fruits are widely used by the Newar community to perform 'Bael marriage' of young girls before menstruation. Due to its medicinal properties, it is becoming popular and is available as a juice in the market. Similarly, Churi fruit is consumed fresh and its seeds are processed to produce ghee by the Chepang community. Sisno (Nettle) is increasingly transiting into commercial farming, due to diverse health claims for treating high blood pressure, or diabetes. Nettle powder is available in supermarkets and consumed as soup or in vegetable dishes.

\subsubsection{Consumer motives and barriers}

Limited empirical evidence on common barriers and motives for consumption has been collected thus far. Tamrakar et. al., 2020 studied the drivers of healthy eating in a workplace in Nepal. Among the barriers to healthy eating that stood out were: the unavailability of healthy options, the lack of convenient and ready-prepared healthy foods, the higher cost of healthy foods and individual preferences for non-healthy foods (Tamrakar et al., 2020). During the FGDs, most common barriers to increased fruit and vegetable consumption relate to high prices and unaffordability, restricted product availability (seasonality), limited disposable income or limited awareness_as yet (reported as growing) on the role of fruit and vegetable in healthy diets. During the FGDs, participants highlighted the unaffordability of fruit and vegetables hampering consumption the most, in their view. With regards to seasonality, consumers are able to afford and consume, for example, mangos during harvest season, which becomes a prohibitive item between harvest seasons due to high prices.

The above suggest a number of drivers that guide consumer choice, notably food affordability, availability, convenience, individual preferences (quality) and awareness. Consumers' preferences are influenced by the traditional diversity of foods in the Nepali culture (see Section 4.6.1 for more information), underlining the tendency to consume new fruit and vegetables varieties that emerge.

Based on our data and FGDs, we conclude that price (affordability), availability, individual preferences (quality) and awareness are the most important barriers that affect consumption behavior of fruit and vegetables in Nepal. Factors that counter and drive fruit and vegetable consumption are prices, availability, cultural preferences, convenience and health claims. 


\section{Conclusion}

\subsection{Increase in production leads to lower fruit and vegetable consumer prices}

Increases in production do not automatically lead to lower prices. Seasonality and demand in fruit and vegetables have a strong influence on prices, which his more pronounced in fruits than vegetables. Increasing production is not easy for fruit and vegetables farmers, whose attention revolves around fetching higher prices.

\subsection{Fruit and vegetable production is profitable for smallholders}

Introducing small-scale technologies can lead to increased farmers' profitability by lowering labor costs, and freeing (female) farmers to potentially undertake other income-generating tasks. Labor input is a major factor in current farming systems. Sufficient available labor is a key constraint, as it is becoming increasingly limited, at the same time as small-scale technologies (i.e. tools and equipment for land preparation, irrigation kits, harvesting tools) remain untapped. Introduction of small-scale technologies requires little investment and know-how, but can lead to lower labor costs in the medium-long term. As it stands now, margins are high for smallholder fruit and vegetable farmers, who practice good crop management and have access to water thorough irrigation schemes, even in smaller units of area.

\subsection{More efficient value chains and consumer prices}

Limited evidence has been gathered on efficient value chains leading to lower consumer prices. Stability of supply is key to make value chains more efficient. On the other hand, stability of actors' incomes improves as transaction costs and risks are lowered, for example by reducing post-harvest losses or addressing the high fragmentation in fruit and vegetable value chains.

\subsection{Fruit and vegetable value chain efficiency}

Markets become more secured as actors start to trust each other, enhancing coordination in value chains and, ultimately, increasing efficiency. In secured markets, the relationship between actors and stability of supply are paramount. In the eyes of current fruit and vegetable farmers, higher incomes still depend largely on prices fetched, bound to fluctuations even in more secured markets.

\subsection{Direct farmer-consumer relations are limited}

Fruit and vegetable farmers cater better for consumer needs when in direct contact. Consumers' emerging appetite for pesticide-free products, for example, is to be met by a number of fruit and vegetable farmers willing to transit into more complex farming systems (i.e. larger, irrigated plots). As more intermediate actors come into the sector, smallholder farmers have less incentives to innovate However, direct farmer-consumer market channels have a limitation in scalability due to the current market dynamics with many existing intermediary actors predominating. 


\subsection{Little evidence is found that diverse fruit and vegetables lead to an increase in consumption}

Higher diversity in fruit and vegetable crops produced and traded leads to a more diverse food environment, an aspect that is traditionally embraced by the Nepali culture throughout the years.

The willingness of consumers to consume new foods cannot be overlooked. However, little evidence is found with regards to more diverse foods leading to an increase in consumption of fruit and vegetables.

\subsection{Prices of fruit and vegetable are higher}

Prices of vegetable and fruits are considerably higher than for cereals; often, the difference is three or four fold depending on the time of the year and season, and the influx of imported products. Higher prices for fruit and vegetables actors help offset the higher risks faced in fruit and vegetable value chains. Unfortunately, high fruit and vegetables prices drive up the costs of a healthy diet in Nepal, calculated to exceed Nepali's yearly average income by $72 \%$.

\subsection{Women participation}

Women have become increasingly involved in agricultural production, including for fruit and vegetables, as mostly men migrate to work abroad or in cities. Women have, to a lesser extent, been involved in value-addition (processing, marketing) but where they have, there is greater evidence of women controlling the income they earn from sales. Where women have become more involved only in production there is less evidence of a direct correlation between these efforts and their empowerment.

\subsection{Higher income by women leads to higher consumption of fruit and vegetable}

There is an indirect correlation between higher income generated by women and increased household consumption; while women, when controlling income, allocate more towards food, limiting factors are: 1) economic, e.g. when higher fruit and vegetable prices make purchases prohibitive; and

2) normative perceptions of, especially, vegetables that deter women from preparing more of them. Literature and field studies found that increased income controlled by women increases overall food consumption but whether this usually includes more fruit and vegetables is unclear.

\subsection{Public standards are not enforced}

Food safety is garnering attention from the public, spurred by unfortunate cases reported on imported fruit and vegetables. Although standards on food safety, and especially on pesticide residues, are formulated, enforcement of sector-wide policies to ensure food is safe in (some) markets has a way to go yet. 


\subsection{Nudging and public extension directed at consumes is limited}

In Nepal, a common belief among sector actors, and especially from public institutions, is that improving the production of fruit and vegetables enhances consumption of fruit and vegetables. Many policies and strategies launched by the government of Nepal build upon this premise. Nevertheless, no evidence gathered so far confirms this assumption. Moreover, limited consumer-focused activities have so far taken place at a national level.

\subsection{Consumer behavior}

The Government are leading efforts to push the food safety and self-sufficiency agendas and of which many actors have taken notice of in Nepal. However, ensuring that food is safe, together with the creation of reliable and trusted markets and communication channels with consumers, remains a daunting challenge. This high level of lack of clarity erodes consumers' acceptability of fruit and vegetables.

Opposing forces drive consumers' intake: on the one hand, price (affordability), availability, individual preferences (quality) and awareness are barriers that affect consumption behavior. On the other hand, affordability of prices, availability of fruit and vegetables, cultural preferences (i.e. taste, origin), convenience (readily-made) and nutritional values counter the factors above. It is unclear, unfortunately, what the net intake of fruit and vegetables among consumers precisely is, in any case believed to be lower than minimum recommended intake. 


\section{References and websites}

ADB, 2012. Technical Assistance Consultant 's Report Nepal : Improving Access to Finance Sector Development Program Asian Development Bank Improving Access to Finance Sector AFC Consultants International. Asian Dev. Bank.

Aryal, K.K., Mehata, S., Neupane, S., Vaidya, A., Dhimal, M., Dhakal, P., Rana, S., Bhusal, C.L., Lohani, G.R., Paulin, F.H., Garg, R.M., Guthold, R., Cowan, M., Riley, L.M., Karki, K.B., 2015. The burden and determinants of non communicable diseases risk factors in Nepal: Findings from a nationwide STEPS survey. PLoS One 10, e0134834. https://doi.org/10.1371/journal.pone.0134834

Aryal, K.P., Chaudhary, P., Pandit, S., Sharma, G., 2009. Consumers' Willingness to Pay for Organic Products: A Case From Kathmandu Valley. J. Agric. Environ. 10, 15-26. https://doi.org/10.3126/aej.v10i0.2126

Banjara, R.K., 2016. CHALLENGES OF ORGANIC FARMING FACED BY NEPALESE FARMERS. Int. J. Agric. Ext. Rural Dev. Stud. 3, 31-37.

Bhattarai, R.R., Rijal, R.K., Mishra, P., 2013. Post-harvest losses in mandarin orange: A case study of Dhankuta District, Nepal. African J. Agric. Res. 8, 763-767. https://doi.org/10.5897/AJAR12.1766

CASA, 2020. Vegetable Sector Strategy - Nepal. Commer. Agric. Smallholders Agribus. 27.

FAO, 2019. Country gender assessment of agriculture and the rural sector in Nepal.

Gautam, D.M.B., Bhattarai, D.R., 2012. Postharvest horticulture.

Gautam, I.P., Gotame, T.P., 2020. Diversity of Native and Exotic Fruit Genetic Resources in Nepal. J. Nepal Agric. Res. Counc. 6, 44-55. https://doi.org/10.3126/jnarc.v6i0.28114

Herfort, A., Bai, Y., Venkat, A., Mahrt, K., Ebel, A., Masters, W.A., 2020. Cost and affordability of healthy diets across and within countries, Cost and affordability of healthy diets across and within countries. https://doi.org/10.4060/cb2431en

IOM, 2019. Migration in Nepal: a Country Profile 2019. Int. Organ. Migr. 155.

Iyob, B., Witte, E., 2017. Cereal Systems Initiative for South Asia in Nepal (CSISA-NP) Agronomy \& Seed Systems Scaling Semi-Annual Report.

Joshi, O., Parajuli, R., Kharel, G., Poudyal, N.C., Taylor, E., 2018. Stakeholder opinions on scientific forest management policy implementation in Nepal. PLoS One 13, 1-15. https://doi.org/10.1371/journal.pone.0203106

Kartli, I.K., 2005. Value Chain Analysis of Broccoli.

Madjdian, D.S., Bras, H.A.J., 2016. Family, Gender, and Women's Nutritional Status: A Comparison Between Two Himalayan Communities in Nepal. Econ. Hist. Dev. Reg. 31, 198-223. https://doi.org/10.1080/20780389.2015.1114416

Ministry of Finance, 2020. Economic Survey 2019/20. Gov. Nepal Minist. Financ. Kathmandu 1-144. Ministry of Finance, 2019. Economic Survey 2018/19. Gov. Nepal Minist. Financ. Kathmandu 1-340.

Ministry of Health, 2019. Non-Communicable Disease Risk Factors: Bhutan STEPS Survey Report 2019, Ministry of Health.

MoAD, 2016. Agriculture Development Strategy (ADS) 2015-2035. Minist. Agric. Dev.

MoALD, 2020. Statistical information on Nepalese Agriculture 2075/76 [2018/2019]. Minist. Agric. Livest. Dev.

NABIC, 2019. Survey on needs for: Quality Infrastructure Processing Industries services among Food in Western Nepal.

Noora, S., 2020. An Analysis of Production and Sales of Choerospondias Axillaris. Int. J. Hortic. Agric. Food Sci. 4, 10-13. https://doi.org/10.22161/ijhaf.4.1.2

NPC, 2017. Multi-Sector Nutrition Plan: 2018-2022. Natl. Plan. Comm.

OECD, 2013. Financial Literacy Framework. pp. 139-166. https://doi.org/10.1787/9789264190511-7en

Pandey, Raj, I., Joshi, K., Joshi, Raj, S., Shrestha, Joshi, A., Dhakal, M., 2017. Package of Practices for Climate Resilient Value Chain Development of Major Vegetables.

Paudel, K.C., Pieber, K., Klumpp, R., Laimer, M., 2003. Evaluation of Lapsi tree (Choerospondias axillaris, Roxb.) for fruit production in Nepal [WWW Document]. Die Bodenkultur. URL 
https://www.researchgate.net/publication/232175714_Evaluation_of_Lapsi_tree_Choerospondias_ axillaris_Roxb_for_fruit_production_in_Nepal (accessed 9.20.21).

Shrestha, S., Joshi, N.R., Pandey, S., 2021. Value Chain Analysis of Mango (Mangifera Indica L.) In Saptari District, Nepal. Malaysian E Commer. J. 4, 7-19. https://doi.org/10.26480/mecj.01.2021.

Singh, J.K., Acharya, D., Gautam, S., Adhikari, M., Park, J.H., Yoo, S.J., Lee, K., 2019. Sociodemographic and diet-related factors associated with insufficient fruit and vegetable consumption among adolescent girls in rural communities of southern Nepal. Int. J. Environ. Res. Public Health 16, 1-11. https://doi.org/10.3390/ijerph16122145

Tamrakar, D., Shrestha, A., Rai, A., Karmacharya, B.M., Malik, V., Mattei, J., Spiegelman, D., 2020. Drivers of healthy eating in a workplace in Nepal: A qualitative study. BMJ Open 10. https://doi.org/10.1136/bmjopen-2019-031404

The Kathmandu Post, 2019. High levels of pesticide residue found in cauliflower and bitter gourd samples [WWW Document]. URL https://kathmandupost.com/health/2019/10/23/high-levels-ofpesticide-residue-found-in-cauliflower-and-bitter-gourd-samples\#: :text=According to the pesticide residue, Kalimati Fruits and Vegetables Market.

Tiwari, A., Bhandari, T., 2020. Study on Capital Investment and Marketing of Kiwi Fruit in Ilam, Nepal. Acta Sci. Agric. 4, 13-20. https://doi.org/10.31080/asag.2020.04.0844

USAID, 2014. USAID's Business Literacy Program in Nepal. United States Agency Int. Dev.

USAID, 2013. USAID Country Profile: Property Rights and Resource Governance Dominican Republic. United States Agency Int. Dev. 1-40.

USAID, 2011. Value Chain/ Market Analysis of the Ginger Subsector. United States Agency Int. Dev. Vaidya, A., Oli, N., Aryal, U., Karki, D., Krettek, A., 2014. Disparties in fruit and vegetable intake by Socio-demographic characteristics in peri-urban Nepalese adults: findings from the Heart-health Associated Research and Dissemination in the Community (HARDIC) Study, Bhaktapur, Nepal. J. Kathmandu Med. Coll. 2, 3-11. https://doi.org/10.3126/jkmc.v2i1.10512 


\title{
Appendix 1 Description of actors
}

\author{
Types of actors Description \\ Input Agro vet: \\ suppliers/providers Agro vets provide all types of essential agricultural inputs and services to farmers. Agriculture inputs \\ provided by agro vets include seeds (also saplings), pesticides, fertilizers, and agri-machinery (tools and \\ equipment)(CASA, 2020). There is a high demand for hybrid vegetable seeds in Nepal. About $60 \%$ of \\ commercial-scale producers uses hybrid seeds (Sahaj project study). \\ There is an estimated annual demand of 700,000 $t$ of chemical fertilizer in Nepal, whereas only about \\ $50 \%$ is fulfilled by imports. In Nepal, only state-owned Agriculture Inputs Company Limited (AICL) and \\ Salt Trading Corporation (STC) can import and distribute chemical fertilizer. The rest is informal imports. \\ There is a government subsidy of about $20-25 \%$ in fertilizers. \\ Government: Municipality office and Agriculture Knowledge Centre (Krishi Gyan Kendra): \\ The Government of Nepal has established Krishi Gyan Kendra offices under the provincial Ministry of Land \\ Management, Agriculture and Cooperatives (MOLMAC) in various parts of Nepal. Each Gyan Kendra Office \\ is responsible for providing services from one to three adjoining districts. The Gyan Kendra provides \\ technical assistance to agricultural units of the Municipality Offices. There is no formal reporting system \\ by the Agricultural unit of the Municipality to the Gyan Kendra as they are the independent local \\ government bodies of Nepal. However, there is no clarity in the service delivery from both the \\ government bodies and sometimes duplication of activities. Gyan Kendra and Municipality offices are \\ heavily involved in the subsidy program for distribution of seeds, fertilizers, farm machinery, irrigation \\ machines, etc.
}

The formation of the federal government structure has brought transformation of government services through the municipalities. For agricultural services, both urban and rural municipalities are responsible for regular technical services through a separate agriculture unit and appointed technical human resources.

Cooperatives:

As per the Department of Co-operative statistics, there are 34,512 registered co-operatives operating in the country serving 6.3 million smallholder farmers and more than 60,517 people are employed directly in Cooperative business. Out of this total, there are 10,921 agriculture (32\%), 193 fruits and vegetable $(1 \%), 13,578$ saving and credit (39\%), 4, 371 multipurpose (13\%) cooperatives. In fruits and vegetable cooperatives, there is a cash saving of Rs7.524 million and credit services of Rs12.491 million to their 1,203 members ( $57 \%$ female and $43 \%$ male).

Example of cooperatives - FWEAN. Federation of Woman Entrepreneurs' Associations of Nepal (FWEAN) is an apex body of Women Entrepreneurs' Associations in Nepal (WEAN). Its mission is to inspire and empower women and their business in order to reach the goals to transform socio-economic empowerment of women through entrepreneurship. FWEAN, in collaboration with the Society of Local Volunteers' Effort (SOLVE) Nepal has been implementing socio-economic empowerment of disadvantaged women and girls of southern Lalitpur (SEED) project with financial support of women's bank Finland and Finn Church Aid Nepal.

Farmers Two types of fruit and vegetable farmers prevail in Nepal: Smallholder farmers, or subsistence, with a landholding between $0.5-1$ ha; Commercial farmers owning a land size between 1 to 5 ha. Both groups combined represent about $50 \%$ of the farmer base. The remainder of farmers are considered, according to the Government of Nepal, and through its Agriculture Development Strategy (AGS), as landless or near landless - about 1.6 million families.

Trading Farmer's groups/cooperatives:

Agricultural cooperatives in Nepal have played an important role for collective marketing and contributed to economic development especially for the smaller farmers. Farmer's groups and cooperatives are currently focusing on saving and credit activities. Cooperatives provide inputs (seeds, fertilizer, micronutrients, and equipment, as well as marketing and technical support to their members. Middlemen (Trader/commission agent):

Traders, or commission agents, are middlemen who buy fruit and vegetables from farmers, selling in turn to market wholesalers. They become more active in areas where there is no presence of groups/cooperatives and difficult road access.

Middlemen play an important role in the collection of fruit and vegetable produced by farmers. Due to perishable nature of fruit and vegetables, they usually own a vehicle (pick-up van) for transporting from the farm area up to the market centers or hire a vehicle on a need basis. They appear to have a strong business relationship with traders located in the major market centers, communicating on market prices, 
and quantity of fruit and vegetables, among other foods. Collected fruit and vegetables are sold to the wholesale shop owners on a regular basis.

Wholesaler:

Wholesalers are mainly involved in buying vegetables from traders and selling them to retailers. They can also store products. They are mainly located in major market centers such as Kalimati market, making use of certain market and physical infrastructure such as office buildings, open stores, or shop sheds.

Retailers:

Retailers purchase fruit and vegetables from wholesalers, followed by retail sales to consumers. Commonly, retailers grade and display fruit and vegetables in their shops/sheds.

Market places Local Haat Bazar (market place):

Haat Bazar is an open market that serves as a trading venue for local farmers in rural areas to sell their products while promoting local food systems. It generally takes place on a weekly or bi-weekly basis in a playground or any available open space, which is accessible to most families. Haat Bazar provides avenues for those farmers who lack access to markets due to transportation. Foods sold in the Haat Bazar are usually locally produced with high nutrition and medicinal values. About $20 \%$ of vegetables from farmers are sold in the local Haat Bazar (NEAT report).

With the similar principal, urban Haat Bazar are operating within the premises of hotels and restaurants within the Kathmandu valley. Such markets are selling pesticide-free fruits and vegetables from their specified farmers who practice growing pesticide-free fruits and vegetables. All these farmers have been farming pesticide-free fruits and vegetables, either IPM or organic.

Regional markets:

Before the federal government, there were about 74 wholesale markets across the country registered under the Agribusiness Promotion and Market Development Directorate.

National markets:

Kalimati Fruits and Vegetable wholesale market is the leading market in Nepal. This market covers 60 to $70 \%$ of the Kathmandu valley consumers' demand (CASA study report). There are 45,243 registered traders in this market (USAID study).

Fruit and vegetable shops:

Fruits and vegetables are sold from most of the retail shops these days to attract consumers so that they also purchase other food items. There are fruit shops, which sell all types of seasonal fruits as well as imported varieties and seasonal juice in urban areas of Nepal. There are shops which sell both vegetables and fruits. Most of these retail shops suppliers are from wholesalers, one located in Kuleshwor in Kathamandu and other regional wholesale markets.

Supermarkets:

A number of supermarket chains are available in major cities in Nepal. They cater for the said middle class consumers and those consumers who have less time for shopping. The major large-scale supermarket chains popular among the urban consumers are tabulated below.

\begin{tabular}{lll}
$\#$ & Supermarket & Website \\
\hline 1 & Bhat-Bhateni Supermarket and Departmental store & https://www.bbsm.com.np/ \\
\hline 2 & Bigmart & https://bigmart.com.np/ \\
\hline 3 & Saleways Supermarket & https://salesways.com/ \\
\hline 4 & Salesberry Department Store & https://www.salesberry.com.np/ \\
\hline 5 & Bluebird Departmental Stores & http://www.bluebirdmart.com.np/ \\
\hline
\end{tabular}

In addition, there are smaller supermarket chains located across the country.

Online E-commerce:

Currently, online shopping platforms offer deliveries of essential goods including fruits and vegetables along with other food products. With the Covid-19 pandemic, an increase in the delivery of daily essential goods including fruits and vegetables is observed. Daraz is the biggest e-commerce platform in Nepal. Some of the online shopping platforms are Foodmandu, Bhojdeals, Kathmandu Organics, Kheti, Farmers' Market at Le Sherpa.

Institutions:

Homestays is now an alternative tourism services in Nepal to experience Nepali culture and ethnicity. As per the government statistics, there are about 100 homestays across the country. Locally grown organic vegetables and other agricultural products are fed to guests, usually tourists from abroad and also from urban Nepalis. 


\section{Appendix 2 List of Focus Groups Discussions (FGDs) and Key Informant Interviews (KIIs)}

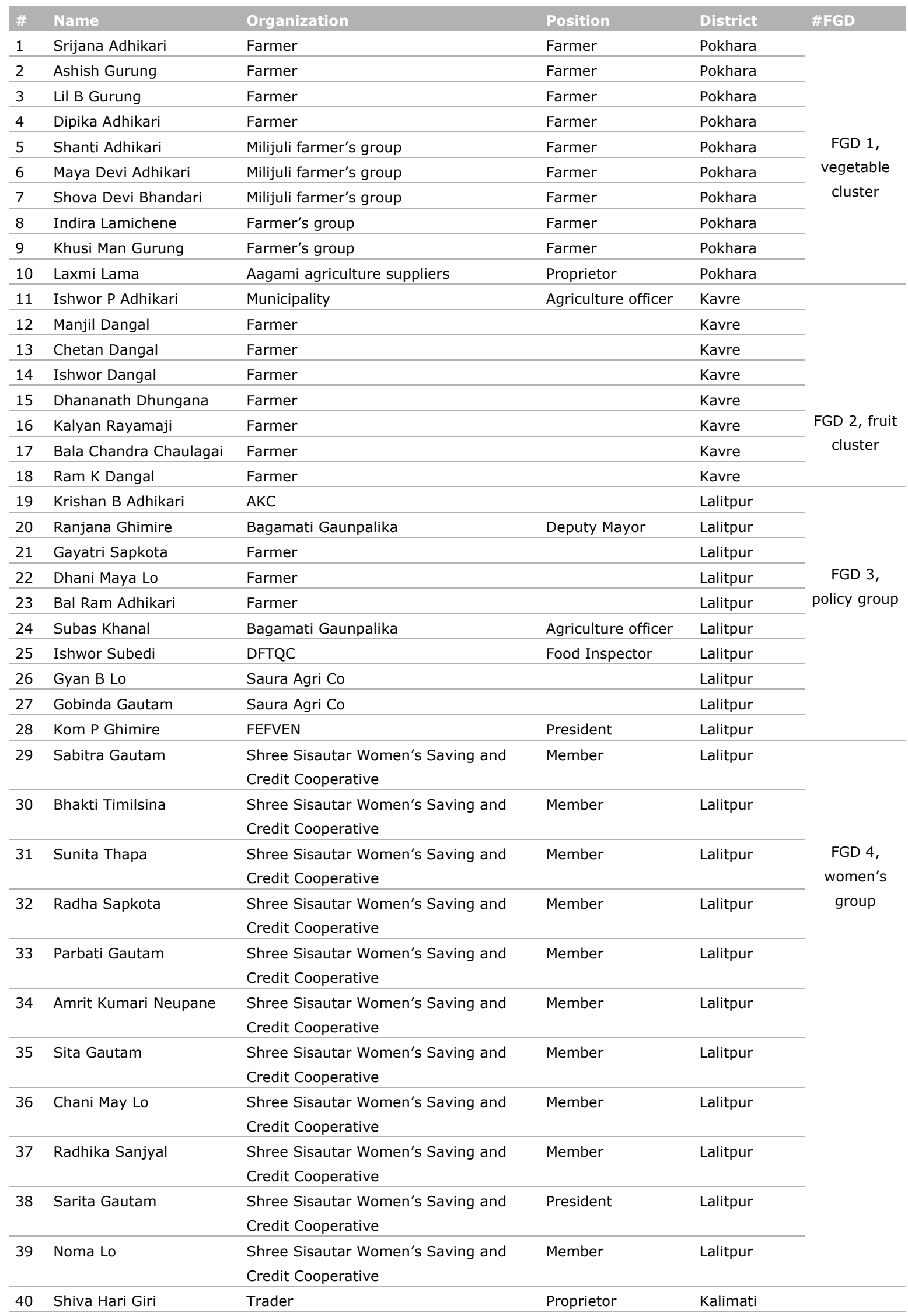




\begin{tabular}{|c|c|c|c|c|c|}
\hline \# & Name & Organization & Position & District & \#FGD \\
\hline 41 & Dharma Raj & Trader & Proprietor & Kalimati & \multirow{10}{*}{$\begin{array}{l}\text { FGD 5, } \\
\text { traders }\end{array}$} \\
\hline 42 & Tiak Prasad Humagain & Trader & Proprietor & Kalimati & \\
\hline 43 & Pramod Singh & Krishi Seed & Proprietor & Kalimati & \\
\hline 44 & Shahadev Raj Bharib & Trader & Proprietor & Kalimati & \\
\hline 45 & Sri Ram Acharya & Trader & Proprietor & Kalimati & \\
\hline 46 & Srimad Wagle & Trader & Proprietor & Kalimati & \\
\hline 47 & Hari Krishna Thapa & Trader & Proprietor & Kalimati & \\
\hline 48 & Ram Khadka & Trader & Proprietor & Kalimati & \\
\hline 49 & Ram Krishna Duwa & Trader & Proprietor & Kalimati & \\
\hline 50 & Surendra Shrestha & Trader & Proprietor & Kalimati & \\
\hline
\end{tabular}

\begin{tabular}{|c|c|c|c|c|c|}
\hline \# & Name & Organization & Position & District & Address \\
\hline 1 & Ishwor Subedi & DFTQC & Food Inspector & Kathmandu & Babarmahal \\
\hline 2 & Khom Pd Ghimire & FEFVEN & President & Lalitpur & Satdobato \\
\hline \multirow[t]{2}{*}{3} & Sarita Gautam & Shree Sisautar Women's & President & Lalitpur & Ghusel \\
\hline & & Saving and Credit Cooperative & & & \\
\hline \multirow[t]{2}{*}{4} & Radha Sapkota & Shree Sisautar Women's & & Lalitpur & Ghusel \\
\hline & & Saving and Credit Cooperative & & & \\
\hline \multirow[t]{2}{*}{5} & Sunita Thapa & Shree Sisautar Women's & & & Ghusel \\
\hline & & Saving and Credit Cooperative & & & \\
\hline 6 & Laxmi Lama & Aagami agriculture suppliers & Proprietor & Pokhara & \\
\hline \multirow[t]{3}{*}{7} & Laxmi Khanal & FWEAN & Executive & Kathmandu & Baneshwor \\
\hline & & & Committee & & \\
\hline & & & Member & & \\
\hline 8 & Hajuri Bista & Kitchen Recipe & Proprietor & Lalitpur & Dhobighat \\
\hline 9 & Poonam Thapa & PTB & Officer & Lalitpur & Satdobato \\
\hline \multirow[t]{2}{*}{10} & Arniko Raj Bhandari & FNCCI & Member- & Kathmandu & Teku \\
\hline & & & Community group & & \\
\hline 11 & Raju Rai & FWEAN & Officer & Kathmandu & Baneshwor \\
\hline 12 & Govinda Gautam & KIWI Farmer & Proprietor & Lalitpur & Ghusel \\
\hline 13 & Keshav Dutta Joshi & CEPREAD & Program Director & Lalitpur & Dhobighat \\
\hline 14 & Kashi Gurung & Entrepreneur & Proprietor & Pokhara & \\
\hline \multirow[t]{2}{*}{15} & Binay Shrestha & Kalimati Vegetable Market & Diector & Kathmandu & Kalimati \\
\hline & & Development Board & & & \\
\hline
\end{tabular}




\section{Appendix 3 Fruits and vegetables sentinel groups}

\section{Sub-group Health association}

1 (Dark) green leafy vegetables (GLV or DGLV) Contribute to iron, vitamin C, vitamin A and folate intake Positive association with Coronary heart disease (CVC), stroke, allcause mortality, but negative with CVD

2 Red, orange and yellow vegetables Contribute to vitamin A, fyolate Positive association with CHD, total cancer

3 Cruciferous vegetables Positive association with total cancer

4 Other vegetables

5 Red, orange or yellow fruits

Contribute to vitamin C, vitamin A and folate Positive association with CHD

$6 \quad$ Citrus fruits Contribute to vitamin C (and helps to improve iron/zinc bioavailability), folate Positive association with CHD, stroke, CVD, mortality

$7 \quad$ Apples, Pears Positive association with CHD, stroke, CVD mortality

8 Other fruits 


\section{Appendix 4 List of projects in the fruit and vegetable sector}

List of ongoing projects in the fruit and vegetable sector

- Knowledge-based Integrated Sustainable Agriculture and Nutrition (KISAN) 2 project, USAID,

- Feed the Future initiative, implemented by Winrock, US\$32.7 million.

- Nepal Agricultural Market Development Programme (SAHAJ). Sahaj is a joint initiative of the Government of Nepal and the Government of Switzerland

- 'Spices and Seeds Value Chain Improvement for Rural Development in Nepal' funded by the Italian Ministry of Foreign Affairs (AICS) and 'Skill Up! Strengthening Skills Development, Creating Future Perspectives' funded by the Ministry of Economic Development and Cooperation (BMZ) of German. Both projects are implemented by CEAPRED.

- Commercial Agriculture for Smallholders and Agribusiness Programme (CASA),

- The UKaid-Nepal Sakchyam Access to Finance Programme (SAKCHYAM) funded by UKaid.

- Value chain development of fruits and vegetables in Nepal (2018-2022), funded by KOICA and UNDP.

- High Value Agriculture Project in Hill and Mountain Areas (HVAP), IFAD, FNCCI/AEC, SNV

- Suaahara (Good Nutrition) project- USAID, Save the Children as main implementing partner

- Prime Minister Agriculture Modernization Project (PMAMP)

- The Rural Enterprise and Economic Development (REED), funded by World Bank (US\$80 million), and implemented by the Ministry of Agriculture and Livestock Development

- Cooperative Market Development Programme (CMDP), funded by UNDP, Government of Nepal 
Wageningen Economic Research

P.O. Box 29703

2502 LS The Hague

The Netherlands

T +31 (0)70 3358330

E communications.ssg@wur.nl

www.wur.eu/economic-research

Wageningen Economic Research REPORT

2021-109
The mission of Wageningen University \& Research is "To explore the potential of nature to improve the quality of life". Under the banner Wageningen University \& Research, Wageningen University and the specialised research institutes of the Wageningen Research Foundation have joined forces in contributing to finding solutions to important questions in the domain of healthy food and living environment. With its roughly 30 branches,

6,800 employees (6,000 fte) and 12,900 students, Wageningen University \& Research is one of the leading organisations in its domain. The unique Wageningen approach lies in its integrated approach to issues and the collaboration between different disciplines. 



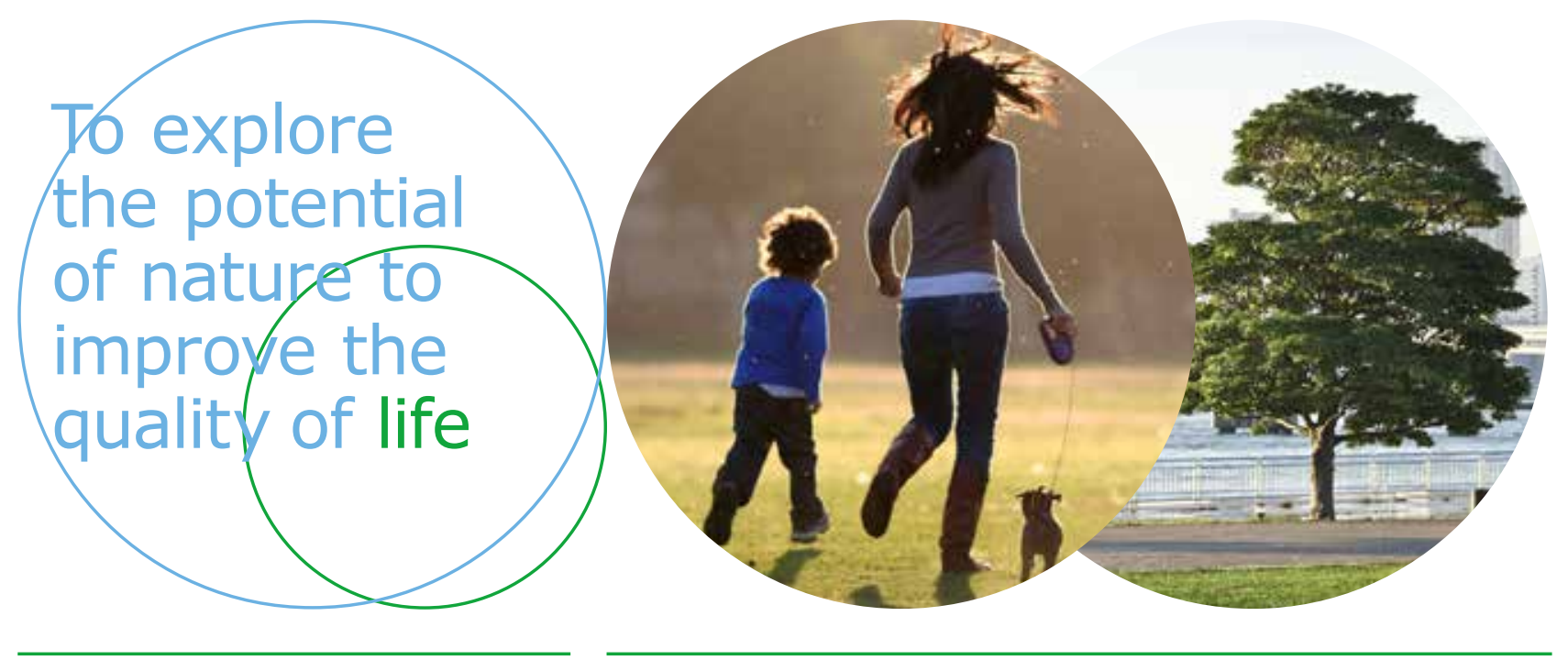

Wageningen Economic Research P.O. Box 29703

2502 LS Den Haag

The Netherlands

$\mathrm{T}+31(0) 703358330$

E communications.ssg@wur.nl

www.wur.eu/economic-research

Report 2021-109

ISBN 978-94-6395-075-6
The mission of Wageningen University \& Research is "To explore the potential of nature to improve the quality of life". Under the banner Wageningen University \& Research, Wageningen University and the specialised research institutes of the Wageningen Research Foundation have joined forces in contributing to finding solutions to important questions in the domain of healthy food and living environment. With its roughly 30 branches, 6,800 employees $(6,000 \mathrm{fte})$ and 12,900 students, Wageningen University \& Research is one of the leading organisations in its domain. The unique Wageningen approach lies in its integrated approach to issues and the collaboration between different disciplines. 